\title{
Uma Ferramenta de Apoio à Modelagem Baseada na Dinâmica de Sistemas
}

Rogério Eduardo Garcia 


\title{
Uma Ferramenta de Apoio à Modelagem Baseada na Dinâmica de Sistemas
}

\author{
Rogério Eduardo Garcia
}

Orientador: Prof. Dr. Paulo Cesar Masiero

Dissertação apresentada ao Instituto de Ciências Matemáticas e de Computação da Universidade de São Paulo, como parte dos requisitos para obtenção do título de Mestre em Ciências - Área de Ciências de Computação e Matemática Computacional.

São Carlos - SP

Novembro de 1998 


\begin{abstract}
A minha esposa, Cássia, pelo seu amor, compreensão e incentivo durante todos esses anos e à minha filha, Caroline.
\end{abstract}




\section{AgRADECIMENTOS}

Ao Prof. Dr. Paulo Cesar Masiero pela orientação, apoio, incentivo, muita dedicação e ensinamentos sem os quais esse trabalho não teria sido concluído.

Aos amigos da república: André, Mário Teixeira, Mário, Milton, Robson, Ronaldo, Shiro e Silvio, pela amizade, companheirismo, apoio e disposição para incentivar e colaborar.

Ao amigo Shiro (Antonio Marcos), pelo grande incentivo.

Aos colegas de mestrado do ICMC, em especial aos amigos Ciro e Julio (Mineiro), pelos momentos de estudo e alegria compartilhados.

Aos colegas do LABES, em especial ao Marcos Quinaia, Cris, Andrea, Djalma e Fredson pela camaradagem, apoio e momentos de descontração.

A Beth, à Laura e à Marília, às bibliotecárias e a todos os funcionários do ICMC que direta e indiretamente contribuíram com este trabalho.

Aos meus pais que sempre me apoiaram e incentivaram.

A familia de minha esposa pelo apoio e carinho.

À minha esposa, Cássia pelo amor, dedicação, paciência e incentivo que venho recebendo desde que a conheci.

Ao Conselho Nacional de Desenvolvimento Científico e Tecnológico - CNPq pelo suporte financeiro. 


\section{Índice Analítico}

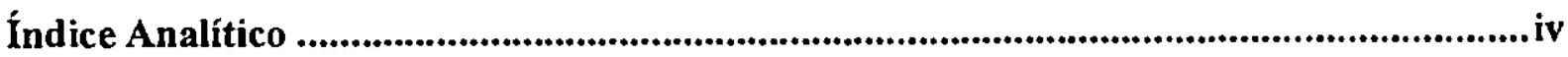

Lista de Figuras ..................................................................................................................vi

Lista de Tabelas..............................................................................................................viii

Resumo …............................................................................................................................... ix

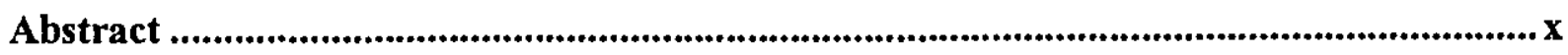

Capítulo 1 -Introdução............................................................................................................

1.1 Contextualização ….................................................................................................. 1

1.2 Objetivos ................................................................................................................ 2

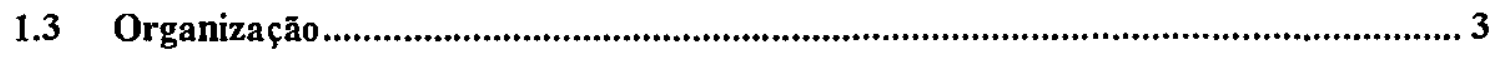

Capítulo 2 -Revisão Bibliográfica ............................................................................................... 4

2.1 Considerą̧ões Iniciais ................................................................................................... 4

2.2 Processo de Desenvolvimento de Software................................................................... 4

2.2.1 Características do Processo de Desenvolvimento de Software.............5

2.2.2 Aspectos Gerenciais.............................................................................8

2.3 Modelos para Gerenciamento de Projeto de Sofţware ...............................................11

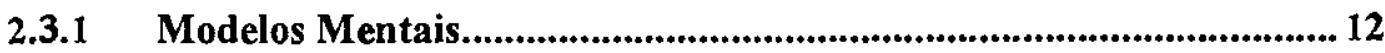

2.3.2 Modelos Baseados em Planilhas Eletrônicas .........................................13

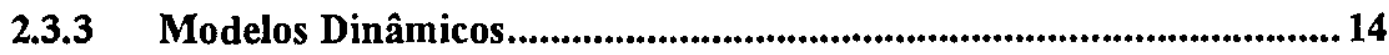

2.4 Dinâmica de Sistemas.......................................................................................17

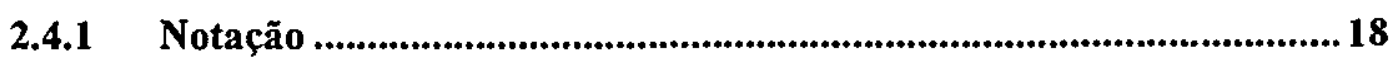

2.4.2 Um Exemplo de Sistema Dinâmico: Projeto de Software...................20

2.4.3 Ferramentas para Edição e Simulação de Modelos de Sistemas

Dinâmicos ....................................................................................................................26 


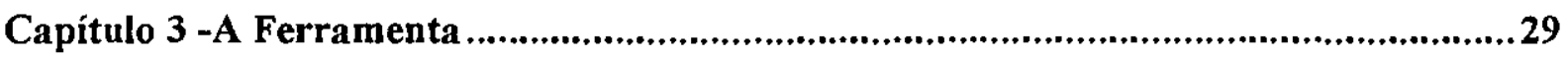

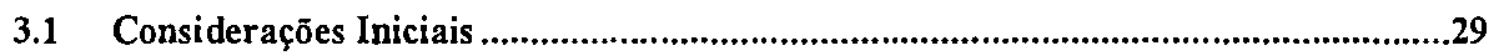

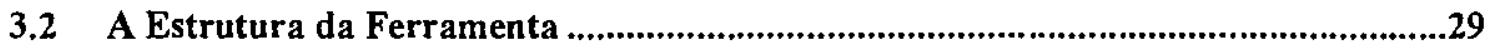

3.3 O Modelo Conceitual da Ferramenta ..........................................................................

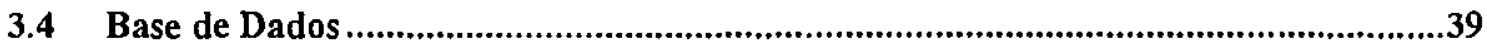

3.5 Implementação e Interface da Ferramenta ..............................................................43

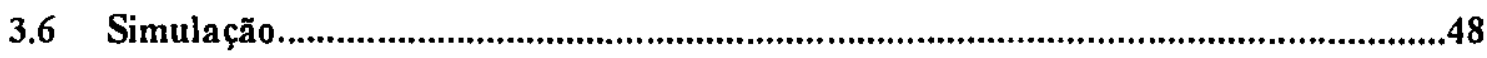

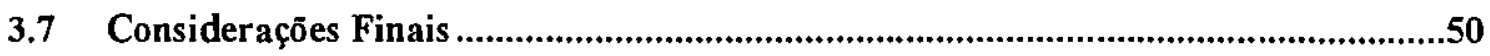

Capítulo 4 -Simulação de Sistemas Dinâmicos......................................................... 51

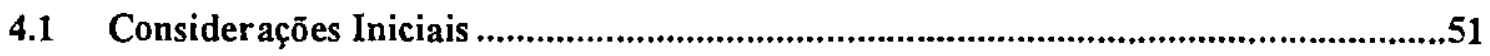

4.2 O Modelo de Recursos Humanos de Processos de Software ......................................51

4.2.1 Simulação do Modelo ...................................................................5 56

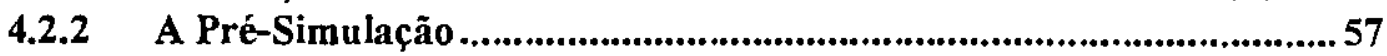

4.2.3 Resultado da Simulação do Modelo.................................................. 58

4.2.4 Avaliação do Comportamento do Modelo ........................................59

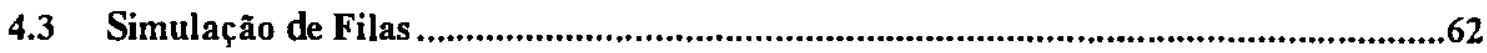

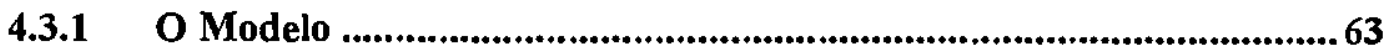

4.3.2 Simulação do Modelo ......................................................................65 65

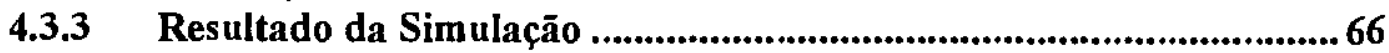

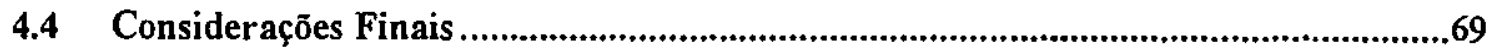

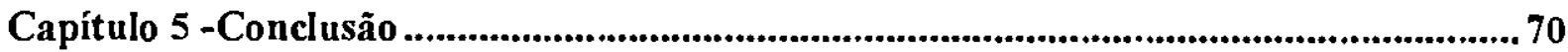

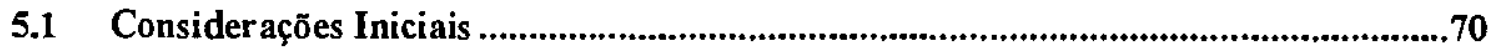

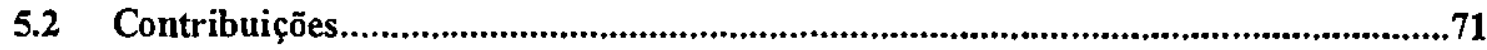

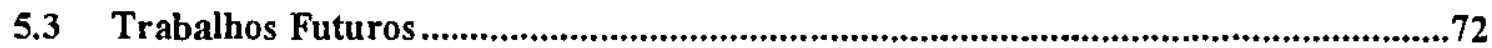

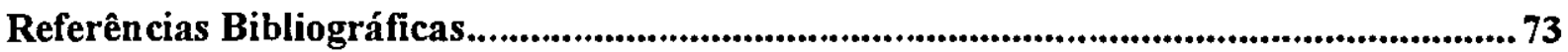

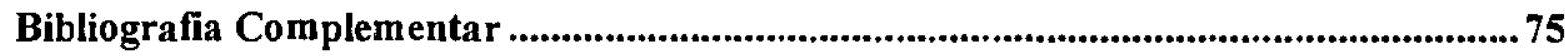




\section{Lista de Figuras}

Figura 1 - Visão Global do Desenvolvimento de Projetos Adaptada de [ROBERTS64] ..................6

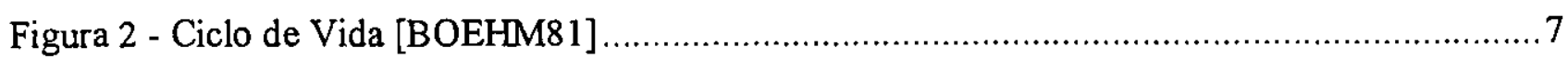

Figura 3 - Modelo Simplificado de Desenvolvimento de Software [ABDEL-HAMID89a] ..............8

Figura 4 - Ajuste ao Modelo de Desenvolvimento de Software (1) [ABDEL-HAMID89a] ............. 9

Figura 5 - Ajuste ao Modelo de Desenvolvimento de Software (2) [ABDEL-HAMID89a] ............ 10

Figura 6 - Ajuste ao Modelo de Desenvolvimento de Software (3) [ABDEL-HAMID89a] ............. 10

Figura 7 - Criação de Modelos [KREUTZER86] ......................................................... 11

Figura 8 - Estrutura do Capability Maturity Model (CMM) [SAIEDIAN95] ................................ 16

Figura 9 - Notação da Dinâmica de Sistema [FORRESTER61] ............................................ 19

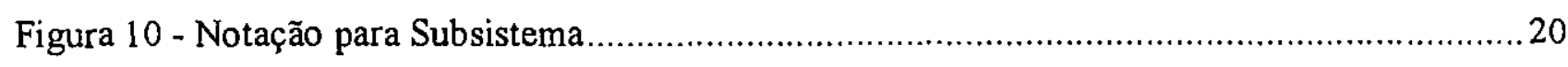

Figura 11 - Subsistemas do Projeto de Software [ABDEL-HAMW09b] ..................................2 21

Figura 12 - Estrutura dos Subsistemas do Projeto de Software [ABDEL-HAMD89a] .................22

Figura 13 - Modelo do Subsistema de Recursos Humanos [ABDEL-HAMID90] ........................23

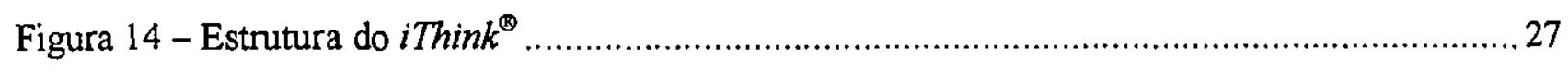

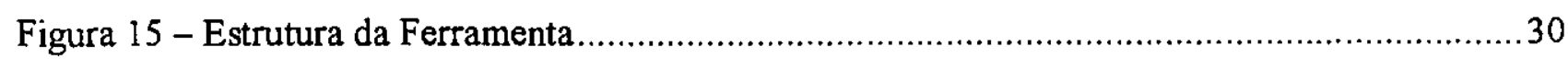

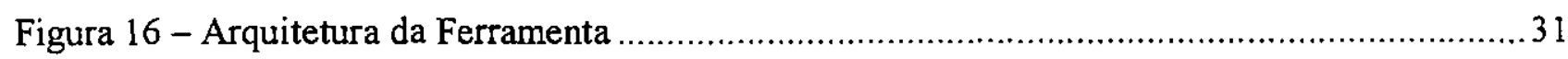

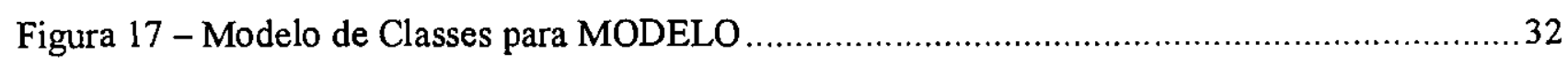

Figura 18 - Modelo de Classes para a Estrutura das Classes .................................................. 32

Figura 19 - Modelo de Classes para SUBSISTEMA …................................................... 33

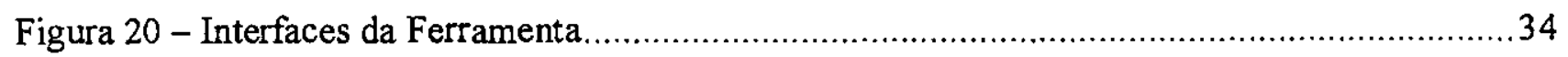

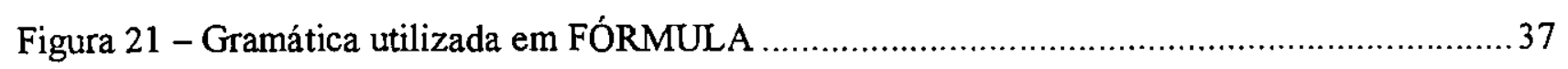

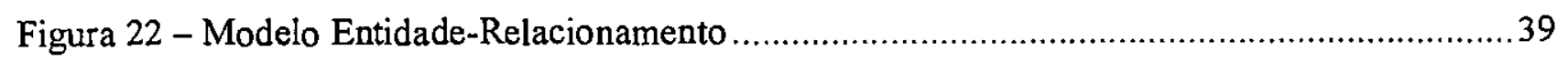

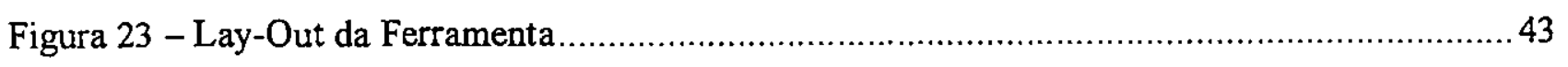

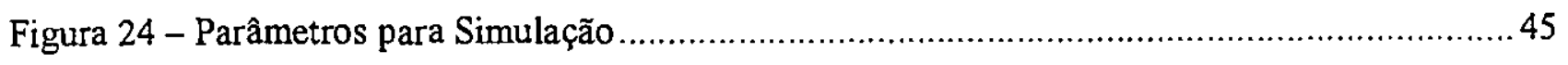




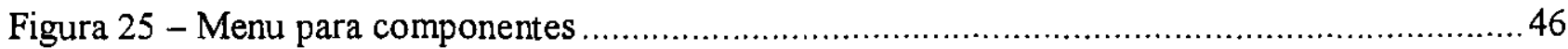

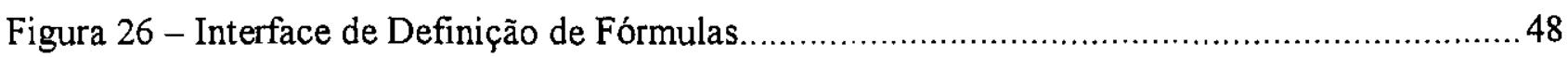

Figura 27 - Edição do primeiro nivel (SubSistemas) ……....................................................... 52

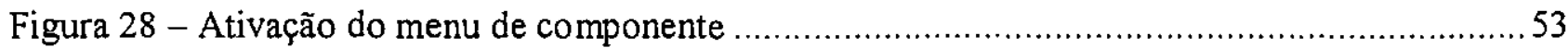

Figura 29 - Edição do Subsistema de Recursos Humanos..............................................................5

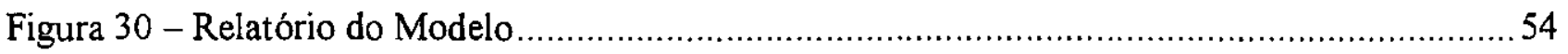

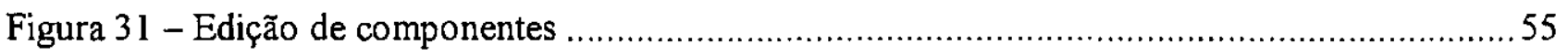

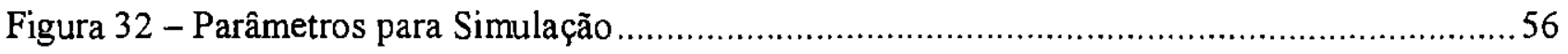

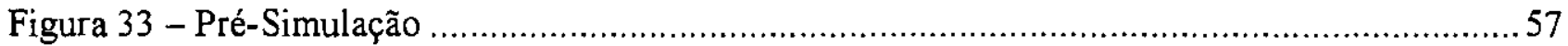

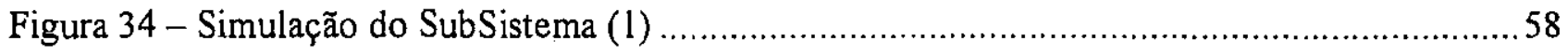

Figura 35 - Visualização dos Resultados Obtidos na Simulação ...................................................59

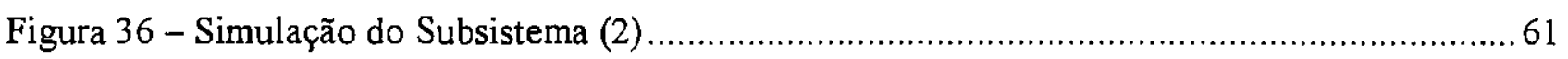

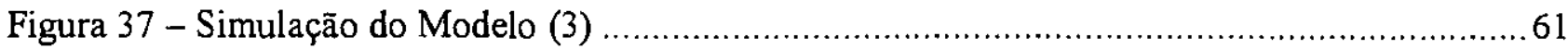

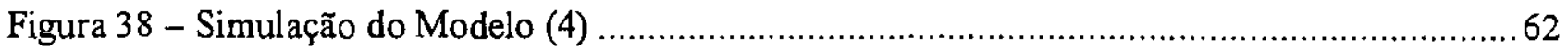

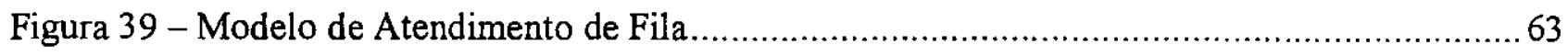

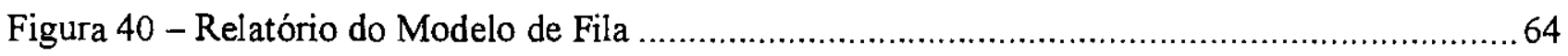

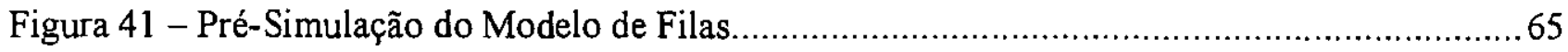

Figura 42 - Parâmetros da Simulação do Modelo de Filas ................................................................6

Figura 43 - Resultado da Simulação do Modelo de Fila (1) .........................................................67

Figura 44 - Resultado da Simulação do Modelo de Fila (2) ……...............................................67

Figura 45 - Resultado da Simulação do Modelo de Fila (3) ........................................................6 68

Figura 46 - Resultado da Simulação do Modelo de Fila (4) ............................................................ 69 


\section{Lista de Tabelas}

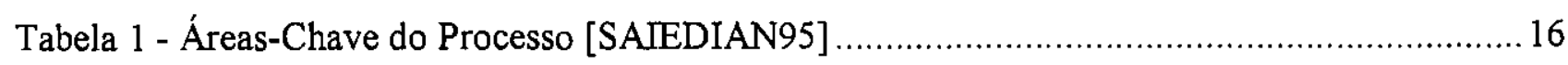

Tabela 2 - Valores Iniciais e Expressões do Modelo [ABDEL-HAMID90] ………..........................25

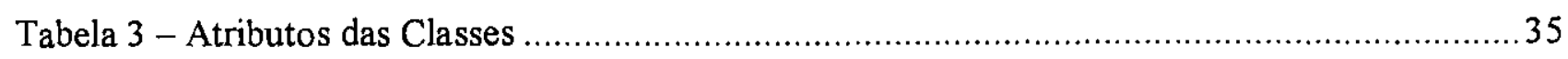

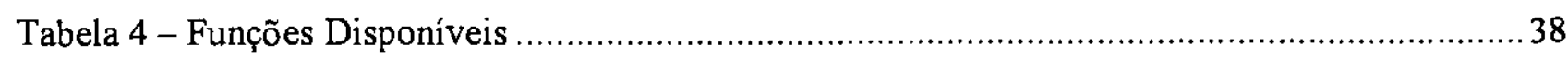

Tabela 5 - Utilização de Atributos pelas Classes ..................................................................... 41

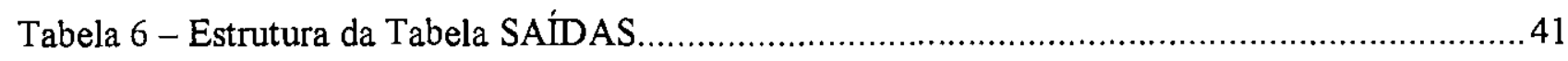

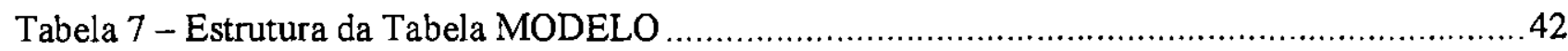

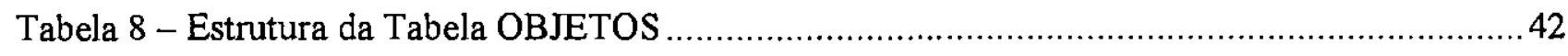

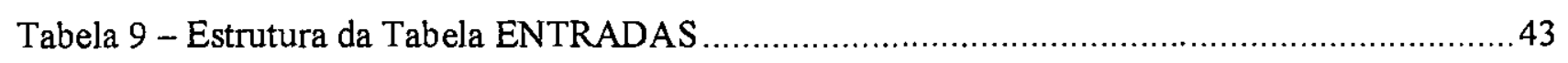

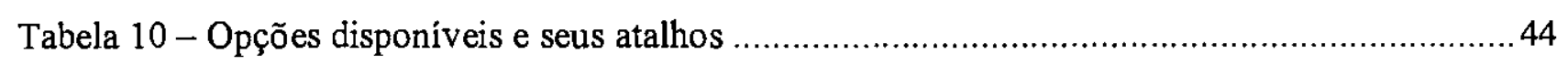

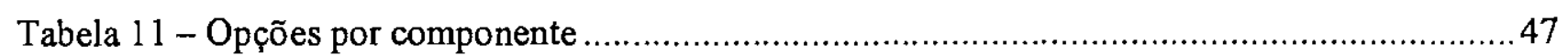




\section{Resumo}

O processo de desenvolvimento de software consiste em um complexo interrelacionamento de recursos com o objetivo de produzir e manter um software em operação. $O$ emprego de tais recursos, se gerenciados adequadamente, pode permitir que a produção de software seja feita dentro de prazos e orçamentos estabelecidos, além de influenciar na qualidade final do produto. Para tanto, mais que planejar o desenvolvimento, é necessário acompanhar e avaliar a evolução do mesmo a cada momento do desenvolvimento. Mudanças de estado entre $o$ início e o fim do processo de desenvolvimento exigem uma avaliação que considere os ciclos de retroalimentação. A modelagem de processos dinâmicos permite que a avaliação seja feita visualizando-se os elementos do sistema e seus relacionamentos. A simulação do comportamento do sistema é feita com base em relações matemáticas, permitindo a visualização do consumo de recursos no decorrer do tempo.

Este trabalho apresenta uma ferramenta de apoio à modelagem de sistemas dinâmicos que permite simular o comportamento do modelo, apresentando os resultados obtidos em tabelas e gerando gráficos que representam as tendências do modelo criado. Uma atividade gerencial do projeto de software é modelada e simulada para exemplificar a utilização da ferramenta e outro modelo é apresentado, mostrando a possibilidade de aplicação da ferramenta em outras áreas. 


\section{Abstract}

The software process is a complex conglomerate of resources to develop and keep a software in use. Use of these resources, if adequately managed, may allow software production according to the schedule and budget planed, as well as influence the final product quality. To obtain this, besides development planning, it is needed to control and evaluate continuously the development process. Changes of state between the start and end of the development process requires an evaluation based on feedback cycles. The modelling of dynamic processes allow that they be evaluated visualising the system's components and their relationships. Simulation of system behaviour is performed based on mathematical relationships that allow resource consumption visualisation based on time.

This work presents a tool to support modelling of dynamic systems and allows the model's simulation. It presents the results in tables and generates graphics representing the model's behaviour and its trends. A software project management task is presented and simulated to show the tool's use and another model is presented showing the application of system dynamics in other areas. 


\section{Introdução}

\subsection{Contextualização}

A engenharia de software progrediu ao ponto de que muitos dos aspectos relevantes para a tecnologia de produção de software foram identificados, consideráveis avanços tratando desses aspectos ocorreram e ferramentas para dar suporte à produção de software foram desenvolvidas, podendo ser facilmente encontradas no mercado [THAYER81]. Um projeto top-down, por exemplo, usa linguagens de programação de alto nível padronizadas e suporte a sistemas de bibliotecas de programas fontes que contribuem para que a produção de software possa ser feita dentro de prazos e orçamentos menores [MERWIN78].

Porém, os problemas do desenvolvimento de software não são puramente técnicos, mas também sociais, culturais e orientados a pessoas. Há diversas abordagens orientadas a pessoas que podem influenciar consideravelmente a incidência desses problemas: recrutamento, alocação mais eficaz de mão-de-obra, treinamento e motivação de pessoal (por exemplo, por intermédio de organização em equipes). 0 problema nas tarefas que tratam dos aspectos "soft" no contexto organizacional - sistemas para construir sistemas - reside na complexidade, e freqüentemente não se entende seu funcionamento. $\mathrm{Na}$ verdade, um tanto freqüentemente eles não funcionam [YOURDON96]. Isso tem ocorrido apesar dos esforços de muitas organizações para formalizar e conduzir seus processos de software pelas linhas do Capability Maturity Model (CMM) [SAIEDIAN95]. O principal motivo da falha consiste na desconsideração do aspecto dinâmico do processo - especialmente o tempo de espera e os 
ciclos de retroalimentação (feedback loops) - e na ignorância do processo "soff", que consiste na maior regra do mundo real quanto ao comportamento do projeto de software [YOURDON96]. Na verdade, esse conceito de dinamismo pode ser aplicado a um largo espectro de processos: não sendo relevante somente a projetos de Reengenharia de Processos de Negócio (Business Process Reengineering - BPR)[YOURDON96].

A representação do mundo real em modelos tem por principal objetivo permitir a percepção e o entendimento do "comportamento" de uma organização, ou seja, como as coisas acontecem no ambiente real e seus relacionamentos. Essa representação pode ser de um ambiente sistemático existente ou a ser desenvolvido, seja qual for sua natureza. Os métodos utilizados para representar o comportamento dos sistemas tiveram seu princípio sem considerar a existência de equipamentos que pudessem auxiliar na sua representação. Por isso, os métodos existentes limitam-se a uma representação estática do mundo real.

Com a evolução da informática, tais métodos passaram a ser implementados em ferramentas que auxiliam a representação, facilitando a utilização desses métodos e abrindo um grande número de alternativas possíveis a partir de então. Essa evolução possibilitou não somente o aparecimento de ferramentas facilitadoras do processo de modelagem do comportamento de um sistema, mas também possibilitou a automatização do processo de desenvolvimento de projetos. Porém, isso não faz parte do escopo deste trabalho.

Esse auxílio da informática trouxe a possibilidade da representação não apenas estática do comportamento de um sistema, mas também de uma representação cuja estrutura interna permite uma simulação comportamental de forma dinâmica, permitindo o acompanhamento e avaliação do comportamento do modelo em uma variação de tempo. A natureza estática dos modelos tem como principal deficiência sua inabilidade para integrar o conhecimento técnico a ser representado com os aspectos sociotécnicos, tais como processos de medição, conhecimento e produtividade.

\subsection{Objetivos}

Seguindo uma notação proposta por Forrester na década de 60 , pode-se expressar os aspectos intangíveis do processo de desenvolvimento de software, como por exemplo os 
aspectos sociotécnicos da produção de software e verificar sua influência sobre o mesmo. Essa modelagem se dá por intermédio da construção de um modelo capaz de representar a dinâmica de sistemas inerentes ao processo de desenvolvimento de software.

Assim, este projeto tem por objetivo o desenvolvimento de uma ferramenta, que permita a edição e simulação de modelos que representem a dinâmica de sistemas. Para tanto faz-se necessário um estudo sobre dinâmica de sistema, com o intuito de elucidar os requisitos de tal ferramenta.

Depois de desenvolvida, a ferramenta deve ser utilizada para exemplificar a modelagem de dinâmica de sistema, de preferência utilizando um modelo relacionado ao processo de desenvolvimento de software.

\subsection{Organização}

Este trabalho está organizado em cinco capítulos, cujo conteúdos são descritos a seguir.

O primeiro, é introdutório e descreve a contextualização do problema e os objetivos a serem atingidos. O segundo apresenta a revisão bibliográfica com ênfase nos aspectos dinâmicos do processo de desenvolvimento de software, a apresentação de métodos para modelar os aspectos dinâmicos e a uma notação proposta para representação de aspectos dinâmicos.

O terceiro capítulo traz a descrição da ferramenta, estrutura, organização, interface, e outros aspectos da implementação. O quarto capítulo apresenta a utilização da ferramenta mostrando a edição e a simulação de dois modelos, sendo que o primeiro trata-se de um modelo hipotético de gerenciamento de recursos humanos para processo de desenvolvimento de software e o segundo trata-se de um modelo hipotético de tratamento de fila. As conclusões deste trabalho são apresentadas no capítulo 5. 


\section{Revisão Bibliográfica}

\subsection{Considerações Iniciais}

Esta revisão bibliográfica tem por objetivo apresentar a modelagem de aspectos dinâmicos, enfocando sua utilização para a gerência de projetos de software. Dessa forma, a revisão bibliográfica foi estruturada partindo de um enfoque genérico, como é o processo de desenvolvimento de software, tratando de suas características e aspectos gerenciais e evidenciando a retroalimentação do processo, que caracteriza a dinâmica de sistemas.

Em seguida são discutidos os tipos de modelos aplicáveis à dinâmica de sistemas, finalizando com uma apresentação dos conceitos de dinâmica em sistemas, em que é apresentada a notação para representar tais modelos. Tal notação é utilizada para construção de um exemplo e sua simulação, mostrando o que se espera da simulação de sistemas dinâmicos.

\subsection{Processo de Desenvolvimento de Software}

Desde meados da década de 1970 esforços têm sido dispensados para disciplinar o processo de desenvolvimento de software, aplicando-se mais rigorosamente disciplinas de engenharia à produção de software [PRESS95]. Tal disciplina, a engenharia de software, abrange os aspectos técnicos de desenvolvimento de software, tais como projeto, teste e validação e os aspectos gerenciais desse processo. Ambos são parte do problema e da solução 
para o processo de desenvolvimento de software, porém houve uma disparidade de atenção dispensada a cada um deles.

A tecnologia de desenvolvimento tem progredido, novas técnicas e aprimoramentos têm surgido, abordando tópicos tais como codificação (programação estruturada, programação orientada a objetos), projeto estruturado, teste e verificação formal. As linguagens evoluíram, ferramentas de suporte melhoraram o processo de produção de software. Por outro lado, o tratamento de aspectos gerenciais pela engenharia de software não teve uma evolução comparável aos avanços da tecnologia de desenvolvimento. Falta uma visão global do processo de desenvolvimento que permita ao responsável por um projeto visualizar o processo como um todo, integrando aspectos tecnológicos e gerenciais [ABDELHAMID90].

A evolução do tratamento dos aspectos gerenciais pode trazer a redução ou mesmo a eliminação de falhas no software produzido, além de possibilitar a diminuição de atrasos (ou o cumprimento de prazo) e custos no processo de produção de software [THAYER79].

\subsubsection{Características do Processo de Desenvolvimento de Software}

De uma forma geral, para o desenvolvimento de qualquer projeto, o primeiro passo é estabelecer o objetivo a ser alcançado, ou seja, o que o produto deverá fazer, e a quais necessidades ele deverá atender. Em seguida define-se o que é necessário para a produção, seus insumos e estágios intermediários. A partir de então é possivel fazer uma estimativa de tempo, recursos e custos necessários para a produção. Na figura 1 apresenta-se um esboço das atividades do processo de desenvolvimento de um projeto de qualquer natureza.

Pode-se notar que existe um cicio de atividades que representa o acompanhamento contínuo durante todo o desenvolvimento de um projeto. Esse acompanhamento representa o lado das atividades gerenciais. As tarefas desenvolvidas para produção do projeto não encontram-se aqui representadas, pois trata-se de uma particularidade de cada projeto, considerando-se as mais diversas naturezas possíveis. 
É possível fazer uma comparação das atividades gerenciais e as primeiras atividades inerentes ao desenvolvimento de software. A fase "Necessidade de um Produto" corresponde ao levantamento das necessidades do usuário a serem atendidas pelo software. A produção de um relatório claro, conciso e não ambíguo, capaz de ser entendido por desenvolvedores e usuários do sistema é necessária para futura verificação

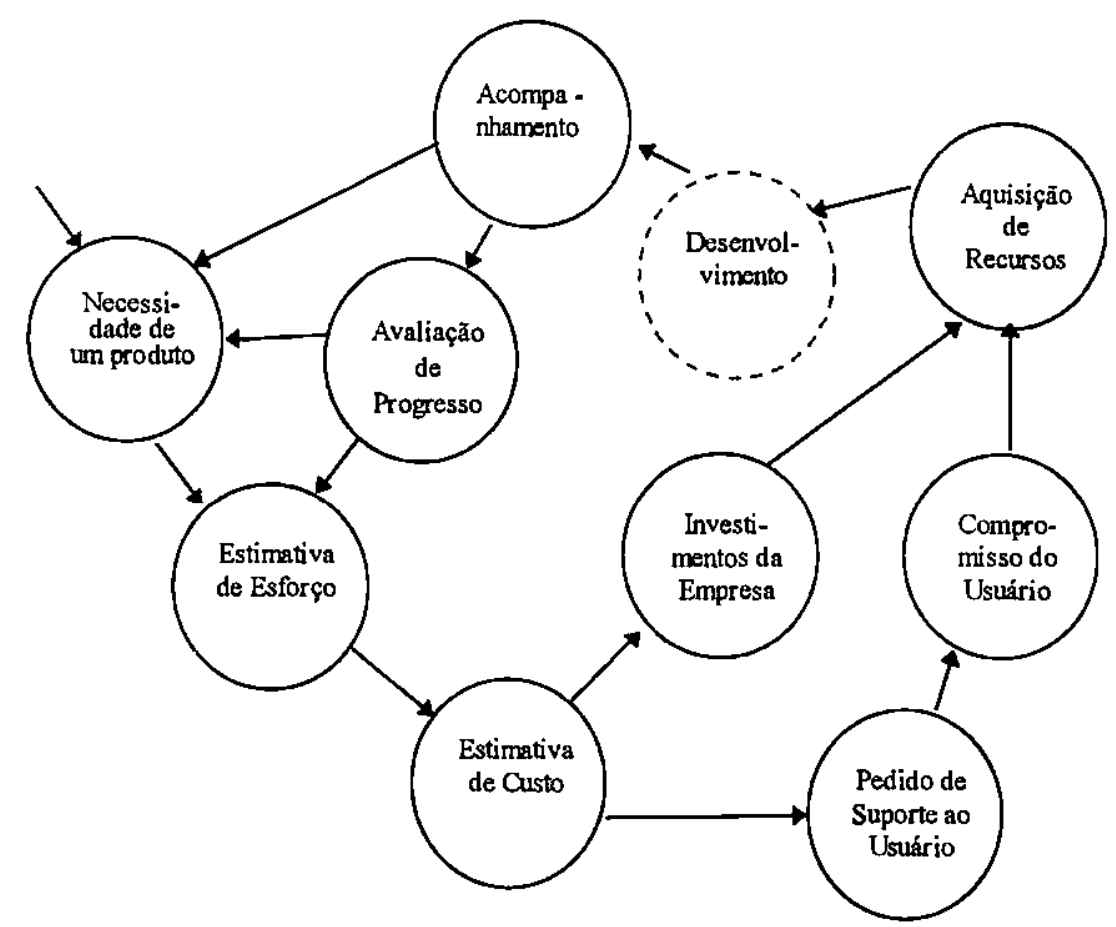

Figura 1 - Visão Global do Desenvolvimento de Projetos Adaptada de [ROBERTS64]

"Estimativa de Esforço" e "Estimativa de Custo", no que diz respeito ao desenvolvimento de software, são comumente chamados de Estudo de Viabilidade, ou seja, verifica-se se os esforços e investimentos necessários para a produção e implantação de um software vão produzir uma relação custo/benefício vantajosa.

"Aquisição de Recursos" consiste na aquisição dos recursos necessários, tais como equipamentos e ferramentas de apoio ao desenvolvimento, e na alocação de recursos humanos, contratação e treinamento, se necessário, para possibilitar a produção dentro de uma prazo estabelecido.

A partir do "Desenvolvimento", não "importa" qual a abordagem utilizada na produção de software, o que importa é o conhecimento do andamento do projeto para um acompanhamento efetivo, com a avaliação da evolução, permitindo estimar o tempo para 
término. Em seguida volta-se a avaliar a necessidade do usuário e a estimativa de esforço, completando o ciclo.

A figura 2 mostra um modelo de ciclo de vida de desenvolvimento de software. Esse modelo distribui o esforço total para o desenvolvimento de um software em fases distintas, com início e término de cada uma e cada uma com propósito bem determinado [BOEHM81].

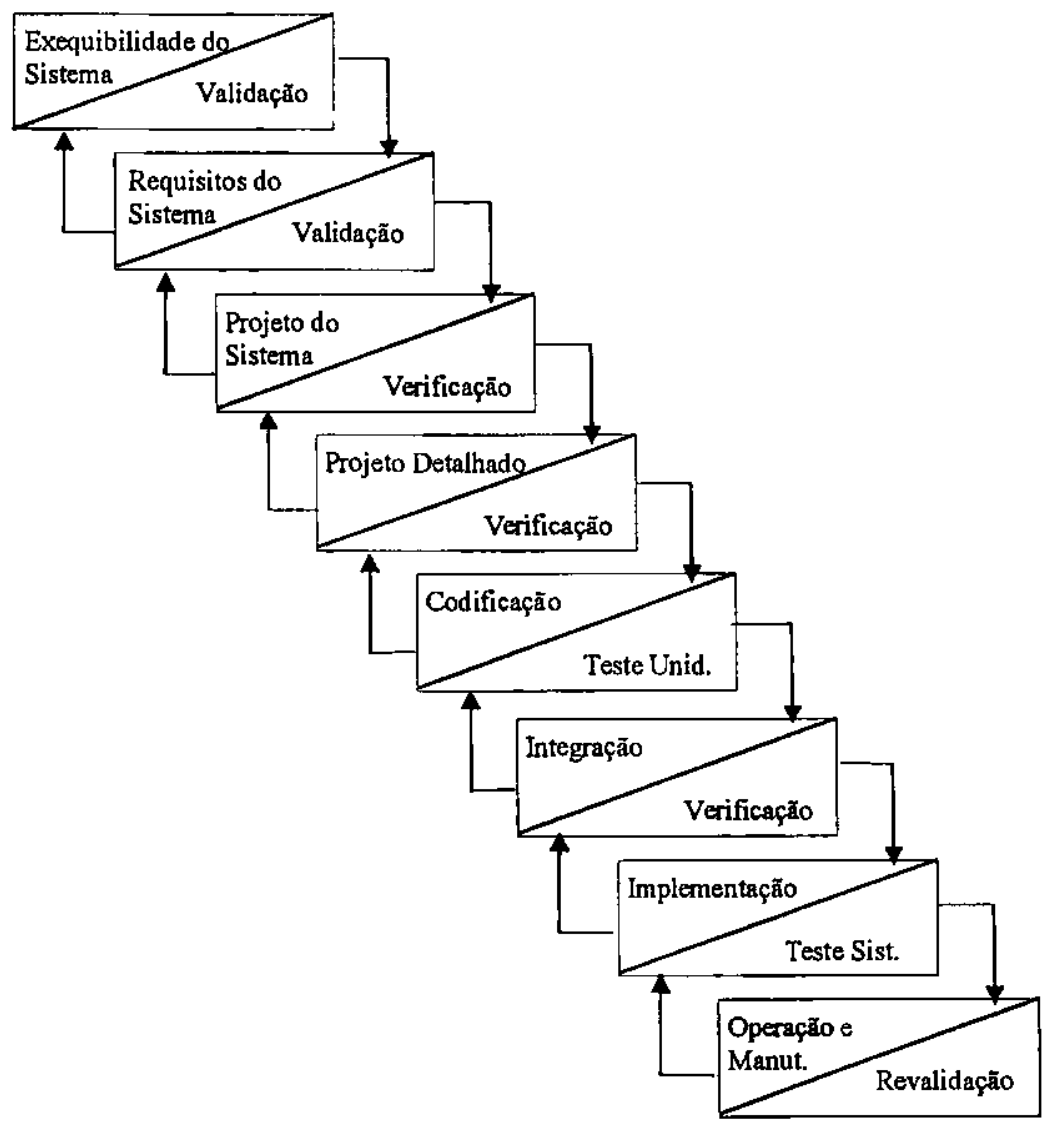

Figura 2 - Ciclo de Vida [BOEHIM81]

O ciclo de vida não é seguido de forma linear. A natureza iterativa no processo de desenvolvimento de software fica evidenciada na figura 2. Por exemplo, ao revisar um projeto e concluir que o mesmo tem alguma falha pode-se retornar ao início para corrigir ou alterar o projeto. Obviamente, quanto mais tarde for detectada uma falha ou erro, maior será o custo para sua correção, o que caracteriza retrabalho.

Quando um projeto é desenvolvido, cada fase do ciclo de vida pode ser "administrada" separadamente, ou seja, ter seu levantamento de necessidades, recursos e 
alocação de mão de obra para a execução de sua tarefa. Enfim, ter sua própria estratégia de implementação.

\subsubsection{Aspectos Gerenciais}

As atividades de gerenciamento de projeto são freqüentemente vistas como é mostrado na figura 3 [ABDEL-HAMID89a].

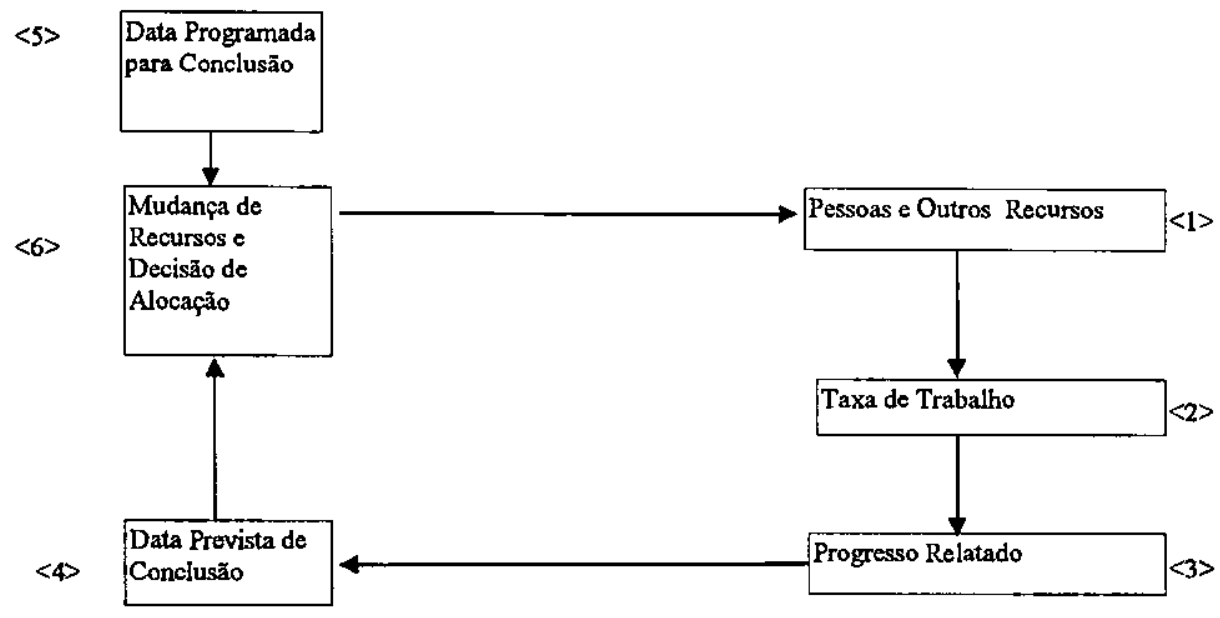

Figura 3 - Modelo Simplificado de Desenvolvimento de Software [ABDEL-HAMID89a]

O modelo acima consiste em um visão simplificada que mostra como o processo pode ser executado. A primeira atividade consiste na alocação de recursos (1). Em seguida tem-se o acompanhamento da evolução do projeto (2), que permite o relato do progresso conseguido (3). Pode-se então avaliar a evolução do processo e estimar uma data prevista para sua conclusão (4) considerando o tempo que foi utilizado para a produção até o momento e o que falta produzir. A retroalimentação é fechada pela comparação entre o tempo estimado para término (4) e o tempo programado para término (5). Essa comparação pode fazer com que seja tomada a decisão de se alterar a alocação de recursos para o projeto (6). 
Porém, o gerenciamento de projetos de software é muito mais complexo do que o exposto acima. Consiste em um complexo conglomerado de variáveis interdependentes relacionadas de modo não linear. A figura 3 denota um relacionamento direto entre o ato de se aumentar os recursos e pessoas de um projeto e o aumento da taxa de trabalho (produção), ignorando um aspecto vital do ambiente real de produção: o aumento de comunicações e treinamentos, que pode diluir a produtividade da equipe de produção. A diminuição da produtividade reduz a taxa de progresso do projeto atrasando-o ainda mais. Abaixo, na figura 4 , tem-se a incorporação da produtividade no processo de desenvolvimento de um projeto [ABDEL-HAMID89a].

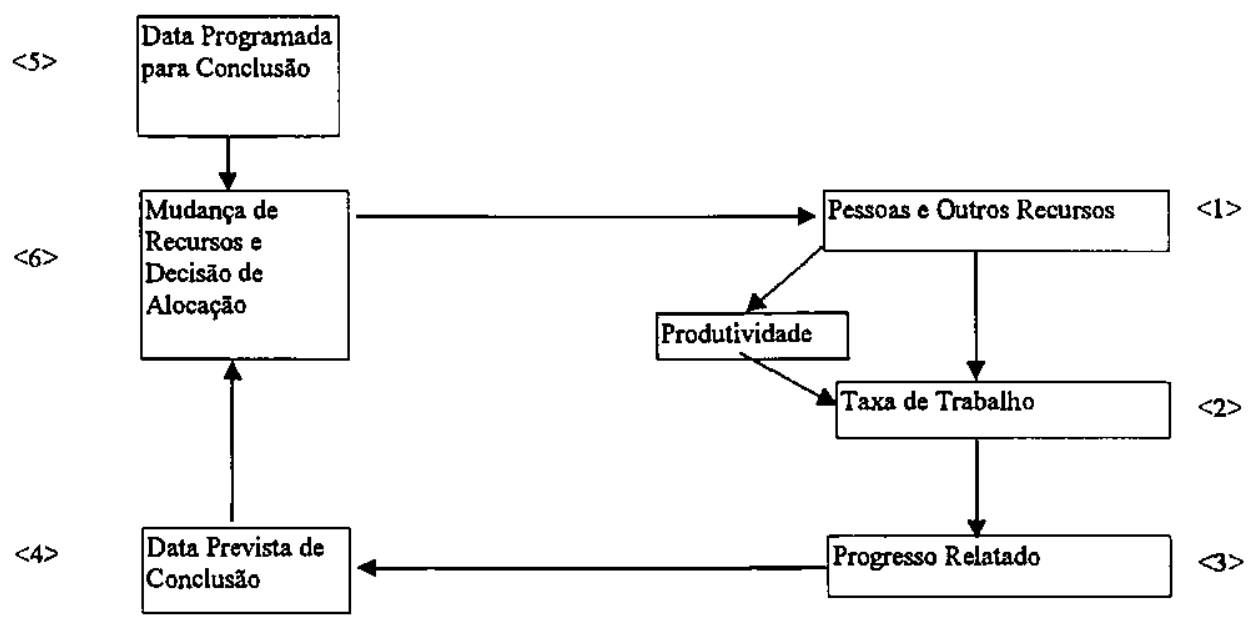

Figura 4 - Ajuste ao Modelo de Desenvolvimento de Software (1) [ABDEL-HAMID89a]

Outra força presente no mundo real não foi exposta ainda: as pressões de possíveis atrasos no cronograma de produção, que influenciam diretamente na produtividade. Essas pressões têm influência também sobre um possível aumento da taxa de erro da equipe de desenvolvimento, provocando assim um aumento na taxa de retrabalho do projeto, que consiste no esforço extra para novamente executar uma tarefa de modo a produzir o resultado esperado. Com o aumento da taxa de retrabalho a equipe de desenvolvimento perde tempo, o que atrasa o progresso do projeto em função da reexecução de tarefas, sejam elas totais ou parciais, de natureza corretiva ou adaptativa a novas situações decorrentes de mudanças no projeto. Outra conseqüência dessa pressão é a evasão de pessoal da equipe de 
desenvolvimento, provocando aumento na rotatividade e a conseqüente diminuição de produtividade. Essas relações são expostas na figura 5 .

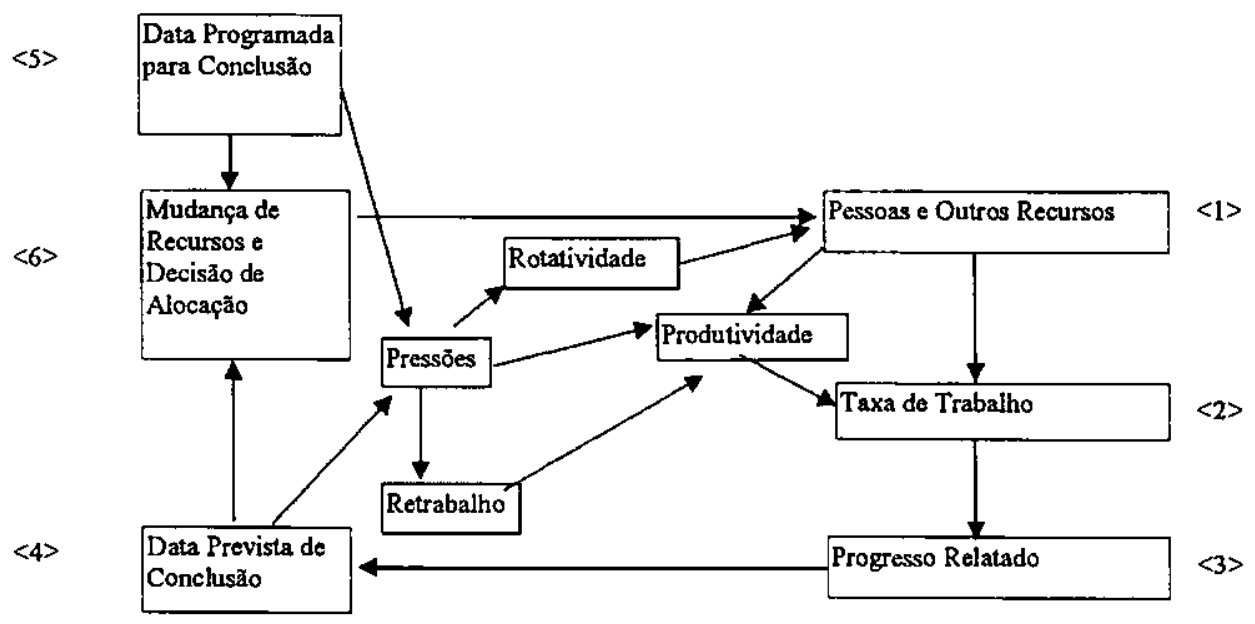

Figura 5 - Ajuste ao Modelo de Desenvolvimento de Software (2) [ABDEL-HAMID89a]

Quanto ao "Progresso Relatado", deve-se considerar que existe uma diferença em relação ao "Progresso Real", ou seja, o que é relatado representa o progresso percebido e ainda com alguma divergência em função do tempo decorrido entre e a percepção e o relato. A figura 6 traz essa consideração.

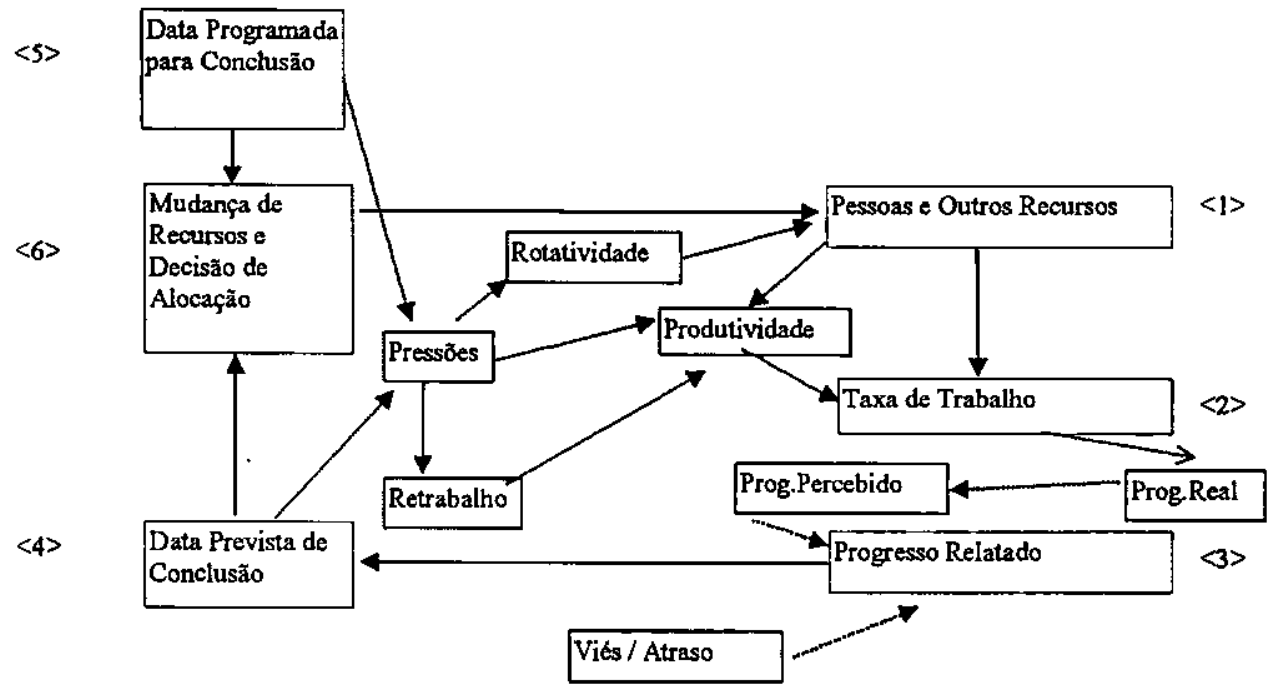

Figura 6 - Ajuste ao Modelo de Desenvolvimento de Software (3) [ABDEL-H.AMID89a] 


\subsection{Modelos para Gerenciamento de Projeto de Software}

O artificio de modelar é centrado no modelador, de modo que se modela o que se entende do mundo. A criação de um modelo depende do conhecimento e das razões estratégicas do modelador que guiada pela percepção, classificação e reação ao ambiente, expressa o modelo por intermédio de estruturas de símbolos. $\mathrm{O}$ ato de construir modelos explora meios alternativos para representação desse conhecimento, enquanto análise e simulação são usados na sua aplicação.

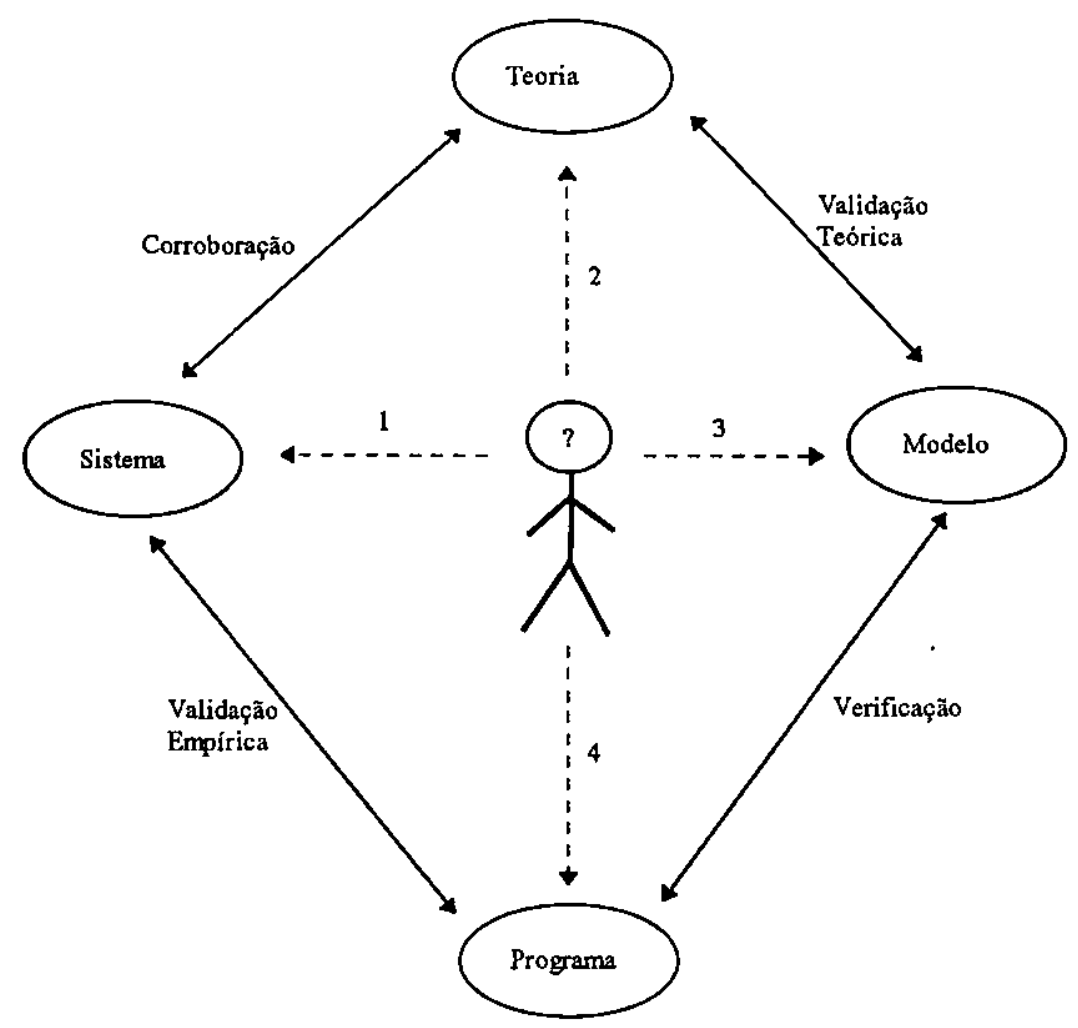

Figura 7 - Criação de Modelos [KREUTZER86]

A figura 7 mostra simplificadamente o processo de modelagem como uma atividade mental. Quatro atividades distintas são identificadas. A primeira é a identificação do sistema, que estabelece o relacionamento entre o observador e uma parte da realidade que $o$ cerca. Um sistema é definido como uma coleção de objetos, seus relacionamentos e o comportamento relevante diante de algum conjunto de propósitos que considera-se como escopo das atividades a serem modeladas, constituindo o foco da modelagem. 
A segunda atividade corresponde à representação do sistema, na qual imagens simbólicas de objetos, relacionamentos e comportamentos são ligadas a estruturas como parte de algum amplo quadro mental de crenças, como base de alguma teoria para entendimento do problema. Não se pode evitar a direção dada por teorias. Teorias podem ser descritivas, usadas para explicações e prognósticos, ou podem ser normativas, usadas para prescrever que algo deve ser feito. Diferentes tipos de teorias levam a diferentes tipos de modelos.

A terceira atividade trata do projeto do modelo. Um modelo é uma representação apropriada de estruturas e processos de um minimundo instanciando algum aspecto da teoria. Um modelo pode crescer de forma indesejada, tendo sua complexidade aumentada de forma inútil [KREUTZER86]. Quanto mais abrangente for o modelo melhor será para se ter uma visão geral, principalmente das influências sofridas e do que ele influencia. Porém, um modelo simplificado pode ser melhor para se visualizar o seu comportamento. Abstrações e generalizações são técnicas importantes para manter modelos complexos intelectualmente gerenciáveis.

A quarta atividade descrita na figura 7 considera a utilização de um computador para a implementação do modelo, podendo ser referida como codificação do modelo. Essa fase é dedicada à criação de programas que simulem o comportamento do sistema [KREUTZER86]. Esse processo de simulação permite uma visualização do comportamento do sistema considerando os parâmetros estabelecidos no modelo.

A criação de modelo do processo de desenvolvimento de software considerando os aspectos gerenciais intangiveis auxiliam os gerentes de projeto em suas atividades de planejamento e acompanhamento do processo. A possibilidade de simular o modelo permite visualizar, no mínimo, a tendência do comportamento do modelo criado auxiliando a tomada de decisão. A seguir são apresentadas três possibilidades para modelagem de projeto de software: Modelos Mentais; Modelos Baseados em Planilhas Eletrônicas e Modelo Dinâmicos..

\subsubsection{Modelos Mentais}

De acordo com o entendimento informal pode-se interpretar um modelo, no contexto de discussões sobre gerenciamento de software e métodos, em termos de abstrações 
gráficas do software - diagrama de fluxos de dados, diagrama entidade-relacionamento, etc - e no contexto de processo de software sob a forma de fluxos de trabalho (work-flows) ou diagramas de fluxo (flowcharts). Porém, raramente são utilizados por gerentes de software para organizar suas atividades, apenas auxiliam a avaliação, planejamento e discussão da estratégia global. Os gerentes de software usam uma variedade de alternativas para construir modelos que representam os problemas e auxiliam a tomada de decisão.

Um modelo mental é o que o termo diz: um modelo no qual uma pessoa planeja como proceder diante de um problema ou situação, podendo ser influenciado por políticas e por um enorme espectro de emoções humanas. Modelos mentais têm como principais características não expressar nada por escrito; não há nada articulado em qualquer forma e simplesmente representam a "prática particular" de gerentes de software sobre como realizam seus trabalhos [YOURDON96].

Enquanto os componentes "oficiais" de um modelo de processo de software cascata versus prototipação, por exemplo - são obviamente importantes, os aspectos "soft" - aspectos intangíveis do comportamento humano ou das organizações - também são importantes. Na verdade, eles são freqüentemente mais importantes pois não são considerados. Então, se a intenção é melhorar o processos de software, é necessário ter um mecanismo para ilustrar, discutir e aprender sobre os componentes "soft" que abrangem todo o processo de software.

Portanto, embora os modelos mentais sejam os mais utilizados por gerentes de software, que tomam decisões sem base em dados concretos, o ideal é ter uma representação do modelo considerado, no mínimo para melhorar o entendimento do processo possibilitando a discussão do modelo. Como conseqüência tem-se um fator que pode ser negativo a princípio: a exposição de idéias que pode causar certo constrangimento. Porém, o fato de poder discutir o modelo traz a vantagem possibilitar a melhora o modelo tornando-o mais representativo.

\subsubsection{Modelos Baseados em Planilhas Eletrônicas}

É comum encontrar gerentes de software utilizando PERT ou Diagramas de Gantt, baseados em uma ferramenta conveniente executada em computadores pessoais, indicando 
caminhos críticos de um projeto. Tais diagramas são úteis para visualização dos aspectos chave do projeto, mas é comum também encontrar gerentes de software utilizando planilhas eletrônicas do tipo Microsoft Excel ou Lotus 1-2-3. Tais ferramentas fornecem informações importantes e muitos gerentes argumentam que elas fornecem um certo grau de percepção do processo. Um número ou fórmula pode ser alterado em qualquer célula e outras células são atualizadas automaticamente de forma apropriada.

Apesar disso, há um problema fundamental: a visualização estática, no sentido de que não apresentam alterações em função do tempo. Embora uma planilha possa vir a representar o comportamento de uma organização de software em função do tempo pela repetição contínua, porém limitada pela capacidade máxima da planilha, não é possível observar o dinamismo no sentido visual [YOURDON96] pois não retratam os relacionamentos entre células.

Um outro problema é a representação somente de coisas tangíveis, coisas mensuráveis, como por exemplo pessoas, dinheiro, estações de trabalho e linhas de código. Há fatores "soft" - moral, motivação, qualidade e acúmulo de conhecimento sobre o método de desenvolvimento de software utilizado - que não são facilmente representáveis em uma planilha pela dificuldade de quantificá-los.

Conhecimento acumulado é um bom exemplo de um fator "soft". Educadores experientes podem ter alguma métrica mais ou menos quantitativa nessa área, porém gerentes podem argumentar que isso não é algo que possa ser medido e expresso em valores quantificados em polegadas ou centímetros, por exemplo. Porém, os gerentes de software são capazes de dizer se a equipe de desenvolvimento tem "pouco" ou "muito" conhecimento acumulado e se o conhecimento acumulado está aumentando ou diminuindo.

Além disso, representações gráficas trazem a vantagem de enfatizar as conectividades e simetrias, fornecendo uma rica sintaxe para definir visualmente conceitos tais como ligações, fluxos e direções, dentre outros, sendo para a maioria das pessoas uma representação mais fácil de ser entendida.

\subsubsection{Modelos Dinâmicos}

Modelos dinâmicos tratam da variação do comportamento de uma organização em função da variação do tempo, considerando a característica de retroalimentação de um 
sistema. No processo de software há componentes que interagem e que mudam todo o tempo. A situação citada acima envolvendo o "conhecimento acumulado" é um exemplo: ele muda dia a dia e os gerentes têm que analisar continuamente a melhor opção para manter a equipe em condições de produzir dentro de prazos e orçamentos.

Uma característica marcante de modelos dinâmicos é a natureza da interação entre os componentes de um processo. Essas interações podem ser incorporadas em um modelo estático (em uma planilha), sendo equivalente ao relacionamento entre células, e podem ser expressas por fórmulas matemáticas envolvendo o conteúdo de outras células. Porém, apesar de ser possível visualizar o inter-relacionamento entre células olhando para o conteúdo das mesmas (fórmulas), esse relacionamento não é visivel olhando para uma planilha como um todo. A combinação de várias interações de componentes pode causar um efeito de propagação em uma organização de software.

$\mathrm{Na}$ busca pela melhoria da qualidade do processo de software o Instituto de Engenharia de Software da Universidade de Carnegie Mellon (SEI) propôs um caminho de melhoramento evolucionário que classifica a maturidade do processo de software, o Capability Maturity Model (CMM), estabelecendo uma estrutura de cinco níveis como exposto na figura 8 , sendo que cada nivel "atua" em áreas-chave relacionadas na tabela 1 [SAIEDIAN95]. As organizações que alcançam níveis 3, 4 ou 5 na escala do Capability Maturity Model (CMM) começaram a atestar que esses aspectos de dinâmica do processo são realmente importantes; e sempre que os fatores "soft" são deixados de lado, o impacto da retroalimentação (feedback) e do tempo de espera do processo pode ter um enorme impacto sobre o sucesso do processo de software [LEHMAN96]. Um exemplo claro e drástico é um defeito não detectado na fase de análise em um modelo de ciclo de vida em cascata, em que o erro só é detectado na fase de teste. Em um processo formal e rigoroso de desenvolvimento de software isso significa voltar à fase de análise e retomar as atividades dessa fase, passar pelo projeto, codificação e retornar aos testes. E tudo isso tem um impacto sobre o tempo de ciclo do processo [YOURDON96]. Esse impacto se dá não somente pelo tempo gasto na correção do erro mas pode vir a influenciar negativamente na produtividade em função do retrabalho, ou aumentar as pressões se o cronograma estiver atrasado ou passar a estar atrasado devido à correção, dentre outros fatores "soft" que podem influenciar o processo de desenvolvimento. A verificação da importância das aspectos dinâmicos pelas organizações que atingem o nível 3, 4 e 5 na escala Capability Maturity Model (CMM) se dá em função da possibilidade de 
comparação entre as estimativas e as realizações pois nesses níveis todos os dados são armazenados na base de dados do processo de software da organização.

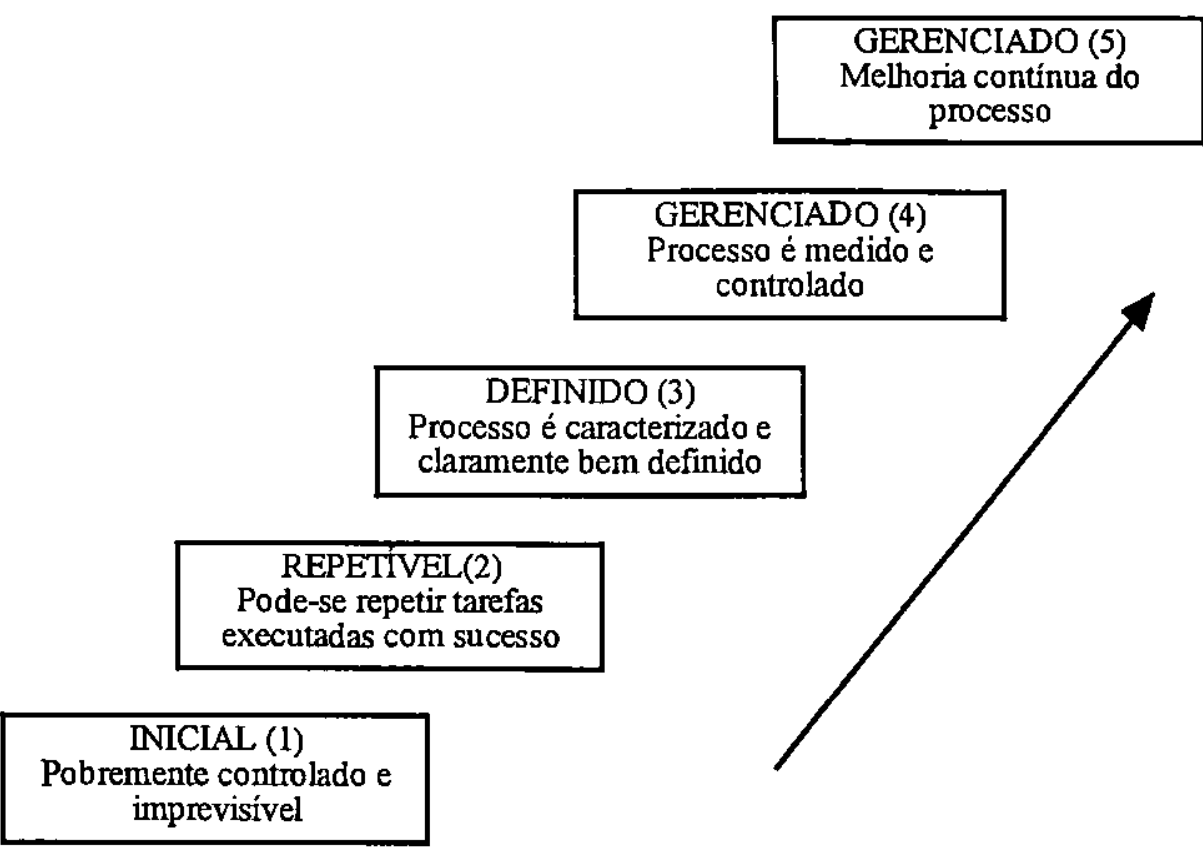

Figura 8 - Estrutura do Capability Maturity Model (CMM) [SAIEDIAN95]

Tabela 1 - Áreas-Chave do Processo [SAIEDIAN95]

\begin{tabular}{|c|c|}
\hline 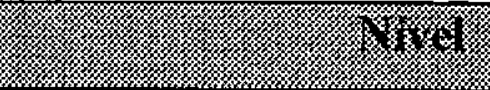 & a \\
\hline Gerenciado & $\begin{array}{l}\text { Gerenciamento da Mudança no Processo } \\
\text { Gerenciamento da Mudança Tecnológica } \\
\text { Prevenção de Defeito }\end{array}$ \\
\hline Controlado & $\begin{array}{l}\text { Gerenciamento da Qualidade do Software } \\
\text { Gerenciamento Quantitativo do Processo }\end{array}$ \\
\hline Definido & $\begin{array}{l}\text { Revisões (peer review) } \\
\text { Coordenação Intergrupos } \\
\text { Engenharia de Produto do Software } \\
\text { Gerenciamento de Software Integrado } \\
\text { Programa de Treinamento } \\
\text { Definição do Processo da Organização } \\
\text { Foco no Processo da Organização }\end{array}$ \\
\hline Repetivel & $\begin{array}{l}\text { Gerenciamento da Configuração do Software } \\
\text { Garantia da Qualidade do Software } \\
\text { Gerenciamento de Subcontrato do Software } \\
\text { Acompanhamento do Projeto de Software } \\
\text { Planejamento do Projeto do Software } \\
\text { Gerenciamento de Requisitos. }\end{array}$ \\
\hline Inicial & - \\
\hline
\end{tabular}


Outra forma de atestar a importância da dinâmica do processo é a comparação de previsões acerca de tamanho do software a ser desenvolvido, feitas no início do projeto com o tamanho atingido, que normalmente falham mesmo feitas por profissionais experientes dentro da organização. Embora nesse caso exista a possibilidade de falha no estabelecimento dos requisitos, a diferença geralmente se dá pela não consideração dos aspectos dinâmicos, pois mesmo sem alterar os requisitos iniciais as estimativas falham.

\subsection{Dinâmica de Sistemas}

Considerando que uma planilha eletrônica é inadequada para representar o dinamismo de um processo de software, pois elas não ilustram as interdependências e os ciclos de retroalimentação (loops de feedback) entre os componentes do processo, os modelos visuais são usualmente melhores para ilustrar a natureza holística do processo.

As técnicas para representar os componentes do sistema, como diagrama entidaderelacionamento, diagrama de fluxo de dado e diagramas orientados a objeto formam a base para modelar o processo de desenvolvimento de software. Essas notações gráficas são de natureza estática, não sendo capazes de representar o dinamismo do processo.

Embora antiga - proposta na década de 1960 — há uma estrutura de Modelos de Sistemas Dinâmicos com a intenção exclusiva de representar a natureza dinâmica e as características de retroalimentação (feedbacks), inicialmente aplicada a atividades industriais, tratando de interações entre fluxos de informações, dinheiro, ordens e materiais, dentre outros [FORRESTER/61].

Porém, embora fácil de ser utilizada para representar um sistema, essa estrutura foi deixada de lado por longo período pela dificuldade da sua utilização. Tudo que a notação gráfica representa é muito trabalhoso, a ponto de tornar-se inviável obter de forma manual a representação e a simulação do modelo em função da repetição dos cálculos, mesmo considerando a utilização de computadores, pois com a tecnologia existente na época não era possível fazer muito principalmente devido aos recursos gráficos escassos.

A explosão da tecnologia trouxe como resultado a possibilidade de utilizar essa estrutura de representação de processos dinâmicos em computadores, por intermédio de uma 
ferramenta que possibilite a representação gráfica e também sua animação, simulando o comportamento do sistema representado em função de uma variação temporal.

\subsubsection{Notação}

O processo de modelagem proposto por Forrester para o desenvolvimento de modelos de dinâmica de sistemas utiliza a notação exposta na figura 9. Do ponto de vista de sistemas dinâmicos, todos os sistemas podem ser representados em termos de "níveis" e "taxas" variáveis, com "variáveis auxiliares" usadas para melhorar a clareza e a simplicidade.

O termo "nível" é uma acumulação, ou uma integração, em função do tempo, de fluxos ou mudanças que entram ou saem do nível. Dessa forma, "nível" pode ser pensado como representando um tanque que armazena algum líquido, e o dinamismo é como o processo do fluido: existe um reservatório no qual entra e sai fluido por dutos diferentes. Os "fluxos" indicam entradas e saídas de um "nível" que, por conseqüência, aumentam ou diminuem seu conteúdo. Correspondem a uma tubulação que conduz líquido de um reservatório para outro.

Ligados aos "fluxos" há os controladores de passagem, que são chamados de "taxas". Enfatizando a analogia com o processo de acúmulo e fluxo de líquidos, pode-se considerar as taxas como sendo uma válvula reguladora de fluxo. Obviamente, fluxos sempre têm uma origem e um destino. Às vezes, a origem ou o destino de um fluxo pode estar fora do escopo de tratamento do modelo construído. Em ambos os casos a representação é feita pela utilização da figura de muvens.

Variáveis tangíveis são "níveis" ou "taxas" representando acumulações de fluxos anteriores ou a seguir. Normalmente é dificil escrever alguma taxa sem fazer uso de algum tipo de cálculo. Essas computações algébricas são denominadas "variáveis auxiliares" e fazem uso de entradas para seus cálculos. Um outro símbolo utilizado é a representação de constantes, que como o próprio nome diz, representa valores inalteráveis no modelo durante a simulação.

E finalmente, em função da complexidade do modelo, pode ser necessária a divisão em vários diagramas. Tem-se então a necessidade de representar um "conector" entre diagramas, que indica as influências de uma variável que aparece em um diagrama sobre elementos que encontram-se em outro diagrama. 
Origem e Destino

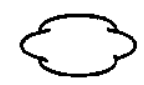

Fluxo de Informações

Outros Fluxos

Constantes

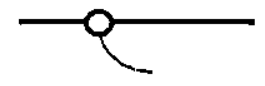

Influente

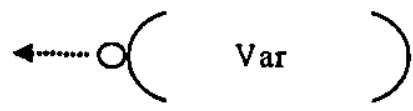

Influência de variável que está em outro diagrama

Influenciado

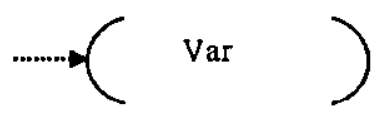

Influenciando variável que está em outro diagrama

Nivel

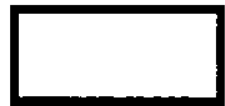

Regulador de Fluxo ou Taxa

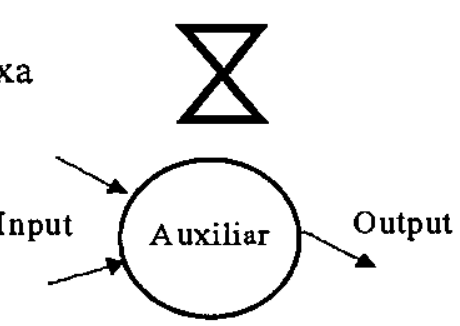

Variáveis Auxiliares

Figura 9 - Notação da Dinâmica de Sistema [FORRESTER61]

Para uma melhor organização do modelo foi introduzida na notação original a representação de subsistema que é feita por um retângulo de cantos arredondados, como exposto na figura 10.Um subsistema contém a representação de um modelo com os mesmos elementos descritos na figura 9 . 


\subsubsection{Um Exemplo de Sistema Dinâmico: Projeto de Software}

As ilustrações sobre o processo de desenvolvimento de software expostas anteriormente mostram que variáveis tangíveis e intangíveis influenciam no processo de desenvolvimento de software. Tais variáveis não são independentes, são ligadas uma nas outras de um modo complexo, fugindo o entendimento de seu comportamento da capacidade de intuição humana. Além disso, a complexidade de um sistema pode levar à necessidade de dividi-lo em subsistemas [RICHARDSON81]. No caso do desenvolvimento de software pode-se considerar os subsistemas mostrados na figura 11.

Nota-se a interação de atividades de natureza gerencial e de natureza técnica da produção de software dada pela troca de influências, caracterizando um ambiente de relações de causa-efeito circular. Nesses ambientes, pode ocorrer o cancelamento ou a ampliação do efeito de uma alteração em uma variável pela reação causada em outra variável.

Dessa forma, organizando-se as variáveis tangíveis e intangíveis que influenciam no processo de desenvolvimento de software, expostas anteriormente nas figuras 4,5 e 6 , nos subsistemas identificados na figura 11, tem-se o quadro exposto na figura 12.

Nessa estrutura (figura 12), são considerados somente as variáveis, não sendo considerada a fase em que o projeto se encontra, denotando a possibilidade de "administração isolada" de fases (Figura 2 - Ciclo de Vida). Vale ressaltar que na figura 12, a fase inicial de levantamento de requisitos e a fase de manutenção (vide Figura 2 - Ciclo de Vida) não são consideradas pois nelas existem relacionamentos com entidades externas ao processo de desenvolvimento de software que não sāo mapeadas, tratando apenas dos relacionamentos 
endógenos do processo de desenvolvimento de software, sendo justificado por fugir ao controle do responsável pelo desenvolvimento de software.

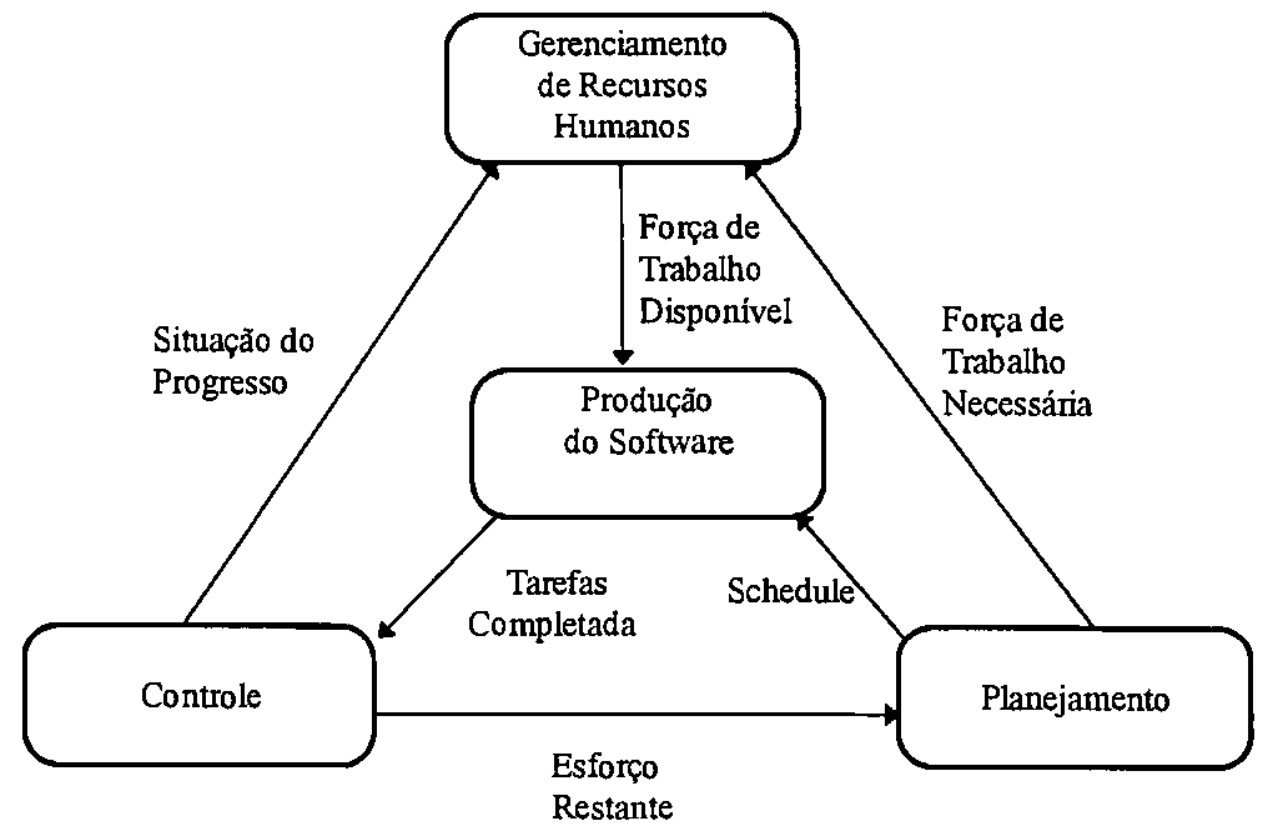

\section{Figura 11 - Subsistemas do Projeto de Software [ABDEL-HAMID89b]}

Usando as convenções propostas por Forrester, apresentadas acima, pode-se obter um modelo que represente o processo de desenvolvimento de software contendo componentes que descrevem o comportamento dos subsistemas do projeto de software. Para isolar o comportamento de alguma atividade específica pode-se ainda subdividir os subsistemas identificados, por exemplo separando as atividades de teste e controle de qualidade

Cada subsistema afeta e é afetado por outros, como por exemplo o subsistema de Gerenciamento de Recursos Humanos, que compreende contratar, treinar, avaliar a assimilação e transferência de recursos humanos entre projetos, com a taxa de contratação em função da força de trabalho necessária para completar o projeto na data planejada, como apresentado na figura 12. Uma visão simplificada desse subsistema é mostrada na figura 13. 


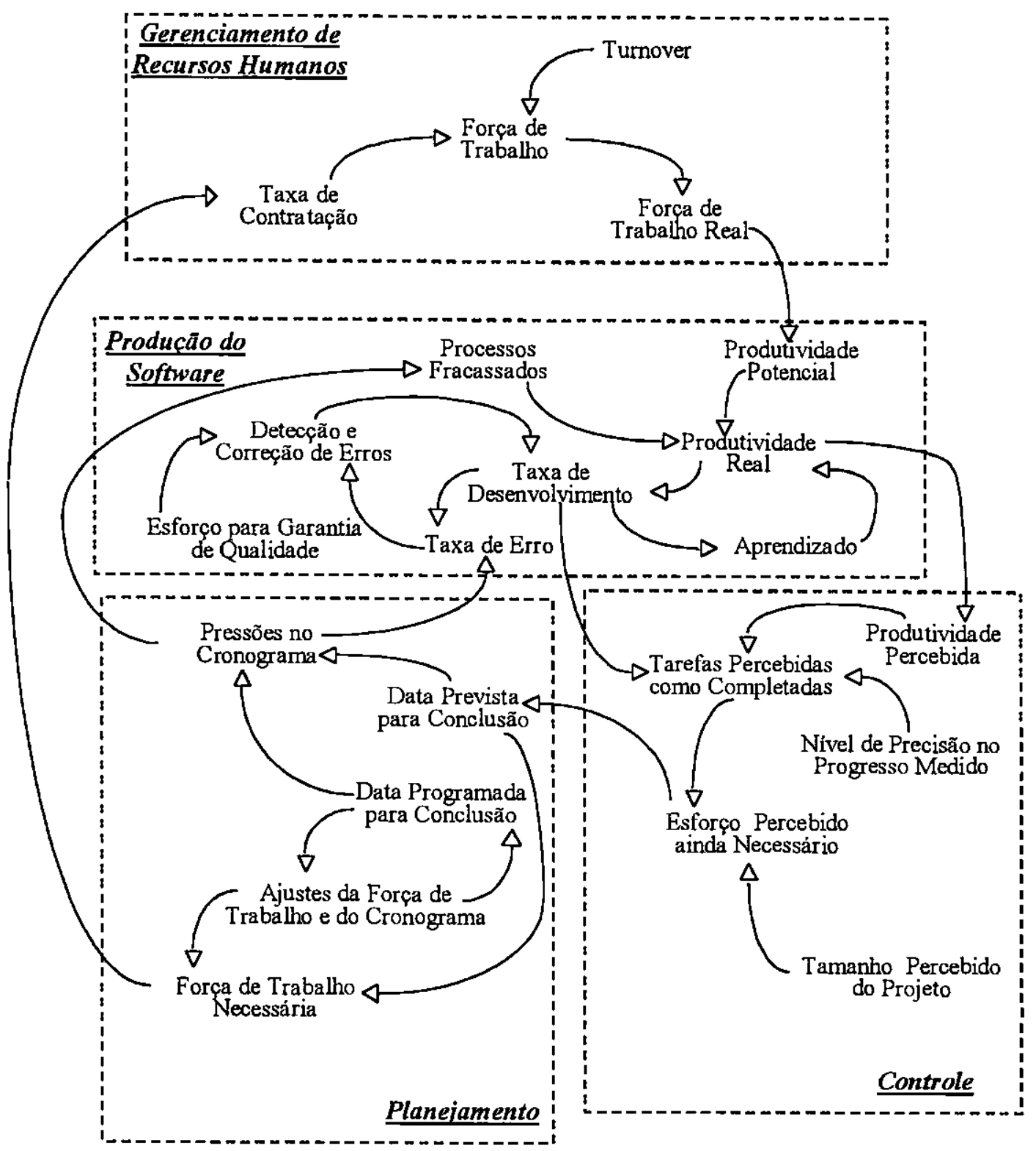

Figura 12 - Estrutura dos Subsistemas do Projeto de Software [ABDEL-HAMD89a]

Da perspectiva do gerente do projeto, os membros da equipe podem ser classificados como novatos ou experientes, representados no modelo mostrado na figura 13 como Força de Trabalho - Novatos e Força de Trabalho - Experientes respectivamente. A distinção é justificada pela diferença de produtividade entre eles, seja por aspectos técnicos ou sociais. O dinamismo do processo de gerenciamento de recursos humanos envolve a contratação de pessoas novas, a promoção de novatos a experientes, quando eles se tornam 
experientes, o eventual desligamento de experientes quando eles saem por qualquer motivo e a transferência de membros da equipe para outro projeto, tanto de novatos como de experientes.

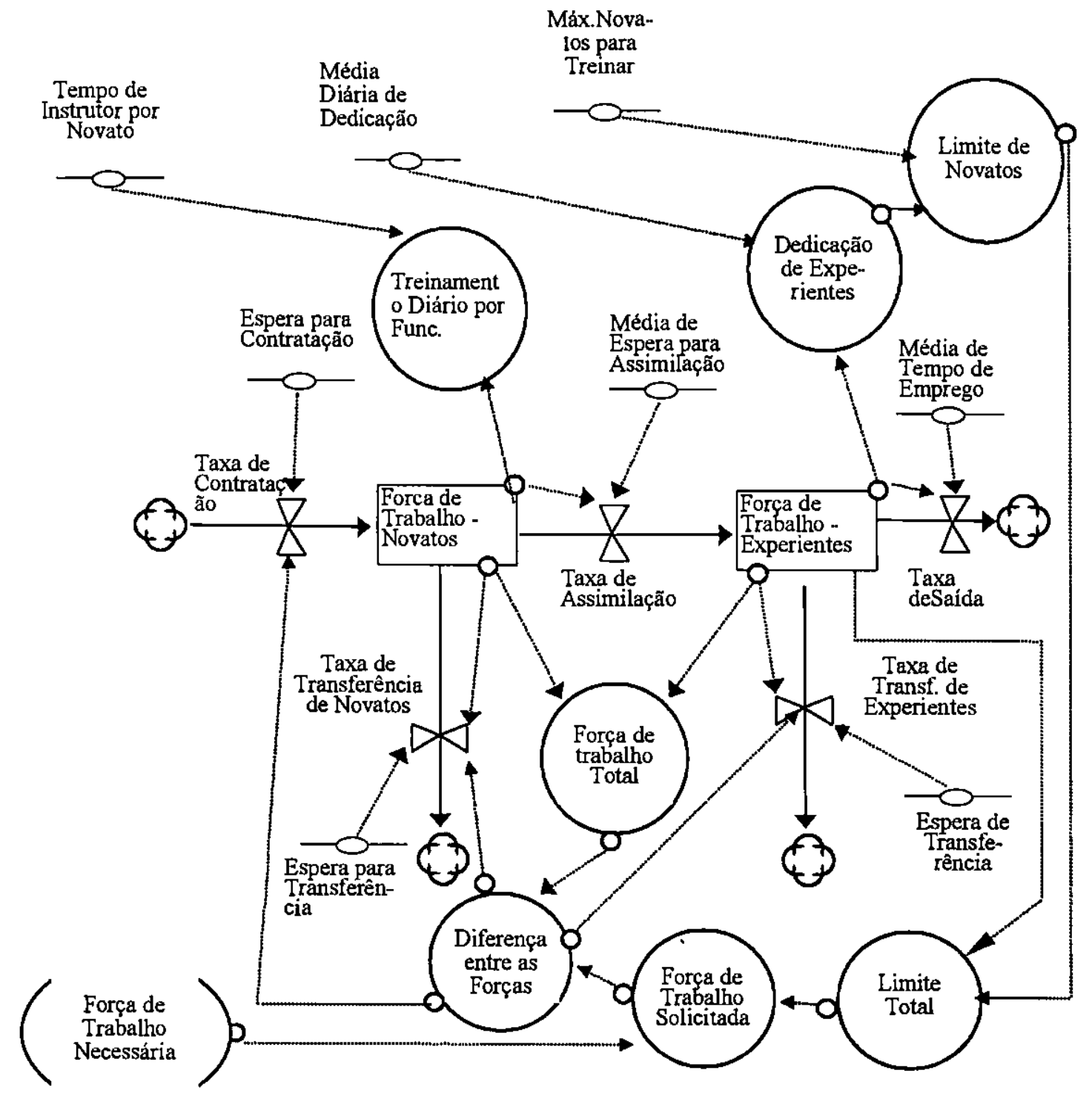

Figura 13 - Modelo do Subsistema de Recursos Humanos [ABDEL-HAMD90]

Pode-se observar na figura 13 que todos que entram em um projeto são considerados novatos pois requerem treinamento considerável para familiarizar-se com a organização, hardware, software, técnicas de programação e métodos de projeto, dentre outros aspectos do projeto. Obviamente nem todos os recém-chegados em um projeto vêm de fora da 
organização, podem ser transferidos de outro projeto interno conhecendo assim a organização e suas características, porém entram como novatos pois precisam de algum tempo para aprender sobre o projeto, seus objetivos, planos de trabalho e detalhes do sistema. Nesse caso, leva-se menos tempo no aprendizado e, conseqüentemente, menor custo comparado aos recrutas externos. E mesmo de dentro da organização, esse tempo é minimizado em função da padronização do processo de software da organização, o que é requisito para atingir o nível 3 da escala do Capability Maturity Model (CMM).

Além da diferença de produtividade, outra razão para a separação entre novatos e experientes foi captar o esforço extra (overhead) envolvido na adição de novos membros na equipe. O treinamento tanto técnico quanto social de recém-chegados é normalmente feito por membros produtivos da equipe [BOTT82], causando um impacto no custo, pois esses membros produtivos têm uma diminuição no tempo dispensado à produção [CANNING77]. Na constante Tempo de Instrutor por Novato é estabelecido um valor médio de consumo de tempo para instrução, ou seja, o tempo médio de um treinador (Força de Trabalho Experiente) gasto por um novato (Força de Trabalho - Novatos). Esse valor é utilizado na variável Treinamento Diário por Func.(ionário) para limitar o tempo dedicado à produção no subsistema de Desenvolvimento.

Em uma organização um desenvolvedor pode trabalhar em mais de um projeto simultaneamente, por isso a Média Diária de Dedicação foi introduzida no modelo e é utilizada para se obter o tempo real de dedicação ao projeto, representada pela variável Dedicação de Experientes. Em Máx. Novatos para Treinar tem-se um valor estabelecido como máximo de treinandos por experiente e pela multiplicação com a Dedicação de Experientes tem-se o Limite de Novatos. A soma algébrica entre Força de Trabalho Experientes e o Limite de Novatos gera o Limite Total que representa o número máximo de empregados desejados no projeto. À Força de Trabalho Solicitada é atribuído o menor valor entre Limite Total e Força de Trabalho Necessária, que foi estabelecido no subsistema de planejamento. A Diferença entre as Forças estabelece a necessidade ou não de contratações indicada pela diferença entre a Força de Trabalho Total e a Força de Trabalho Solicitada, que influenciará na Taxa de Contratação de novos empregados para o projeto em questão. Vale lembrar que "contratar" pode ser a entrada de um novato pela transferência de outro projeto dentro da mesma organização. A tabela 2 complementa a especificação do modelo da figura 13 . 
Tabela 2 - Valores Iniciais e Expressões do Modelo [ABDEL-HAMID90]

\begin{tabular}{|c|c|}
\hline Componentes do Modelo & Fórmulas e Valores Iniciais \\
\hline Tempo de Instrutor por Novato & 0.20 \\
\hline Média Diária de Dedicação & 1 \\
\hline Max. Novatos para Treinar & 1 \\
\hline Espera para Contratação & 45 dias (1.5 mês) \\
\hline $\begin{array}{l}\text { Média de Espera para } \\
\text { Assimilação }\end{array}$ & 80 dias (2.67 meses) \\
\hline Média de Tempo de Emprego & 36 meses \\
\hline Espera de Transferência & 45 dias (1.5 mês) \\
\hline $\begin{array}{l}\text { Treinamento Diário } \quad \text { por } \\
\text { Funci.(onário) }\end{array}$ & $\begin{array}{l}\text { Força de Trabalho Novatos multiplicado por Tempo de } \\
\text { Instrutor por Novato }\end{array}$ \\
\hline Dedicação de Experientes & $\begin{array}{l}\text { Média Diária de Dedicação multiplicado por Força de } \\
\text { Trabalho Experientes }\end{array}$ \\
\hline Limite de Novatos & $\begin{array}{l}\text { Dedicação de Experientes multiplicado por Max. Novatos } \\
\text { para Treinar }\end{array}$ \\
\hline Força de Trabalho Total & $\begin{array}{l}\text { Força de Trabalho Novatos somado a Força de Trabalho } \\
\text { Experientes }\end{array}$ \\
\hline Limite Total & $\begin{array}{l}\text { Força de Trabalho Experientes somado ao Limite de } \\
\text { Novatos }\end{array}$ \\
\hline Força de Trabalho Solicitada & $\begin{array}{l}\text { Minimo entre Limite Total e Força de Trabalho } \\
\text { Necessária }\end{array}$ \\
\hline Diferença entre Forças & $\begin{array}{l}\text { Da Força de Trabalho Solicitada subtrai-se a Força de } \\
\text { Trabalho Total }\end{array}$ \\
\hline Taxa de Contratação & $\begin{array}{l}\text { Diferença entre Forças com retardo de Média de Espera } \\
\text { para Contratação }\end{array}$ \\
\hline Taxa de Assimilação & $\begin{array}{l}0.15 \text { multiplicado por Força de Trabalho Novatos com } \\
\text { retardo de Média de Espera para Assimilação }\end{array}$ \\
\hline Taxa de Saida & $\begin{array}{l}1 \text { dividido por Média de Tempo de Emprego multiplicado } \\
\text { por Força de Trabalho Experientes }\end{array}$ \\
\hline $\begin{array}{l}\text { Taxa de Transferência de } \\
\text { Novatos }\end{array}$ & $\begin{array}{l}5 \% \text { de Força de Trabalho - Novatos com retardo de } \\
\text { Espera de Transferência }\end{array}$ \\
\hline $\begin{array}{l}\text { Taxa de Transferência de } \\
\text { Experientes }\end{array}$ & $\begin{array}{l}\text { 5\% de Força de Trabalho - Experientes com retardo de } \\
\text { Espera de Transferência }\end{array}$ \\
\hline Força de Trabalho - Novatos & 10 \\
\hline $\begin{array}{l}\text { Força de Trabalho } \\
\text { Experientes }\end{array}$ & 15 \\
\hline Força de Trabalho Necessária & 25 \\
\hline
\end{tabular}

É importante notar que o modelo pode ser discutido sem nenhum aspecto de dinamismo e que o caso apresentado acima representa apenas um modelo do gerenciamento de recursos humanos. No ambiente do mundo real pode-se imaginar que um modo apropriado está sendo aplicado para descrever a taxa de assimilação ou a taxa de saída de elementos da 
equipe de desenvolvimento. Por exemplo, uma distribuição normal pode ser gerada a partir de um estudo prévio do comportamento da organização, se é que esse estudo pode ser feito. Algumas taxas porém, são obtidas de forma direta, como é o caso do tempo para contratação de um novo elemento para a equipe [YOURDON96], o que vem corroborar a necessidade de dados históricos para formular o comportamento do modelo.

\subsubsection{Ferramentas para Edição e Simulação de Modelos de Sistemas Dinâmicos}

A primeira ferramenta para simulação de sistemas dinâmicos foi proposta juntamente com o modelo de sistemas dinâmicos. Trata-se de um compilador de propósito especial chamado DYNAMO, que gerava código executável para modelos de sistemas dinâmicos. Esse compilador foi construído para ser utilizado em um IBM 704, e era baseado em FORTRAN.

O compilador DYNAMO parte de um código fonte com estrutura própria, no qual são definidos os elementos do modelo (níveis, varáveis, etc), os valores iniciais e as equações. Esse código é checado para detectar algum erro de sintaxe, erros lógicos que representam inconsistências, detalhes impróprios na estrutura das equações e um resumo da análise é fornecido no final. Caso não seja encontrado nenhum problema, o compilador gera o código executável. Como resultado tem-se uma tabela dos valores assumidos pelas variáveis, considerando as equações definidas no código fonte, em função de uma variação temporal. Tem-se ainda um gráfico impresso expressando tal comportamento. Devido aos recursos disponíveis, o gráfico era impresso utilizando-se uma combinação de letras, cada uma representando uma variável.

Com o compilador DYNAMO é possível simular o comportamento de um sistema dinâmico, seja qual for sua natureza. Porém, por meio de sua utilização não é possível a visualização da dinâmica de sistemas — vale lembrar novamente a disponibilidade de recursos da época - pois não suporta a construção visual de um modelo utilizando-se, por exemplo a notação proposta por Forrester.

Com a evolução tecnológica houve a possibilidade de desenvolver-se uma ferramenta que expresse em um modelo visual a dinâmica de sistema. Vários protótipos e 
trabalhos universitários foram desenvolvidos até que a HPS - High Performance Systems

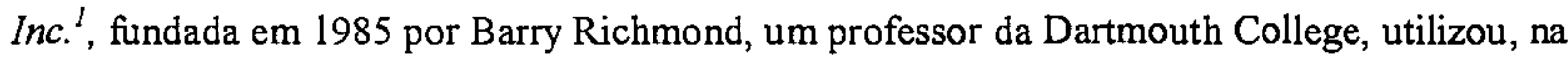
época, a revolucionária interface Macintosh para desenvolver uma ferramenta chamada STHELLA, que deu origem a vários outros módulos. Outro produto dessa empresa é o $i$ Think $k^{\circledast}$ voltado a usuários comerciais, para a área de gerenciamento.

O iThink $^{\otimes}$ consiste em uma ferramenta que parte de um modelo gráfico com definições de comportamento por intermédio de fórmulas e chega à simulação do modelo, que pode ser acompanhada em tabelas e gráficos ${ }^{2}$. Um esboço de sua estrutura é mostrada na figura 14 .

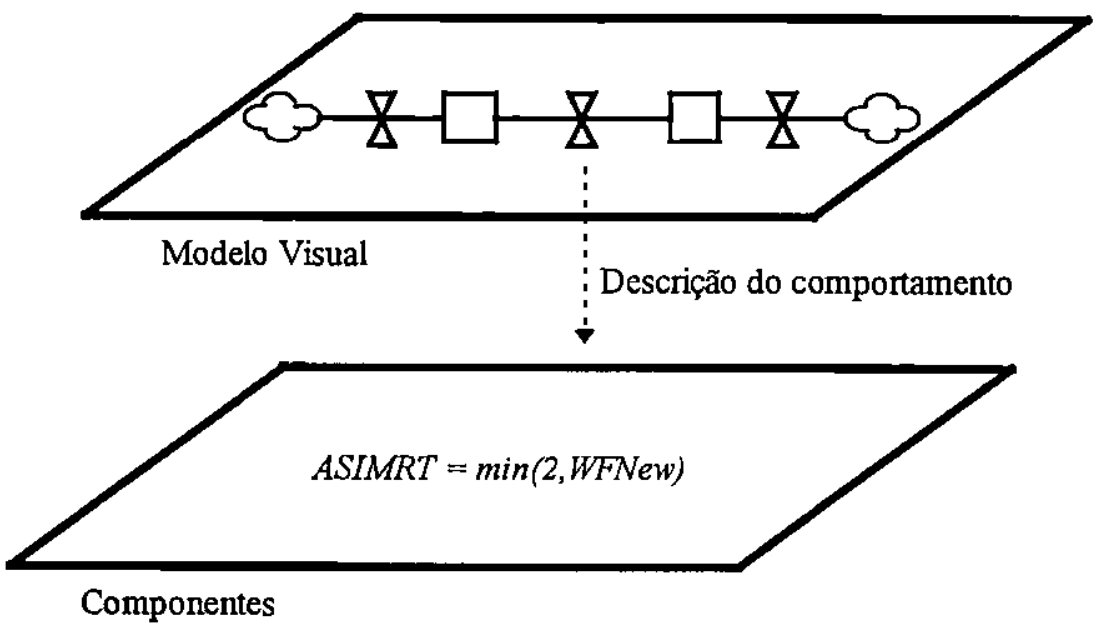

Figura 14 - Estrutura do $i T h i n k^{\oplus}$

Nota-se que essa ferramenta pode ser considerada uma "extensão" do DYNAMO, pois o suporte gráfico tem por objetivo facilitar a construção e visualização do modelo, porém sua simulação dá-se por intermédio das definições expressas nas fórmulas (textos) que descrevem o comportamento dos componentes do modelo, considerando que tais expressões são validadas pelo que for definido no modelo. Obviamente, por tratar-se de um software para ambientes gráficos os resultados obtidos na simulação são exibidos no ambiente gráfico.

\footnotetext{
${ }^{1}$ Endereço Eletrônico: $h$ ttp://www.hps-inc.com

${ }^{2}$ Considerando a utilização de $i$ Think $k^{\otimes} 4.0$ Demo obtida no site da empresa HPS Inc.
} 


\subsection{Considerações Finais}

Neste capítulo foi feita uma apresentação da teoria de dinâmica dos sistemas, relacionando a relevância da dinâmica de sistemas no processo de desenvolvimento de software. Foi mencionada a importância da criação de um modelo visual capaz de evidenciar os relacionamentos entre as variáveis que o compõem, além da necessidade de simular o modelo criado permitindo a visualização de seu comportamento.

Para a criação de um modelo é necessário mensurar os aspectos "soft" da produção de software, o que não é um processo simples, porém é possível que o modelador utilize médias e estimativas próximas da realidade. Com a simulação é possível que sejam avaliadas alternativas e suas conseqüências futuras antes de tomar alguma decisão efetiva. A criação de cenários permite a avaliação de custos e pode ajudar a definir metas a serem alcançadas, de modo a colaborar com o objetivo final: produção de software dentro de prazos e orçamentos com qualidade. Para tanto é necessária a utilização de uma ferramenta que apoie esse processo, tanto de modelagem quanto de simulação de cenários. 


\section{A Ferramenta}

\subsection{Considerações Iniciais}

Com base no que foi exposto no capítulo anterior, que apresentou a modelagem dinâmica voltada à produção de software, apresenta-se neste capítulo uma ferramenta para edição e simulação da dinâmica de sistemas, capaz de possibilitar a representação pela utilização da notação proposta por Forrester, com uma interface gráfica. Para apoiar sua simulação a ferramenta permite o estabelecimento das expressões que determinam o comportamento do sistema, como taxas e variáveis que podem ser expressas por intermédio de fórmulas. Como resultado, deve apresentar o comportamento do sistema em forma de tabelas e gráficos, facilitando a visualização.

Neste capítulo, na seção 3.2 é apresentada a estrutura da ferramenta desenvolvida, na seção 3.3 o modelo conceitual e na seção 3.4 a base de dados. Em seguida, a seção 3.5 apresenta aspectos da implementação e da interface e a seção 3.6 aspectos da simulação de modelos.

\subsection{A Estrutura da Ferramenta}

Para apoiar a modelagem e a simulação da dinâmica de sistemas a ferramenta proposta está estruturada de maneira que uma interface gráfica permite a edição gráfica do modelo. A edição gráfica é dividida em dois níveis, sendo que no primeiro nível é feita a 
definição de subsistemas que integram o modelo e no segundo nivel cada subsistema tem seu modelo estabelecido utilizando-se a proposta de Forrester. Juntamente com o modelo visual é descrito o comportamento do sistema por intermédio de expressões matemáticas e valores iniciais de seus componentes, como é mostrado esquematicamente na figura 15 , usando a sintaxe da ferramenta.

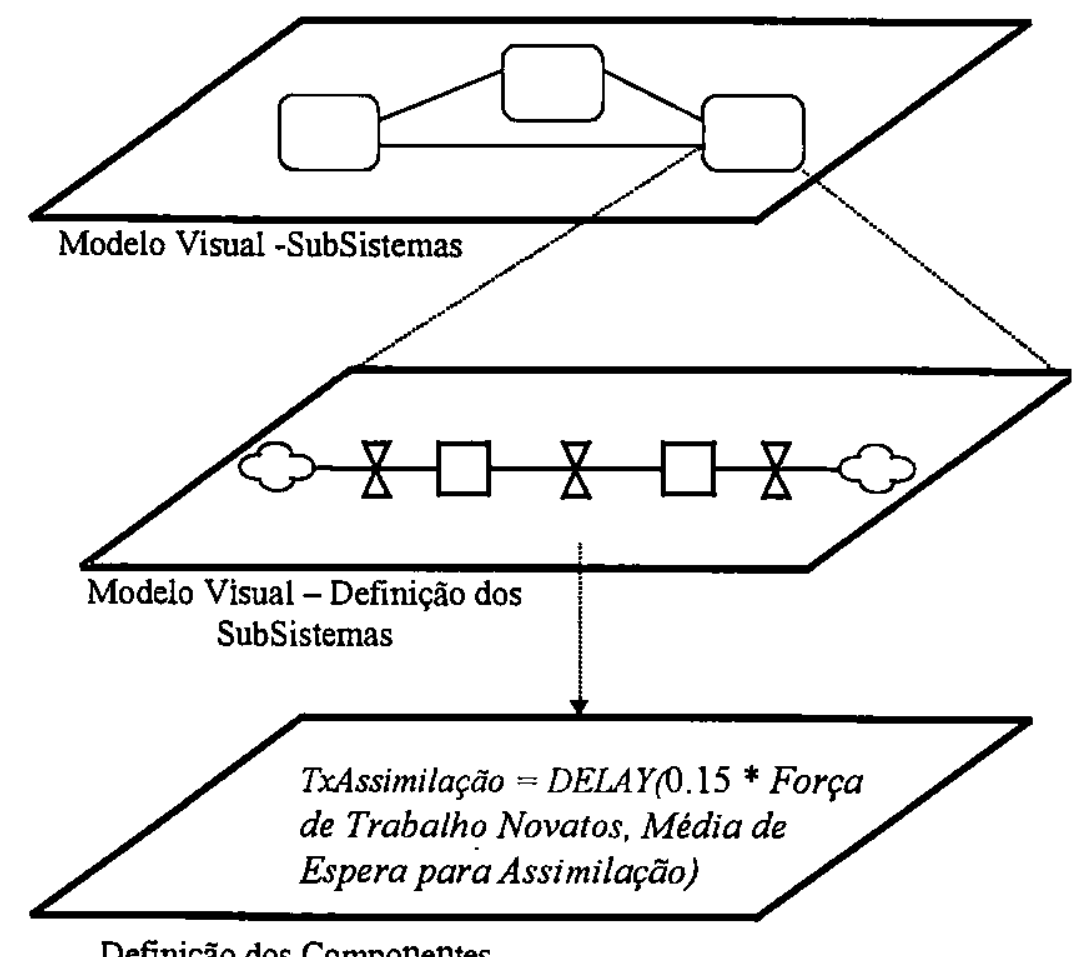

Definição dos Componentes

Figura 15 - Estrutura da Ferramenta

Dessa forma, durante a criação do modelo visual a ferramenta permite que o modelo fique inconsistente e permite que algumas operações sejam feitas, tais como salvar ou imprimir o modelo, mesmo inconsistente. Faz-se necessária uma validação do modelo antes da simulação, na qual são validadas as expressões estabelecidas e verificadas as ligações necessárias e estabelecidas no modelo. Vale lembrar que durante a edição a verificação de algumas regras para relacionar elementos do modelo são executadas, como por exemplo: uma taxa deve ser associada a apenas um fluxo e vice-versa. 
A simulação do comportamento do modelo é feita a partir das expressões estabelecidas, que determinam o comportamento do sistema, como taxas e variáveis, que podem ser expressas por fórmulas. Como resultado, a apresentação do comportamento do sistema é organizada em forma de tabelas podendo-se gerar gráficos que facilitam a visualização. Assim, a ferramenta proposta tem a arquitetura apresentada na figura 16.

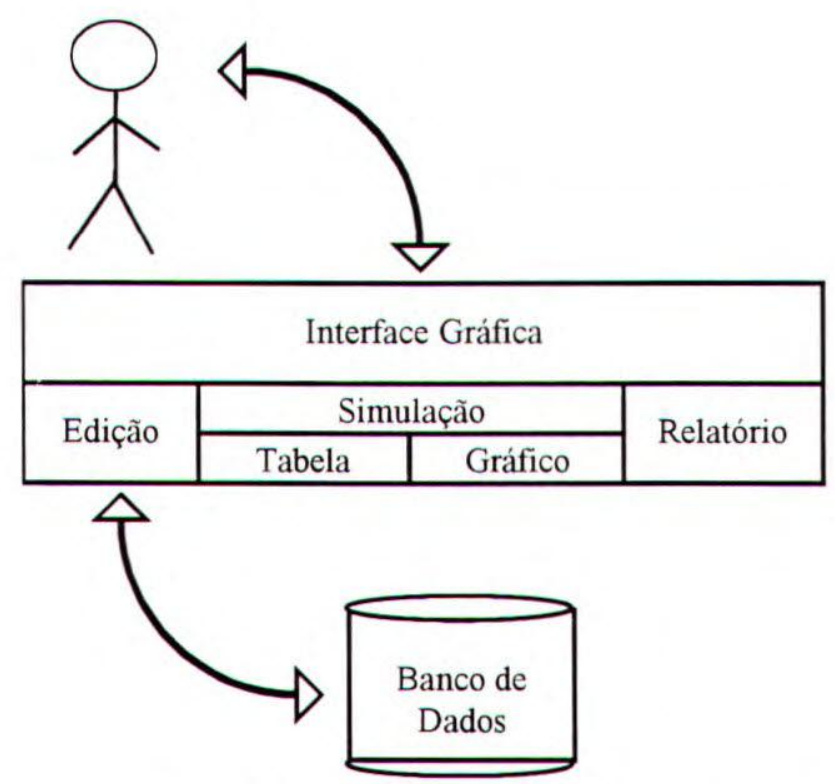

Figura 16 - Arquitetura da Ferramenta

\subsection{O Modelo Conceitual da Ferramenta}

A especificação da ferramenta foi feita com o apoio do método FUSION [COLEMAN94] utilizado-se a ferramenta FusionCASE versão 1.3. Foram gerados os modelos expostos nas figuras 17, 18, 19 e 20 contendo, respectivamente, a descrição do primeiro nível do modelo, a estrutura hierárquica das classes de componentes, o modelo para subsistemas e o modelo de interfaces. 


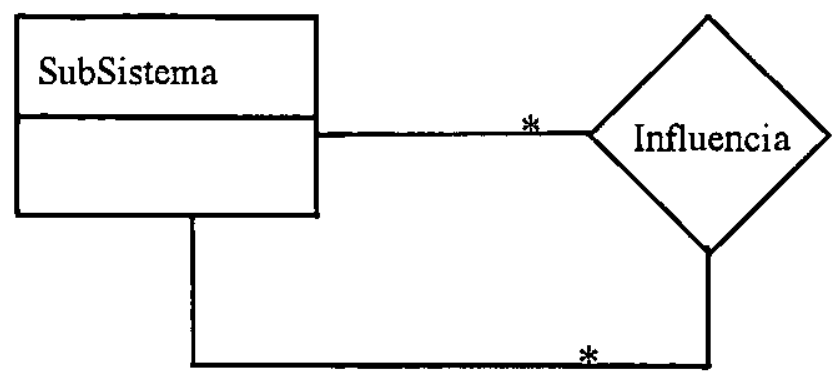

Figura 17 - Modelo de Classes para MODELO

$\mathrm{Na}$ figura 17, é mostrado que, em um primeiro plano, o modelo é definido como um conjunto de subsistemas que podem trocar influências entre si. Cada SubSistema é descrito posteriormente pela definição dos seus componentes relacionados e das fórmulas que determinam o seu comportamento. A definição de subsistema é apresentada na figura 19.

$\mathrm{Na}$ figura 18 são mostradas as classes que representam graficamente os componentes do modelo, com exceção da classe Influência que é representada por um conjunto de objetos da classe Linha, como mostra a figura 19.

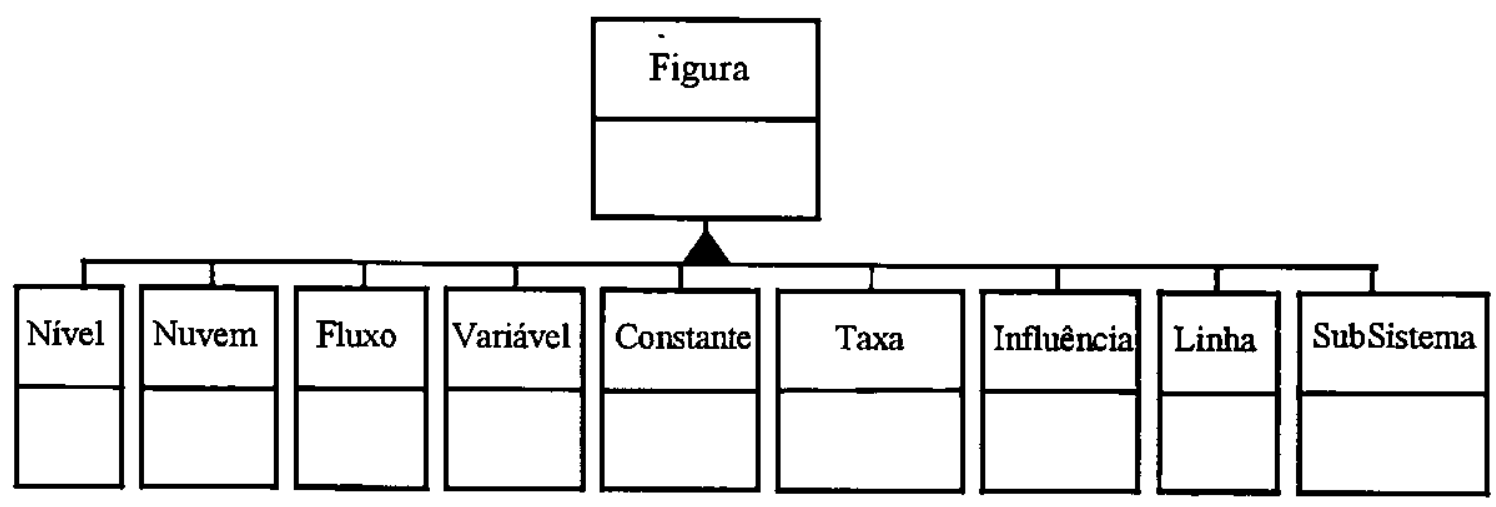

Figura 18 - Modelo de Classes para a Estrutura das Classes 


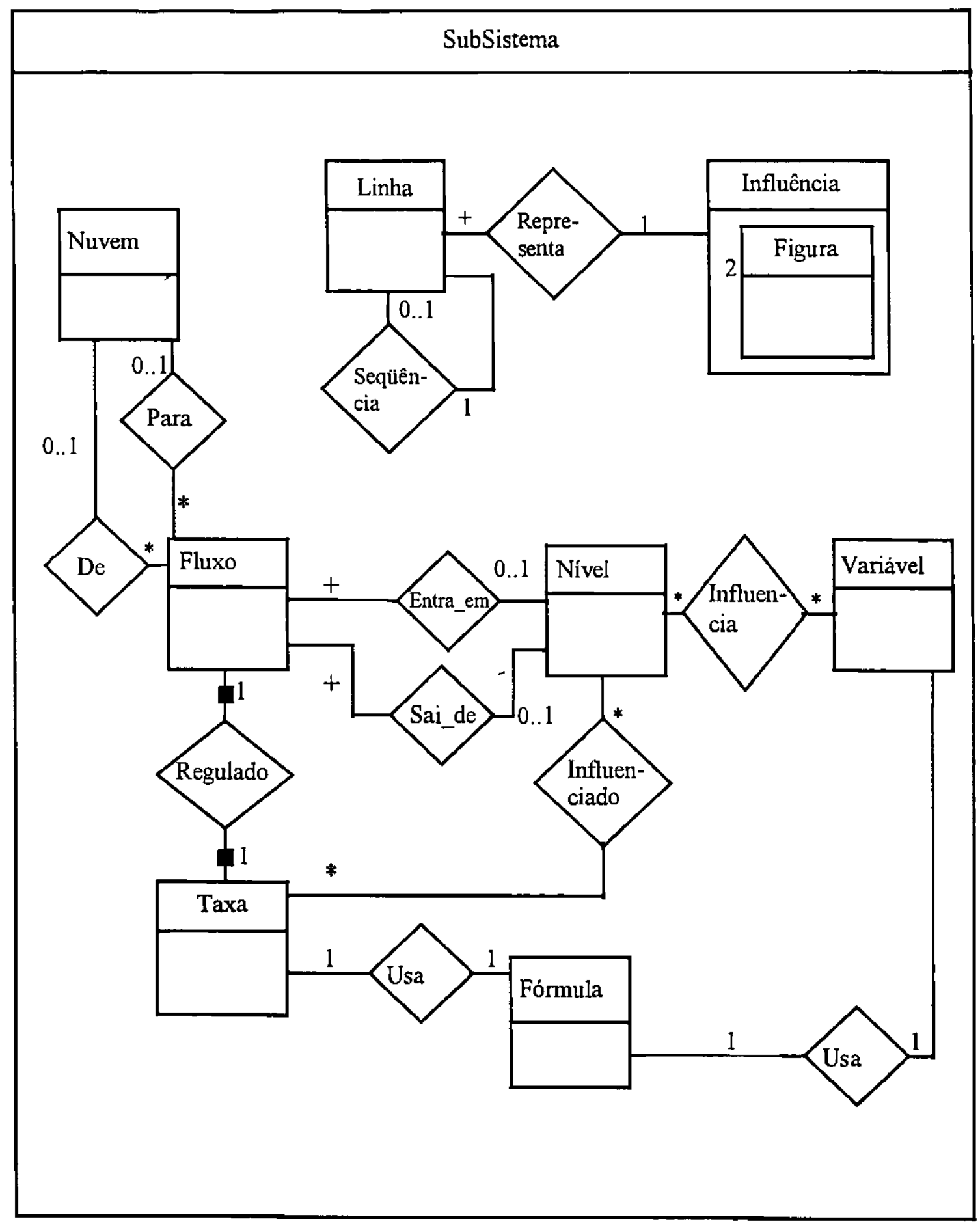

Figura 19 - Modelo de Classes para SUBSISTEMA

Na figura 19, o relacionamento entre Nuvem e Fluxo pode ter Nuvem como origem ou destino do Fluxo, porém uma Nuvem deve pertencer a um dos relacionamentos De ou Para - pois, caso contrário, fica caracterizado o isolamento de um componente do modelo, o que é acusado como um erro de edição durante o processo de validação do modelo 
executado antes da simulação. A classe Influência representa a agregação de duas figuras, sendo válidos os seguintes pares: Taxa e Constante; Constante e Variável; Nivel e Variável e Taxa e Variável. A restrição das figuras que podem participar da agregação é feita pela interface da ferramenta.

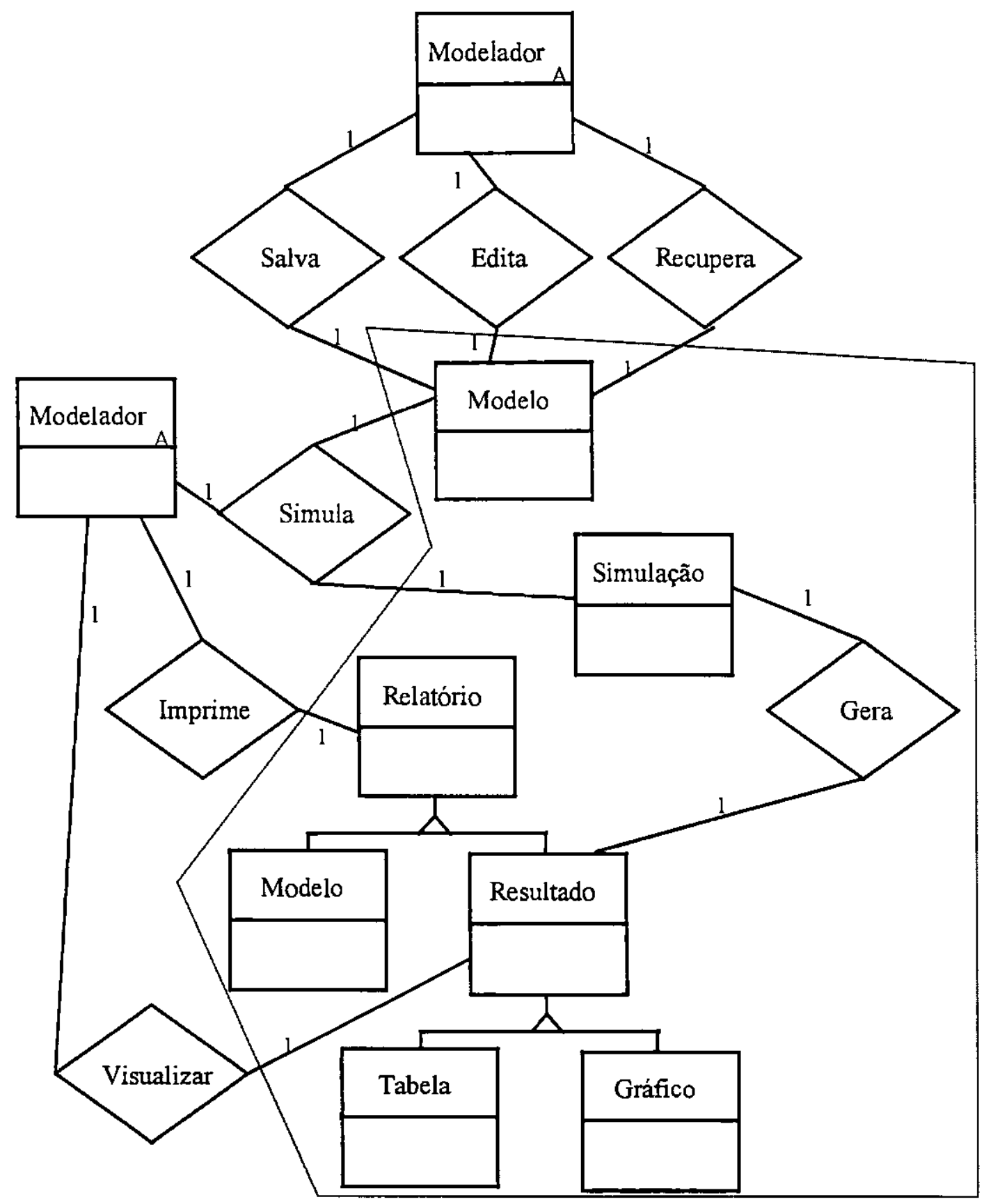

Figura 20 - Interfaces da Ferramenta

Os modelos expostos nas figura 17,18 e 19 descrevem a estrutura interna das classes do domínio do problema. Na figura 20 é mostrado como foi projetado o modelo de 
interface entre o agente Modelador e o Modelo a ser criado, especificando as possibilidades de operações da ferramenta. Os atributos das classes foram omitidos dos modelos apresentados nas figuras 17, 18 e 19 para melhorar a visualização dos mesmos e são listados na tabela 3. Nessa tabela os atributo precedidos do símbolo $\uparrow$ representam uma referência para um objeto de uma outra classe.

\section{Tabela 3 - Atributos das Classes}

\begin{tabular}{|c|c|c|c|}
\hline 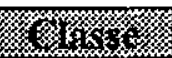 & 傩 & Xk & 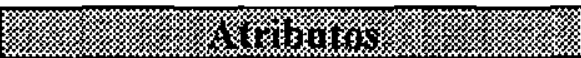 \\
\hline Modelo & $\begin{array}{l}\text { Nome do Modelo } \\
\text { Nome do Modelador } \\
\text { Data } \\
\text { Sinalizador (EM USO) } \\
\text { Exibir Advertência } \\
\text { Simular com Advertência } \\
\text { Parar Com (Quantidade de Erros/Adv.) } \\
\text { Periodicidade } \\
\text { Periodos } \\
\text { Sequiência de Nuvem } \\
\text { Seqüência de Influência } \\
\text { Seqüência de Linha } \\
\text { Seqüência de Fluxo } \\
\end{array}$ & Taxa & $\begin{array}{l}\text { Comentário } \\
\text { Expressão } \\
\uparrow \text { Fórmula } \\
\text { Direção (Horizontal/Vertical) } \\
\text { TOrigem } \\
\uparrow \text { Destino } \\
\uparrow \text { Fluxo } \\
\uparrow \text { Lista de Entrada de Influência }\end{array}$ \\
\hline Figura & $\begin{array}{l}\text { Nome } \\
\text { Tipo } \\
\text { Pai (SubSistema) } \\
\text { Topo } \\
\text { Esquerda } \\
\text { Largura } \\
\text { Altura }\end{array}$ & Fluxo & 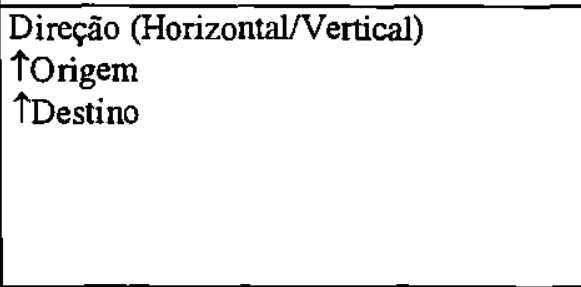 \\
\hline Fórmula & $\begin{array}{l}\text { Expressão } \\
\uparrow \text { Polonesa } \\
\text { Tabela de Funções }\end{array}$ & SubSistema & $\begin{array}{l}\text { Sinalizador de Controle (APAGANDO) } \\
\text { Comentário } \\
\uparrow \text { Lista de Entradas de Influências } \\
\uparrow \text { Lista de Saida de Influências }\end{array}$ \\
\hline Nível & $\begin{array}{l}\text { Valor Inicial } \\
\text { Comentário } \\
\uparrow \text { Lista de Entradas } \\
\uparrow \text { Lista de Saidas } \\
\text { †Lista de Saída de Influências } \\
\end{array}$ & Constante & $\begin{array}{l}\text { Sinalizador de Controle (APAGANDO) } \\
\text { Valor } \\
\text { Comentário } \\
\uparrow \text { Lista de Saída de Influências }\end{array}$ \\
\hline Variável & $\begin{array}{l}\text { Sinalizador de ControIe (APAGANDO) } \\
\text { Expressão } \\
\uparrow \text { Fórmula } \\
\text { Comentário } \\
\uparrow \text { Lista de Entrada de Influências } \\
\uparrow \text { Lista de Saida de Influências } \\
\end{array}$ & Linha & $\begin{array}{l}\text { Direção (Horizontal/Vertical) } \\
\text { Sinalizador de Controle (APAGANDO) } \\
\uparrow \text { Próxima Linha } \\
\uparrow \text { Influência }\end{array}$ \\
\hline Nuvem & $\begin{array}{l}\uparrow \text { Lista de Entradas } \\
\uparrow \text { Lista de Saídas }\end{array}$ & Influência & $\begin{array}{l}\text { TOrigem } \\
\uparrow \text { Destino } \\
\uparrow \text { Linha }\end{array}$ \\
\hline
\end{tabular}

A classe $M O D E L O$ contém alguns atributos que são utilizados para controle da edição devido à geração automática de nomes de objetos em tempo de execução como é o caso das influências, das linhas que representam graficamente (fisicamente no modelo em edição) a 
existência de influências, entre outros objetos, das nuvens e dos fluxos. Durante a criação desses fluxos, por exemplo, a ferramenta pede a identificação da taxa reguladora do fluxo e gera um nome para o fluxo associado baseado no atributo utilizado para controle contido no modelo em edição. Os atributos com esse propósito são Seqüêencia de Nuvem, Seqüência de Influência, Seqüência de Linha e Seqüencia de Fluxo. Outros atributos inseridos em MODELO foram Exibir Advertência, Simular com Advertência, Parar Com (Quantidade de Erros/Advertências), Periodicidade e Periodos. Tais atributos representam os parâmetros utilizados na validação e na simulação do modelo. Além desses atributos, vale ressaltar o atributo Sinalizador, que foi inserido para controle de acesso ao modelo quando recuperado por um usuário da ferramenta registrando que o modelo encontra-se em edição e pode ser somente visualizado, editado e simulado sem que seja salvo.

Os atributos Lista de Entradas e Lista de Saídas contidos nas classes NÍVEL e NUVEM armazenam referências para os fluxos que entram e que saem, respectivamente, de objetos dessas classes. Os atributos Lista de Entrada de Influência e Lista de Saída de Influência armazenam, respectivamente, as influências sofridas e exercidas por VARIÁVEL e por SUBSISTEMA. Nas classes NÍVEL e CONSTANTE existe apenas a Lista de Saída de Influência pois, pela semântica, eles não podem sofrer influência. $O$ mesmo acontece com REGULADOR, que não pode, semanticamente, ser origem de influência. A classe VARIÁVEL possui uma referência para um objeto da classe $F O R M U L A$ que é criado no construtor da classe, embora seja utilizada somente na pré-simulação (na validação da expressão da variável) e na simulação (interpretando a expressão), como descrito posteriormente.

Algumas classes possuem um atributo de controle chamado $A P A G A N D O$, que indica se um objeto pertencente a uma delas está sendo apagado. Esse atributo é utilizado na implementação do controle de eliminação automática de um objeto que estabeleça ou pertença a uma relação entre outros objetos quando um objeto da relação está sendo apagado. Por seu intermédio não é permitido que o modelo mantenha a inconsistência quanto ao relacionamento entre objetos. Por exemplo, caso um objeto da classe nivel seja apagado, automaticamente fluxos e influências associadas também são apagadas. Ainda como exemplo, considerando o modelo do subsistema de Recursos Humanos da figura 13, ao eliminar a variável Força de Trabalho Total as influências sofridas de Força de Trabalho - Novatos e Força de Trabalho - Experientes e a influência exercida em Diferença entre Forças devem ser apagadas, o que desencadearia a eliminação dessas influências das listas de influências da variável que está sendo apagada e provocaria um erro de execução. Além disso, quando um subsistema é eliminado do modelo, 
todos os seus componentes devem ser também eliminados, o que também poderia acarretar tal efeito circular, provocando o erro de execução.

Em FLUXO e em LINHA há também um atributo chamado DIREÇÃO que indica a orientação desses objetos, ou seja, se são verticais ou horizontais. Em FIGURA existe um atributo chamado $P a i$, que armazena a relação de continência entre os objetos que compõem um subsistema e o objeto que o representa, ou seja, todos os componentes de um subsistema guardam o nome do subsistema a que pertencem. Este atributo não armazena dado quando o objeto for um subsistema. Em FÓRMULA existe uma referência para uma estrutura de dados auxiliar criada para auxiliar a implementação da conversão do atributo EXPRESS $\tilde{A} O$ em notação polonesa para posterior interpretação. A Tabela de Funções é utilizada para validação da Expressão e para sua interpretação. Para checar a expressão é considerada a estrutura gramatical mostrada na figura 21. Nota-se que há uma recursividade em Função indicada pela repetição de Expressão dentro da mesma. Vale ressaltar que o looping em abre e fecha parênteses indica a possibilidade de abertura de mais de um parênteses com a respectiva possibilidade de fechamento, sendo que devem estar balanceados, ou seja, abre-se o mesmo número de parênteses que são fechados, respeitando-se a gramática

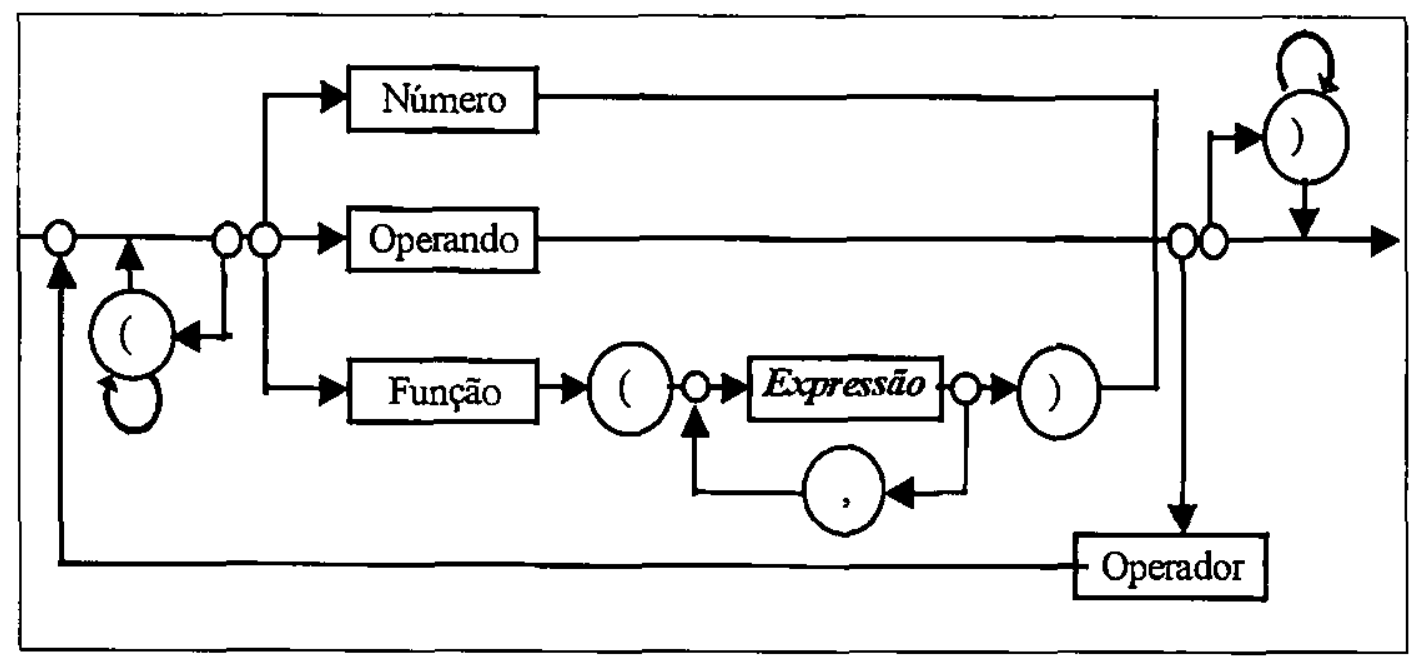

Figura 21 - Gramática utilizada em FÓRMULA

Os operandos devem constar na lista de influências sofridas pelo objeto ao qual a expressão pertence. Como operadores foram definidas as quatro operações básicas e um operador representado pelo símbolo "^” que representa a exponenciação. São considerados delimitadores (Tokens) na expressão, os operadores, vírgulas e parênteses: A ferramenta trata 
um número limitado de funções, sendo que tais funções esperam um número fixo de parâmetros para seus cálculos. As funções válidas estão relacionadas na tabela 4. Os parâmetros das funções podem ser expressões a serem interpretadas antes da interpretação da função, como exposto na gramática (figura 21) pela repetição da expressão dentro de função.

Com a intenção de permitir a modelagem do retardo de reação por parte da organização - que consiste no tempo de espera entre o acontecimento de um evento e a reação aó evento ocorrido - foi implementada a função DELAY, na qual uma valor calculado é mantido em um fila de valores e será levado em consideração para computações posteriores após o decorrer de um tempo de espera, capacitando a ferramenta a modelar o atraso na reação das. organizações.

Tabela 4 - Funções Disponíveis

\begin{tabular}{|l|l|l|}
\hline SEMO N & SE(T) ângulo) & Retorna o seno de um ângulo (dado em radiano) \\
\hline COSO & COS(ângulo) & Retorna o coseno de um ângulo (dado em radiano) \\
\hline MAX() & MAX(N1,N2) & Retorna o maior valor entre dois números \\
\hline MINO & MIN(N1,N2) & Retorna o menor valor entre dois números \\
\hline ABS() & ABS(número) & Retorna o valor absoluto de um número \\
\hline RANDOMO & RANDOM(N) & Retorna um número aleatório entre 0 e N \\
\hline DELAY() & DELAY(T,V) & $\begin{array}{l}\text { Causa uma espera de } T \text { ciclos para o valor } V \text {. Seu } \\
\text { retorno no tempo atual é nulo. }\end{array}$ \\
\hline
\end{tabular}

Para tratar tais funções a seguinte estrutura é utilizada:

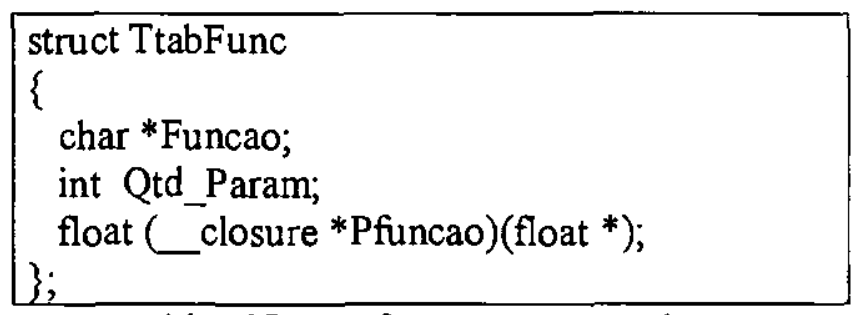

na qual o primeiro componente identifica a função, o segundo armazena a quantidade de parâmetros esperada pela função e o último armazena uma referência ao método que interpreta a função, a partir dos parâmetros fornecidos (float ${ }^{*}$ ). Deve-se notar que o processo de validação, primeiramente, procura identificar a seqüência delimitada pelo token e quando 
identifica-se uma função é verificada a quantidade de parâmetros esperados. O método de computação é invocado somente na interpretação. Esta estrutura facilita a implementação de novas funções pois basta inserir um novo elemento no vetor de funções estabelecendo seu literal de identificação, a quantidade de parâmetros esperados e a função de interpretação, não sendo necessário qualquer alteração no código de validação nem mesmo na interpretação, a não ser a inserção do próprio método de interpretação.

\subsection{Base de Dados}

O projeto lógico da base de dados é mostrado na figura 22. A semelhança entre as estruturas dos componentes do modelo permitiu o agrupamento de todos os componentes em apenas uma tabela: a tabela Objetos. Os dados sobre o modelo, pela normalização, são armazenados em uma tabela específica contendo os dados de controle para a edição e as opções para simulação.

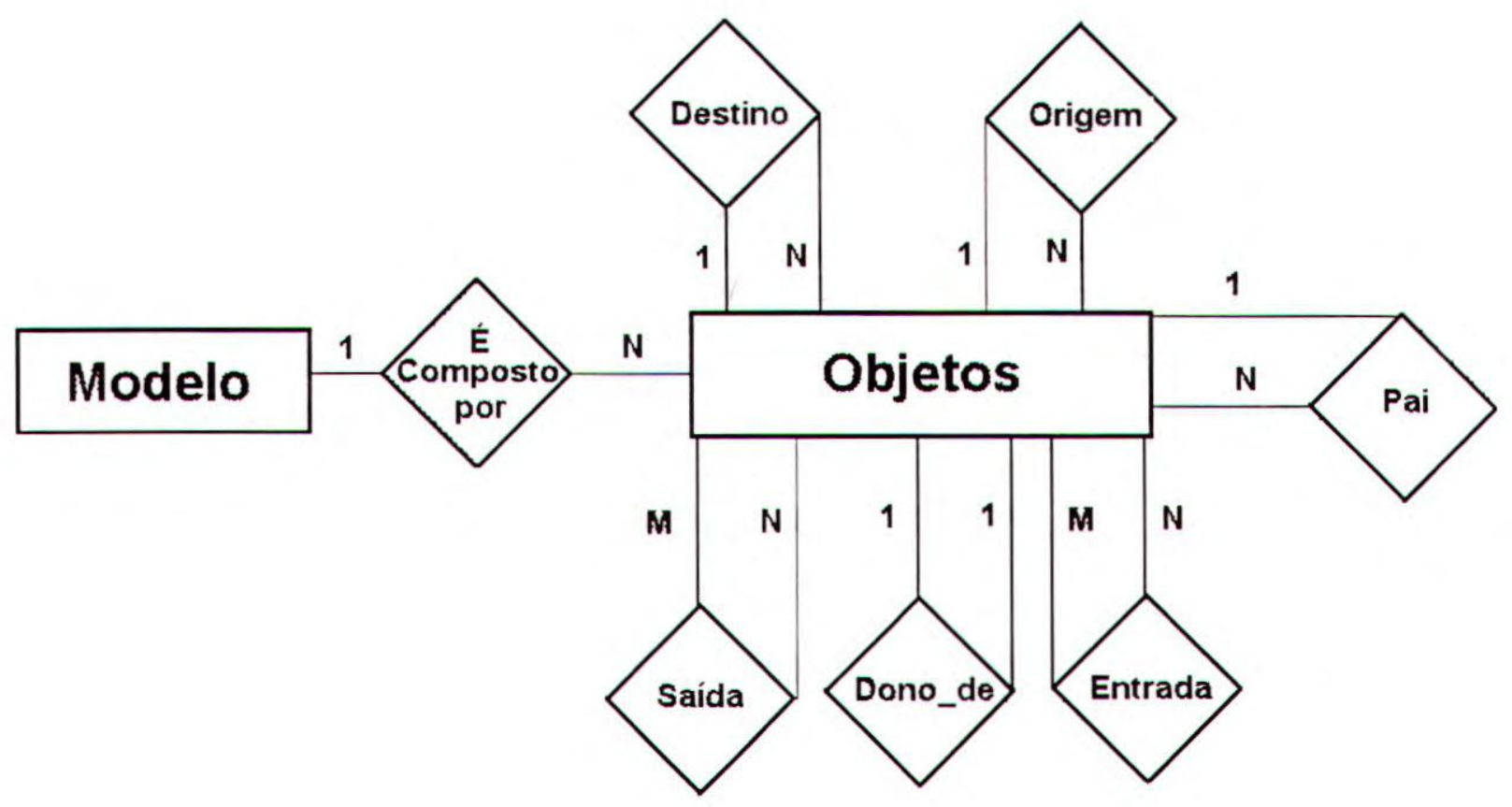

Figura 22 - Modelo Entidade-Relacionamento 
Convertendo o projeto conceitual (Entidade-Relacionamento) para o Modelo Relacional tem-se:

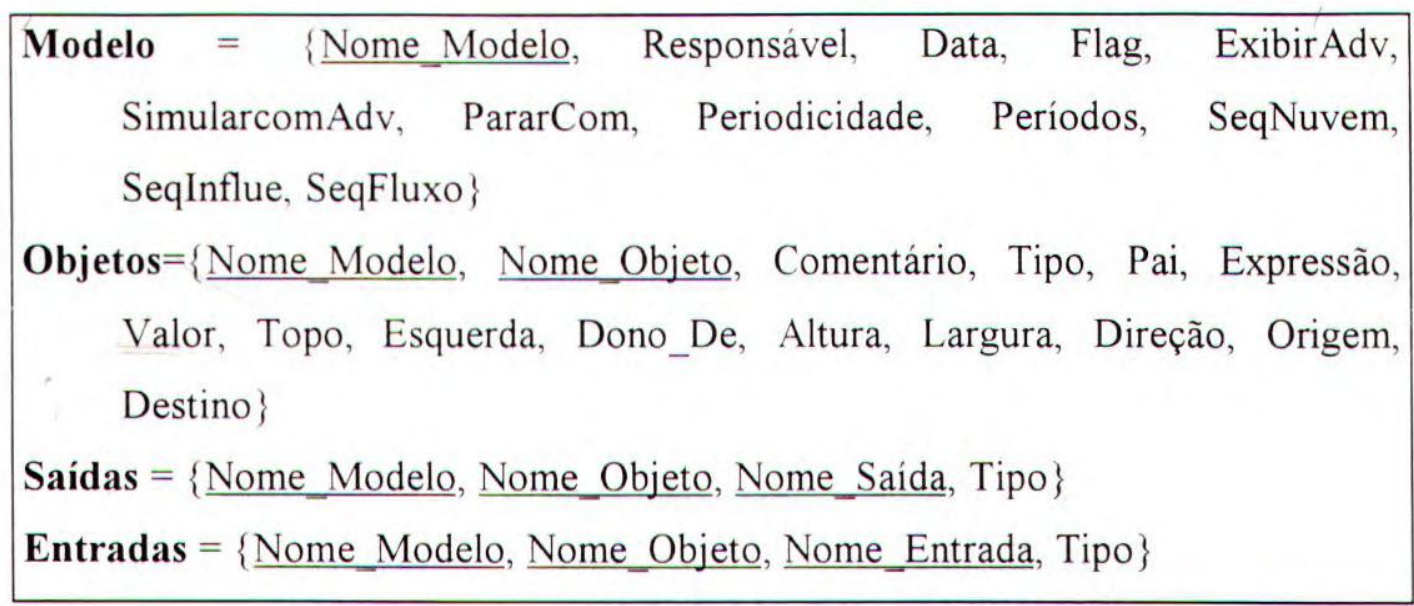

Esta estrutura do Modelo Relacional mostra que existe uma equivalência entre os atributos da classe e os dados armazenados em tabela para a classe MODELO. Para os componentes do modelo existe uma semelhança na estrutura, portanto as classes SUBSISTEMA, NÍVEL, VARIÁVEL, NUVEM, FLUXO, CONSTANTE, TAXA e LINHA são salvas na mesma tabela. O atributo Valor é usado por Constante e por Nível para armazenar seu conteúdo inicial. O atributo Expressão é utilizado por Taxa (ou Regulador) e por Variável. Note que a classe Fórmula não é armazenada; essa classe dá origem a objetos em tempo de execução durante a simulação, mais especificamente na pré-simulação, quando ocorre a validação das expressões por intermédio de um parser implementado na classe FÓRMULA

Os atributos das classes listados na tabela 5 revelam uma semelhança na estrutura das classes. O Modelo Entidade-Relacionamento da figura 22 considera essa semelhança, de modo que foi planejado utilizar apenas uma tabela para armazenar as classes que compõem o modelo. A tabela 5 mostra os atributos utilizados para armazenagem para cada objeto componente do modelo permitindo observar que apenas os atributos Expressão, Valor e Direção são utilizados por apenas 2 classe cada, sendo respectivamente VARIÁVEL e TAXA, NÍVEL e CONSTANTE, e FLUXO e LINHA, considerando que Dono_De, Origem e Destino são atributos para implementação dos auto-relacionamentos cuja cardinalidade é de um para muitos. A única sobreposição de atributos ocorre em Dono_De no qual a classe INFLUÊNCIA armazena a identificação da primeira linha (objeto da classe LINHA) que representa graficamente a influência no modelo de forma correta (sem sobreposição), porém para a 
classe LINHA é armazenado em Dono_De a influência (objeto da classe INFLUÊECIA) por ela representada, sobrepondo a semântica deste atributo, ou seja, para objetos da classe LINHA nele é armazenado um dado que não representa um objeto do qual o objeto da classe LINHA é dono mas sim o objeto que é dono daquela instância de LINHA.

Tabela 5 - Utilização de Atributos pelas Classes

\begin{tabular}{|c|c|c|c|c|c|c|c|c|c|}
\hline 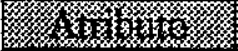 & 4 & 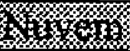 & 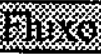 & 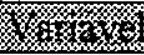 & (1) - & (1) & IX) & 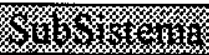 & 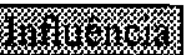 \\
\hline Nome Modelo & $\checkmark$ & $\checkmark$ & $\checkmark$ & $\checkmark$ & $\checkmark$ & $\checkmark$ & $\checkmark$ & $\checkmark$ & $\checkmark$ \\
\hline Nome Objeto & $\checkmark$ & $\checkmark$ & $\checkmark$ & $\checkmark$ & $\checkmark$ & $\checkmark$ & $\checkmark$ & $\checkmark$ & $\checkmark$ \\
\hline Comentário & $\checkmark$ & & - & $\checkmark$ & $\checkmark$ & $\checkmark$ & $\checkmark$ & $\checkmark$ & - \\
\hline Tipo & $\checkmark$ & $\checkmark$ & $\checkmark$ & $\checkmark$ & $\checkmark$ & $\checkmark$ & $\checkmark$ & $\checkmark$ & $\checkmark$ \\
\hline Pai & $\checkmark$ & $\checkmark$ & $\checkmark$ & $\checkmark$ & $\checkmark$ & $\checkmark$ & $\checkmark$ & - & $\checkmark$ \\
\hline Expressão & 二 & - & - & $\checkmark$ & 一 & $\checkmark$ & - & - & - \\
\hline Valor & $\checkmark$ & & - & - & $\checkmark$ & 一 & - & - & - \\
\hline Topo & $\checkmark$ & $\checkmark$ & $\checkmark$ & $\checkmark$ & $\checkmark$ & $\checkmark$ & $\checkmark$ & $\checkmark$ & - \\
\hline Esquerda & $\checkmark$ & $\checkmark$ & $\checkmark$ & $\checkmark$ & $\checkmark$ & $\checkmark$ & $\checkmark$ & $\checkmark$ & - \\
\hline Dono_De & - & 二 & - & - & $=$ & $\checkmark$ & $\checkmark$ & - & $\checkmark$ \\
\hline Altura & $\checkmark$ & $\checkmark$ & $\checkmark$ & $\checkmark$ & $\checkmark$ & $\checkmark$ & $\checkmark$ & $\checkmark$ & - \\
\hline Largura & $\checkmark$ & $\checkmark$ & $\checkmark$ & $\checkmark$ & $\checkmark$ & $\checkmark$ & $\checkmark$ & $\checkmark$ & - \\
\hline Direção & - & $=$ & $\checkmark$ & 二 & $=$ & - & $\checkmark$ & - & - \\
\hline Origem & - & - & $\checkmark$ & - & - & - & - & 二 & $\checkmark$ \\
\hline Destino & - & - & $\checkmark$ & - & - & 一 & $\checkmark$ & - & $\checkmark$ \\
\hline
\end{tabular}

Para a implementação dessas tabelas no sistema gerenciador de banco de dados foram utilizados os tipos de dados básicos permitidos pelo Microsoft SQL Server, versão 4.21, ficando as tabelas relacionais com as estruturas listadas nas tabelas $6,7,8$ e 9 .

Tabela 6 - Estrutura da Tabela SAÍDAS

\begin{tabular}{|l|l|l|l|}
\hline Nome_Modelo & String & VarChar & (1) \\
\hline Nome_Objeto & String & VarChar & 30 \\
\hline Nome_Saída & String & VarChar & 20 \\
\hline Tipo & String & Char & 20 \\
\hline
\end{tabular}


Tabela 7 - Estrutura da Tabela MODELO

\begin{tabular}{|c|c|c|c|}
\hline 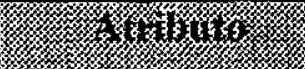 & 3 & 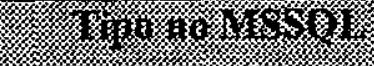 & 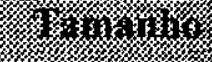 \\
\hline Nome_Modelo & string & VarChar & 30 \\
\hline Responsável & String & VarChar & 20 \\
\hline Data & DateTi & DateTime & \\
\hline Flag & String & VarChar & 01 \\
\hline ExibirAdv & Boolean & Binary & 01 \\
\hline SimularcomAdv & Boolean & Binary & 01 \\
\hline PararCom & Integer & Integer & \\
\hline Periodicidade & String & VarChar & 10 \\
\hline Períodos & Integer & Integer & \\
\hline SeqNuvem & Integer & Integer & \\
\hline SeqInflue & Integer & Integer & \\
\hline SeqLinha & Integer & Integer & \\
\hline SeqFluxo & Integer & Integer & \\
\hline
\end{tabular}

Tabela 8 - Estrutura da Tabela OBJETOS

\begin{tabular}{|l|l|l|l|}
\hline \multicolumn{1}{|c|}{ Nome_Modelo } & String & VarChar & 30 \\
\hline Nome_Objeto & String & VarChar & 20 \\
\hline Comentário & String & VarChar & 40 \\
\hline Tipo & String & Char & 01 \\
\hline Pai & String & VarChar & 20 \\
\hline Expressão & String & VarChar & 40 \\
\hline Valor & Float & Float & \\
\hline Topo & Integer & Integer & \\
\hline Esquerda & Integer & Integer & \\
\hline Dono_De & String & VarChar & 20 \\
\hline Altura & Integer & Integer & \\
\hline Largura & Integer & Integer & \\
\hline Direção & Integer & Integer & 20 \\
\hline Origem & String & VarChar & 20 \\
\hline Destino & String & VarChar & \\
\hline
\end{tabular}


Tabela 9 - Estrutura da Tabela ENTRADAS

\begin{tabular}{|c|c|c|c|}
\hline 4, & 1710 & 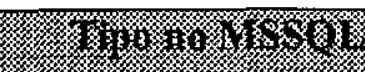 & 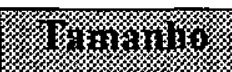 \\
\hline Nome_Modelo & String & VarChar & 30 \\
\hline Nome_Objeto & String & VarChar & 20 \\
\hline Nome_Entrada & String & VarChar & 20 \\
\hline Tipo & String & Char & 01 \\
\hline
\end{tabular}

\subsection{Implementação e Interface da Ferramenta}

A ferramenta proposta foi desenvolvida para ser executa em microcomputadores, em ambiente Windows 95, desenvolvida utilizando o ambiente $\mathrm{C}++$ Builder versão 1.0 da Borland e como sistema gerenciador de banco de dados foi utilizado o Microsoft SQI, Server versão 4.21. Em seu desenvolvimento foram escritas aproximadamente 6.500 linhas de código, distribuídas em 13 classes principais descritas anteriormente nas figuras 17, 18, 19 e 20.

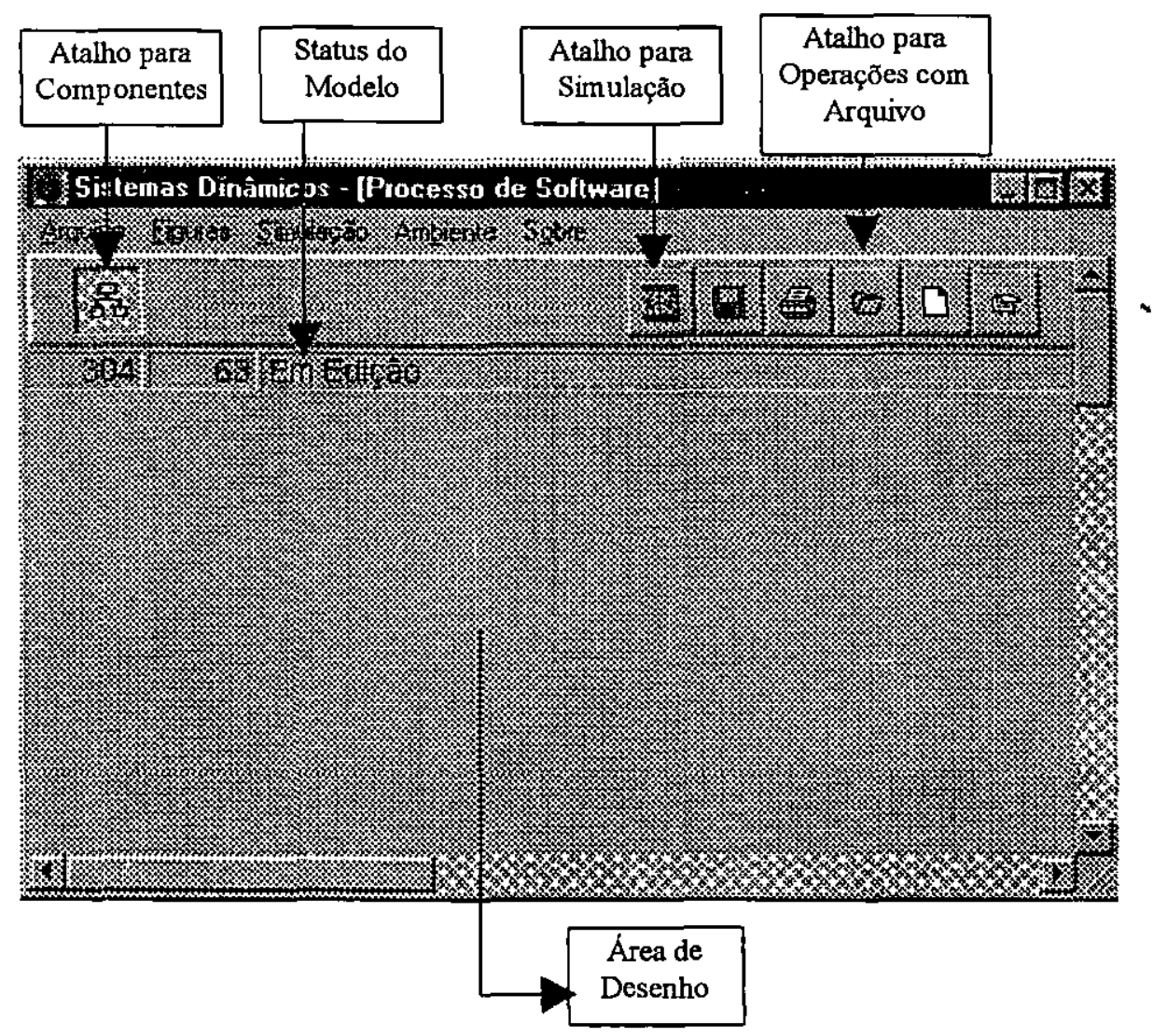

Figura 23 - Lay-Out da Ferramenta 
A interface da ferramenta é apresentada na figura 23, na qual pode-se observar uma seqüência de opções, que são detalhadas na tabela 10. Há uma barra contendo atalhos para algumas opções do menu que estima-se serem mais utilizadas. Tanto na barra de atalho quanto no menu de Figuras no primeiro nivel de edição é disponibilizado apenas Subsistema para definição do modelo. Ao especificar um subsistema, no segundo nível de edição (vide figura 15) a ferramenta passa a dar acesso às opções Nivel, Variável, Nuvem e Constante, deixando de dar acesso à opção SubSistema.

A ferramenta dispõe de uma área de desenho, na qual são mostrados os componentes criados, neste caso somente subsistemas. Em seguida, cada sub-sistema pode ser detalhado, tendo seu comportamento explicitamente traduzido seguindo os conceitos de dinâmica de sistema.

Tabela 10 - Opções disponíveis e seus atalhos

\begin{tabular}{|c|c|c|c|}
\hline (3) & (6) & \multicolumn{2}{|c|}{ 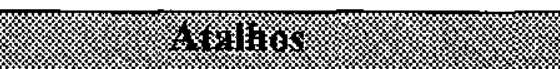 } \\
\hline 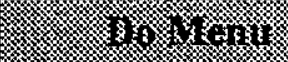 & 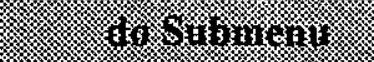 & 月, 3. & 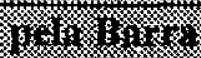 \\
\hline \multirow[t]{9}{*}{ Arquivo } & Abrir & Control $\mathrm{O}$ & $=$ \\
\hline & Novo & Control N & 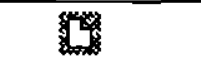 \\
\hline & Fechar & - & 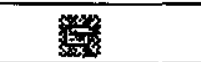 \\
\hline & Excluir & Control Y & - \\
\hline & Salvar & Control S & 표 \\
\hline & Salvar Como & - & - \\
\hline & Visualizar Impressão & - & 獣 \\
\hline & Imprimir & Control P & - \\
\hline & Sair & Alt F4 & - \\
\hline \multirow[t]{5}{*}{ Figuras } & Nivel & - & 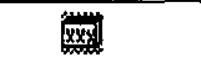 \\
\hline & Variável Auxiliar & - & va \\
\hline & Nuvem & 一 & 5 \\
\hline & Subsistema & - & 品 \\
\hline & Constante & - & 㥪 \\
\hline \multirow[t]{2}{*}{ Simulação } & Opções & - & - \\
\hline & Simular & F9 & I \\
\hline \multirow[t]{3}{*}{ Ambiente } & Exibir Atalhos & - & - \\
\hline & Imprimir Gráficos & - & - \\
\hline & Imprimir Textos & - & - \\
\hline Sobre & - & - & - \\
\hline
\end{tabular}


Por intermédio da opção Abrir é possivel a recuperação de um modelo criado e salvo previamente, identificando o nome dado ao modelo quando salvo. Novo fecha o modelo em edição e cria uma instância para a edição de um novo modelo, estabelecendo valores iniciais para seus atributos de controle e o nome do modelo, sendo semelhante à opção Fechar, que não identifica o novo modelo criado. Porém, ao se tentar salvar um modelo sem identificação, a ferramenta exige o estabelecimento da mesma. A opção Excluir permite a eliminação de um modelo da base de dados. As opções Salvar e Salvar Como invocam o método que armazena os dados do modelo em edição sendo que a opção Salvar Como invoca previamente um método para obter a nova identificação do modelo.

As opções Visualizar Impressão e Imprimir têm seu resultado estabelecido pelos parâmetros Imprimir Gráficos e Imprimir Texto, que são mutuamente exclusivos e estão disponíveis em Ambiente. Ou seja, considerando o que estiver estabelecido nessas opções de Ambiente a visualização ou a impressão traz o modelo gráfico ou a definição do modelo, suas fórmulas e valores iniciais. Além disso, ao simular o modelo, a impressão da simulação também é determinada por estas configurações do ambiente. Em Figuras pode-se escolher o tipo de componente a ser criado na área de desenho, lembrando que no primeiro nível de edição somente é disponibilizado a opção para subsistema e no nível seguinte são disponibilizadas as outras opções, ficando a opção subsistema não disponível.

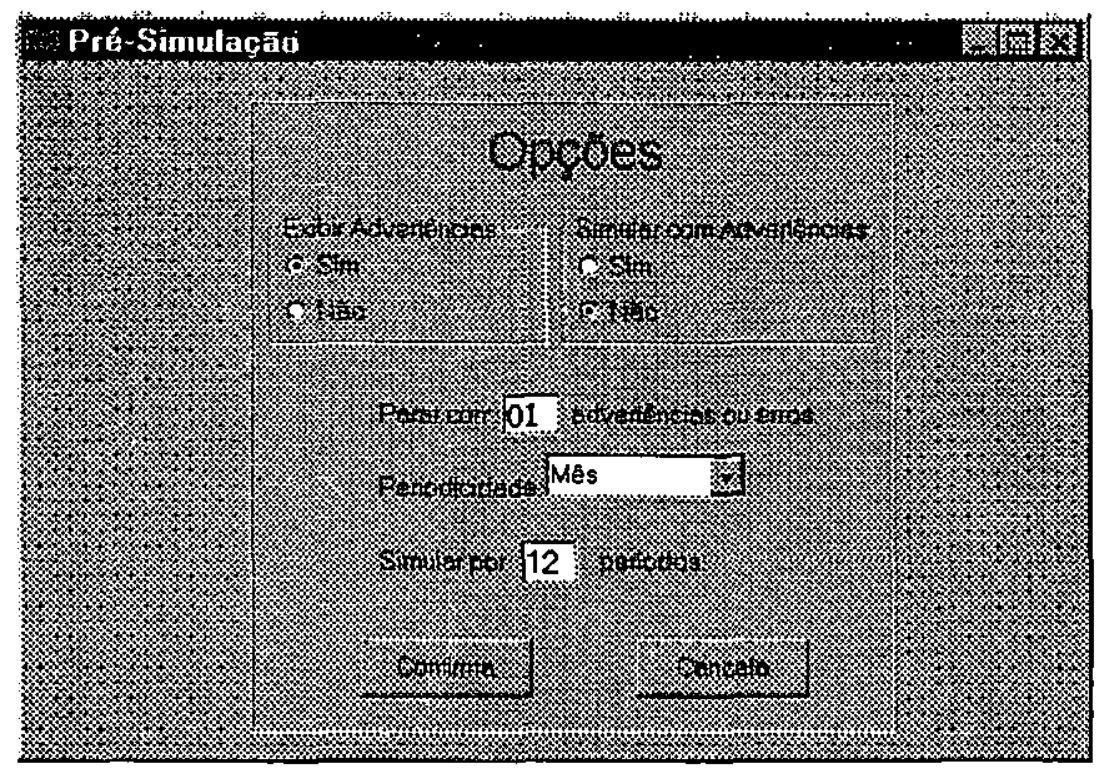

Figura 24 - Parâmetros para Simulação 
A simulação do modelo editado obedece a uma série de parâmetros acessíveis por intermédio da opção denominada de Opções em Simulação, como mostra a figura 24. Os três primeiros referem-se à validação do modelo e os dois últimos à simulação propriamente dita. O primeiro deles é Exibir Advertências, que indica ao software se deve ou não indicar as advertências que possam vir a ser detectadas durante a validação do modelo. Em seguida, a opção de Simular com Advertências indica se o software deve ignorar ou não a presença de advertências na especificação do modelo para simulá-lo. O terceiro parâmetro indica a quantidade de erros ou advertência com que a validação do modelo, antes da simulação, deve ser interrompida. A seguir é estabelecida a periodicidade do modelo em edição a ser considerada ao traçar o gráfico. E, por último, é estabelecida a quantidade de períodos que o software deve simular o modelo.

Nota-se a ausência no menu de alguns componentes da dinâmica de sistema tais como fluxos e influências. Tais componentes, assim como certas funcionalidades da ferramenta, têm seu acesso por meio de um menu exibido na área de desenho e associado a um componente já criado anteriormente utilizando as opções disponíveis em Figura. Esse menu é mostrado com sua composição completa na figura 25. As opções são mostradas dependendo do objeto que as utilizará, pois funcionalmente algumas opções não devem ser disponibilizadas para alguns componentes.

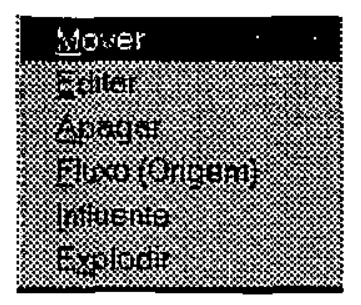

\section{Figura 25 - Menu para componentes}

A tabela 11 mostra a utilização das opções por componente do modelo. Nota-se que apenas a opção Apagar é disponibilizada a todos os componentes. A opção Mover, embora disponível para os componentes criados a partir das opções do menu Figuras, tem sua funcionalidade limitada aos componentes que não possuem relacionamentos com outros componentes, por exemplo, para Nuvens e Niveis que ainda não possuam fluxos de entrada ou saída e também não possuam influencia exercidas, no caso dos Niveis, é possível ativar a funcionalidade representada por essa opção. Tendo ativada a movimentação de algum 
componente, é feita a substituição da opção Mover pela opção Fixar, que desativa a movimentação do componente e retorna o menu a sua configuração original, devendo ser ativada no final da movimentação.

Tabela 11 - Opções por componente

\begin{tabular}{|c|c|c|c|c|c|c|c|}
\hline (1) & 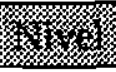 & 格 & X & 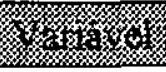 & 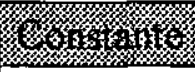 & 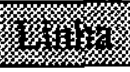 & (1) \\
\hline Mover & $\checkmark$ & $\checkmark$ & $\checkmark$ & $\checkmark$ & $\checkmark$ & - & $\checkmark$ \\
\hline Editar & $\checkmark$ & $\checkmark$ & - & $\checkmark$ & $\checkmark$ & - & $\checkmark$ \\
\hline Apagar & $\checkmark$ & $\checkmark$ & $\checkmark$ & $\checkmark$ & $\checkmark$ & $\checkmark$ & $\checkmark$ \\
\hline Fluxo (Origem) & $\checkmark$ & - & $\checkmark$ & - & 二 & - & - \\
\hline Influente & $\checkmark$ & $\checkmark$ & - & $\checkmark$ & $\checkmark$ & - & - \\
\hline Explodir & - & - & - & - & - & - & $\checkmark$ \\
\hline
\end{tabular}

A opção Explodir é de exclusividade de subsistemas, pois apenas estes podem Ter seu comportamento detalhado por meio de modelos de sistemas dinâmicos, determinando a criação de um nova área de desenho com a mesma da área do primeiro nível para edição de subsistemas. As opções Influente e Fluxo (Origem) ao serem selecionadas têm seu sentido modificado e, conseqüentemente, a respectiva identificação da opção, pois primeiramente identificam a origem e posteriormente o destino de influência e fluxo, passando a identificação a ser Influenciado e Fluxo (Destino).

Ao criar um componente do tipo Nível, Variável, Subsistema, Constante ou Fluxo, com a respectiva Taxa de controle, a ferramenta exige sua identificação, com exceção do Fluxo cuja identificação é gerada, devendo-se especificar somente a identificação da respectiva Taxa. Porém, não se exige a definição de seu comportamento por meio da definição da Expressão, de seu valor inicial e do comentário elucidativo. A opção Editar permite 0 acesso à interface mostrada na figura 26 com o propósito de possibilitar o estabelecimento posterior ou mesmo a correção ou ajustes necessários. Pode-se observar na figura 26 a sobreposição da área destinada à definição da Expressão — destacada pela presença da palavra FÓRMULA — em relação à área destinada à definição de valores, que, dependendo do objeto a Ter seu conteúdo editado, em tempo de execução decide pela apresentação de uma área ou de outra juntamente com a respectiva mensagem que na figura consta como sendo a edição de um Nível ou uma Constante, dado que a mensagem apresentada é 'Valor Inicial'. 


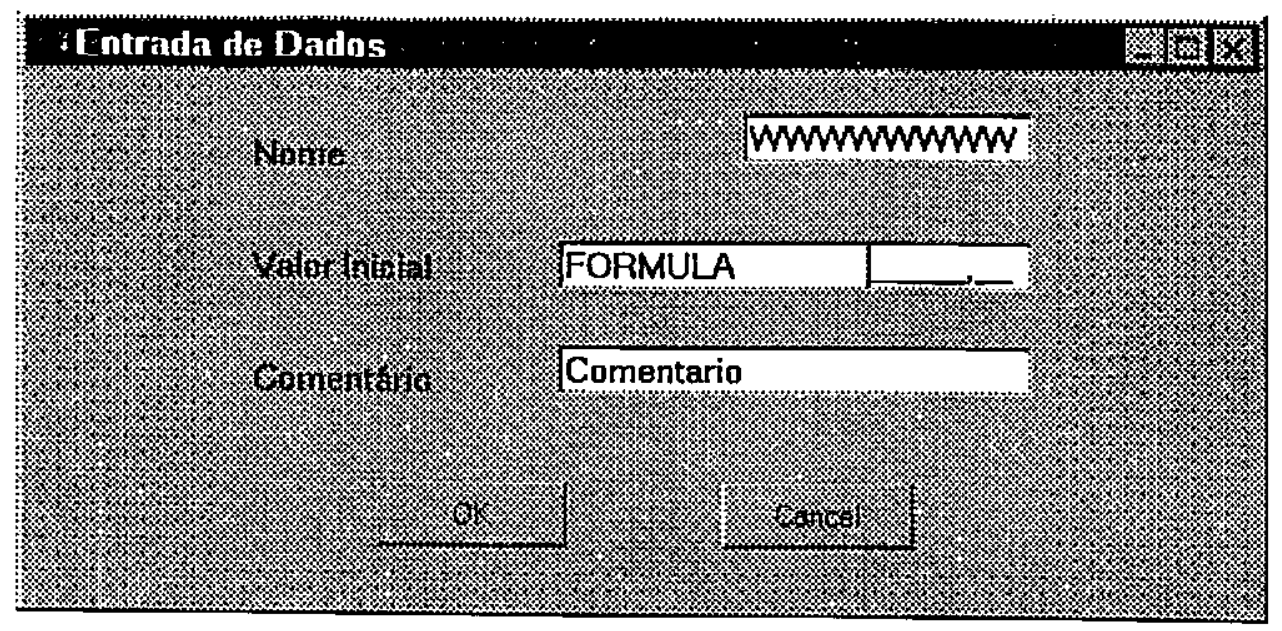

Figura 26 - Interface de Definição de Fórmulas

\subsection{Simulação}

Definido o modelo, ou seja, tendo sua especificação completa incluindo as fórmulas que regem seu comportamento, pode-se simular o modelo e visualizar os resultado da simulação em tabela e gráficos.

Porém, antes da simulação é necessário uma validação do modelo, verificando sua consistência e integridade pois na edição (definição do modelo) a ferramenta permite que o modelo mantenha algumas inconsistências e permite também que algumas operações, tais como salvar e imprimir, dentre outras, sejam executadas com o modelo incompleto. Esse processo de validação é denominado de pré-simulação.

A pré-simulação consiste em um processo de validação dos componentes do modelo no qual cada componente tem seu método de validação invocado e atualiza a tabela de resultado da pré-simulação. O objeto controlador da pré-simulação considera os parâmetros estabelecidos (vide figura 24).

$\mathrm{Na}$ análise do modelo são considerados como erros, impedindo a execução da simulação do modelo, as seguintes situações: 
- constantes que não influenciam nenhum outro componente, denotando o isolamento de componente já que constantes podem apenas influenciar e não são passíveis de sofrer influência;

- nuvem ou nível sem fluxo de entrada e de saída, também denotando isolamento;

- regulador (ou Taxa) ou Variável sem expressão (fórmula) definida ou fórmula expressa indevidamente. Outra ocorrência considerada erro é a taxa ou a varióvel sem entrada de influência, pois espera-se no mínimo uma influência para compor a expressão.

Além desses erros, o parser que analisa a expressão dos componentes, implementado em Fórmula, pode retornar os seguintes erros:

- Operador Não Esperado;

- Operador Esperado;

- Operando Esperado;

- Parêntese Esperado;

- Parênteses Desbalanceados;

- Número de Parâmetros Inválido;

- Expressão Inválida;

- Operando Desconhecido.

Para checar a expressão é considerada a estrutura gramatical mostrada na figura 21. Ainda na análise do modelo são acusadas algumas advertências, que indicam a possibilidade de uma falha no modelo. São elas:

- Constantes ou Niveis com valor inicial zero, caracterizando a possibilidade de falha na modelagem pela omissão do valor;

- Nível sem fluxo de entrada ou sem fluxo de saída, caracterizando a possibilidade de utilização de uma Nuvem, caso não seja desejado acompanhar o conteúdo do respectivo Nivel;

- Subsistema sem fluxo de entrada e sem fluxo de saída caracterizando a possibilidade de isolamento do mesmo. Neste caso foi considerado como advertência, pois na criação de modelos simples em que não haja a necessidade de subdivisão em subsistemas, por restrição de implementação, o 
modelo deve ser criado como um subsistema único no primeiro nível de representação, porém ao modelar sistemas que são decompostos em dois ou mais subsistemas caracteriza o isolamento do mesmo.

Caso o modelo não apresente erros e mesmo que apresente advertências, estando dentro do limite estabelecido pelo parâmetro correspondente, a ferramenta prepara a simulação atribuindo à tabela de resultado os valores iniciais do modelo. Em seguida, os componentes cujas fórmulas regem o comportamento do modelo têm a interpretação de suas fórmula invocada e o resultado é pósto na tabela de resultado, servindo como parâmetro para uma próxima execução. As Constantes têm seu conteúdo repetido por toda a simulação. Este processo é repetido quantas vezes for estabelecido pelo parâmetro Simular com $N$ períodos.

\subsection{Considerações Finais}

Este capítulo apresentou a ferramenta desenvolvida, sua estrutura interna, a organização da base de dados utilizada e outras características. Foram também descritas as funçð̃es disponíveis na ferramenta para descrição do comportamento do modelo em formulações matemáticas. Com esta descrição, pode-se então editar um modelo e simulá-lo, o que é apresentado a seguir. 
CMC - USP

\section{Simulação de Sistemas Dinâmicos}

\subsection{Considerações Iniciais}

Este capítulo mostra a simulação de sistemas dinâmicos utilizando a ferramenta desenvolvida. São apresentados dois exemplos: o modelo de recursos humanos de processos de software e um modelo hipotético de atendimento utilizando uma fila. A seção 4.2 apresenta aspectos da edição do modelo de recursos humanos de processos de software, sua simulação, os parâmetros utilizados na simulação, a pré-simulação e uma avaliação do comportamento do modelo. Na seção 4.3, o modelo de filas é apresentado seguindo a mesma estrutura, ou seja, aspectos da edição do modelo, sua simulação, os parâmetros utilizados na simulação, a présimulação e uma avaliação do comportamento do modelo.

\subsection{O Modelo de Recursos Humanos de Processos de Software}

Para exemplificar a utilização da ferramenta desenvolvida é apresentado neste capítulo o modelo de processo de software. Mostra-se com detalhes o subsistema de Recursos 
Humanos discutido anteriormente no capítulo 2. Seguindo a estrutura da ferramenta (figura 15), primeiramente são representados os subsistemas do modelo, como mostra a figura 27.

Nessa figura é mostrado o momento de edição no qual haviam sido definidos os subsistemas do modelo mas não haviam sido estabelecidas as relações de influência entre os subsistemas. Pode-se observar a única disponibilidade de criação de figuras nesse nível de edição selecionada, como indica a mudança de cor do respectivo botão de atalho. Em seguida são definidas as relações de influência entre os subsistemas por meio da ativação do menu de componente, como mostra a figura 28 , escolhendo-se a opção de Influente, e cada subsistema é definido utilizando os conceitos de dinâmica de sistema como mostra a figura 29, na qual o subsistema de Recursos Humanos é descrito também por meio da opção Explodir no menu de componente.

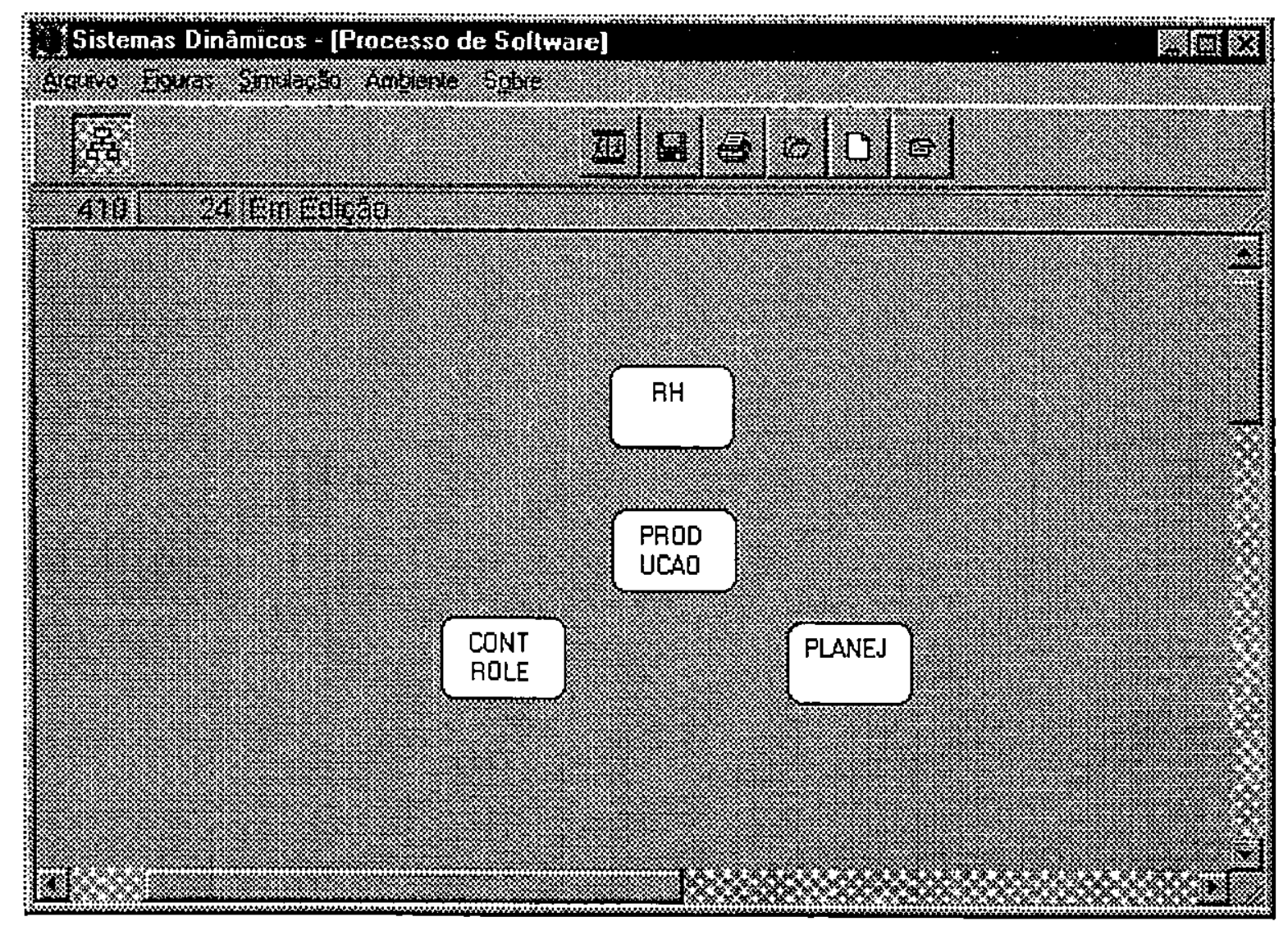

Figura 27 - Edição do primeiro nivel (SubSistemas) 


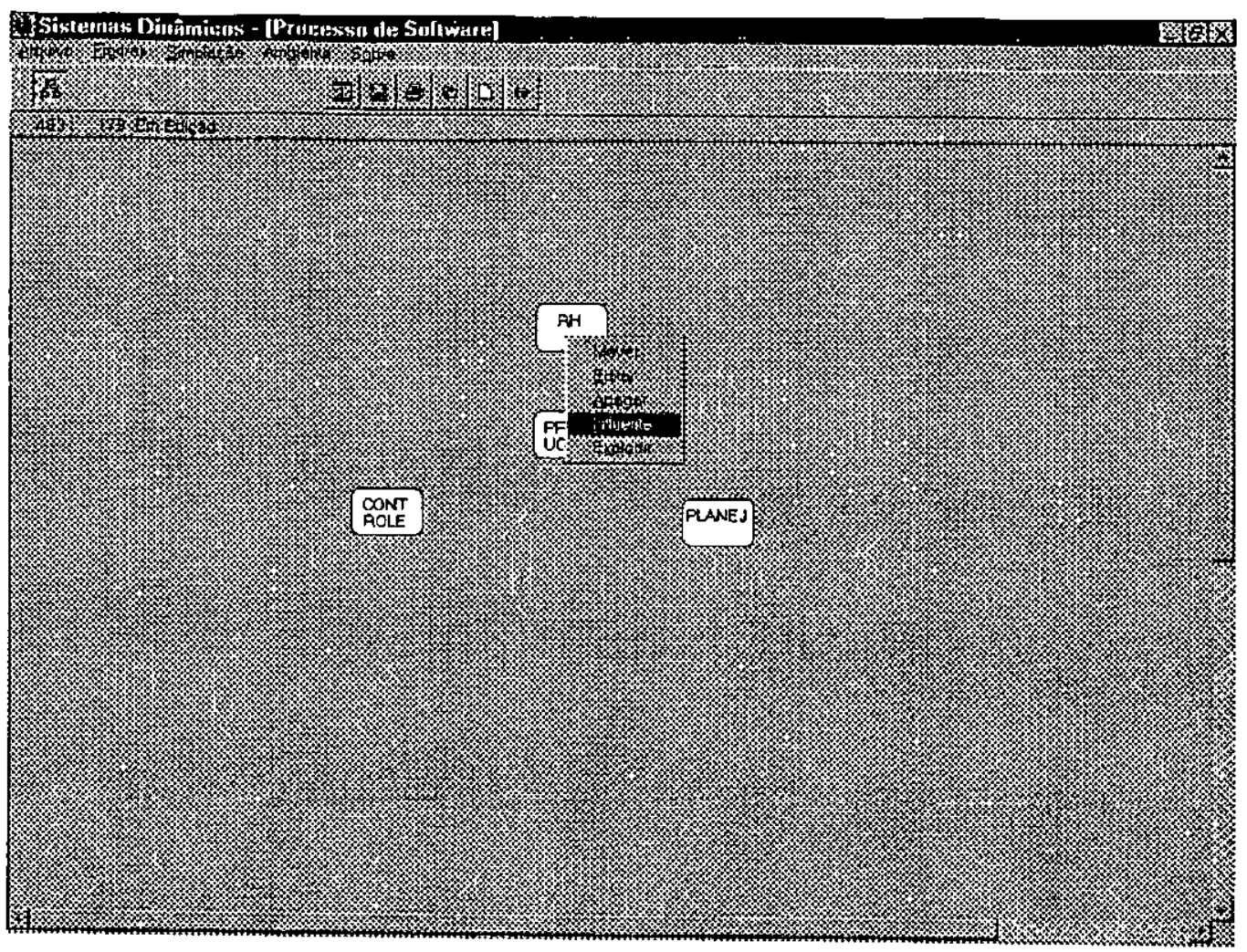

Figura 28 - Ativação do menu de componente

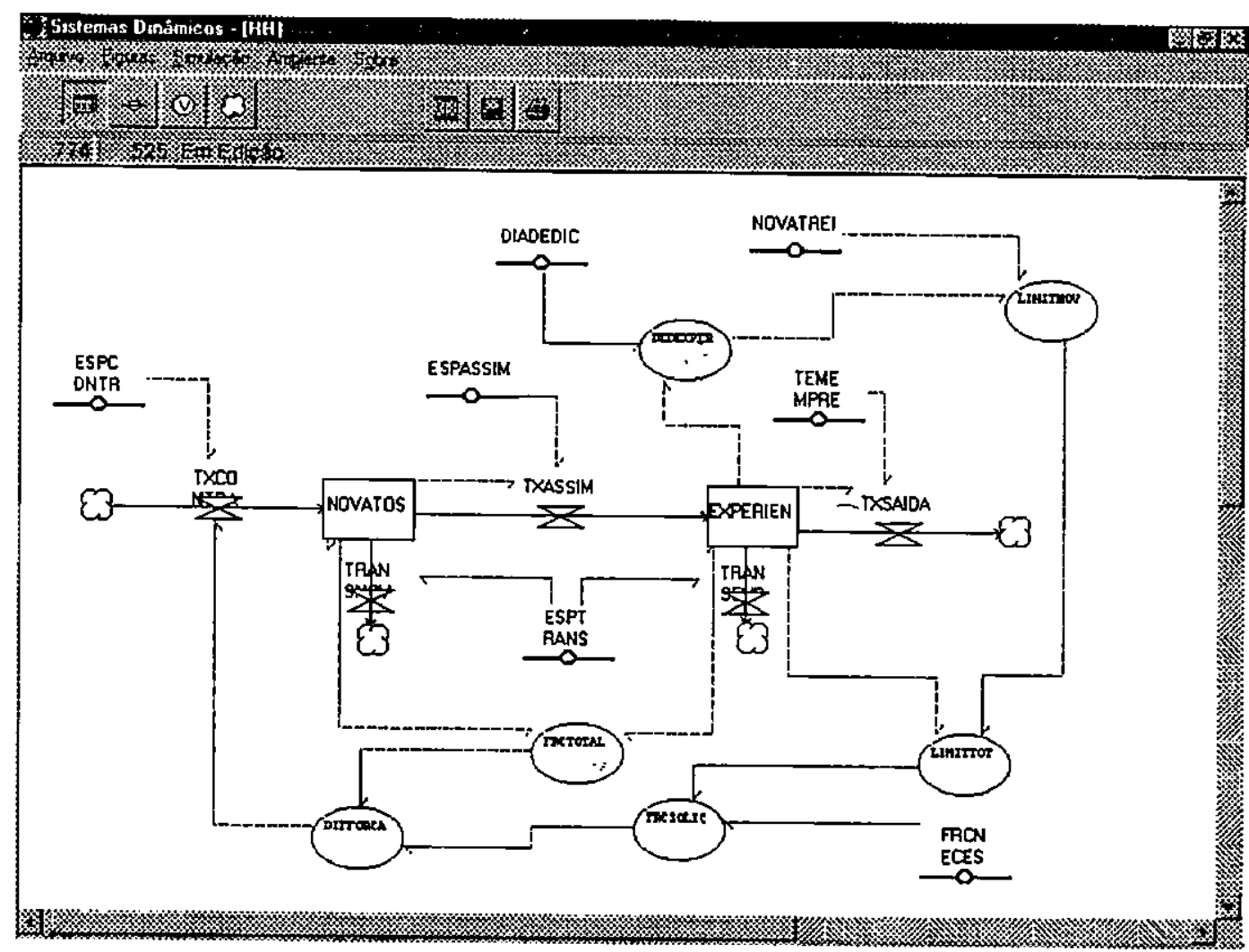

Figura 29 - Edição do Subsistema de Recursos Humanos 
Nota-se nesta representação que foi feita um adaptação do modelo original (figura 13). No modelo mostrado na figura 13, a Força de Trabalho Necessária, representada por FRCNECES, foi considerada uma constante, pois no modelo original de Abdel-Hamid esta variável é gerada pelo subsistema de Planejamento (PLANE), que não foi modelado [AbdelHamid90]. Vale ressaltar que a diferença da nomenclatura dos componentes se dá por uma restrição de implementação que limita os nomes dos componentes a oito caracteres em letras maiúsculas. $O$ limite de oito caracteres foi estabelecido para tentar melhorar a apresentação do componentes, pois é o limite máximo de caracteres possível de estar contido na representação gráfica dos componentes. Já o fato de aceitar somente letras maiúsculas é devido à linguagem $\mathrm{C}$ diferenciar os caracteres maiúsculos de caracteres minúsculos e os objetos são criados com os nomes a eles atribuidos. Ambas as limitações garantem que nomes gerados internamente para Nuvens, Influências, Linhas e Fluxos não coincidam com nomes dados pelo usuário a componentes do modelo por ele criado. Essa restrição poderia ser eliminada facilmente em outras versões da ferramenta, se necessário.

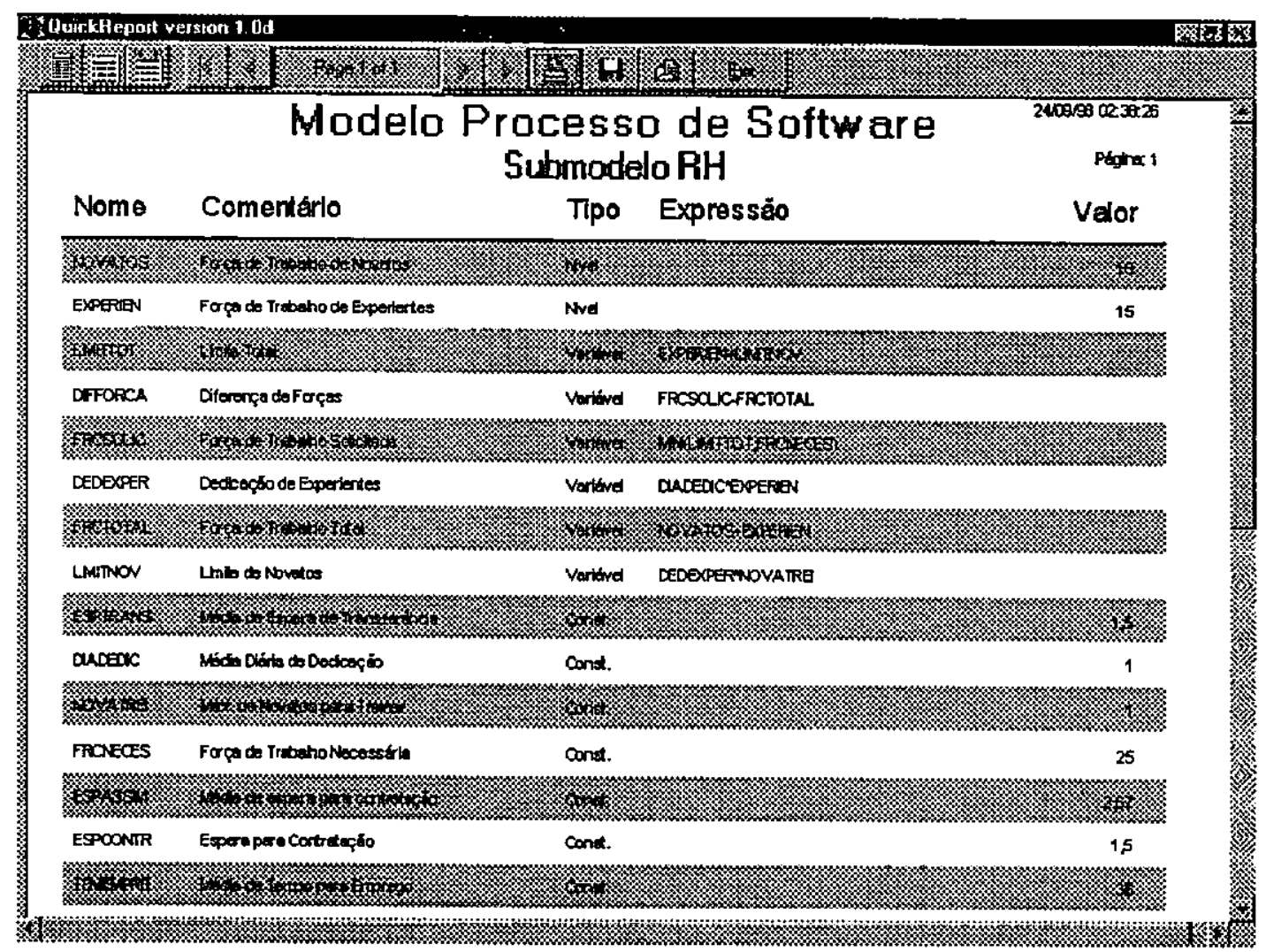

Figura 30 - Relatório do Modelo 
A representação visual do modelo possibilita a visualização das influências e dos ciclos de retroalimentação, porém dificulta verificar os valores e fórmulas dos componentes do modelo, sendo desejável um "radiografia" do modelo com esses dados. Para isso, a ferramenta permite a impressão ou apenas a visualização dos valores e fórmulas estabelecidas. A figura 30 mostra uma visão parcial de um relatório do modelo.

$\mathrm{Na}$ criação dos componentes do modelo que exigem no mínimo uma identificação ou na edição de um componente já criado, dada pela opção Editar do menu de componente, é apresentada a interface de entrada de dados, mostrada na figura 26, que em tempo de execução é sobreposta à área de edição, como mostra a figura 31 , na qual pode-se observar a especificação de CONTRATO seguindo a gramática estabelecida para a fórmula. Tais dados são apresentados no relatório do modelo.

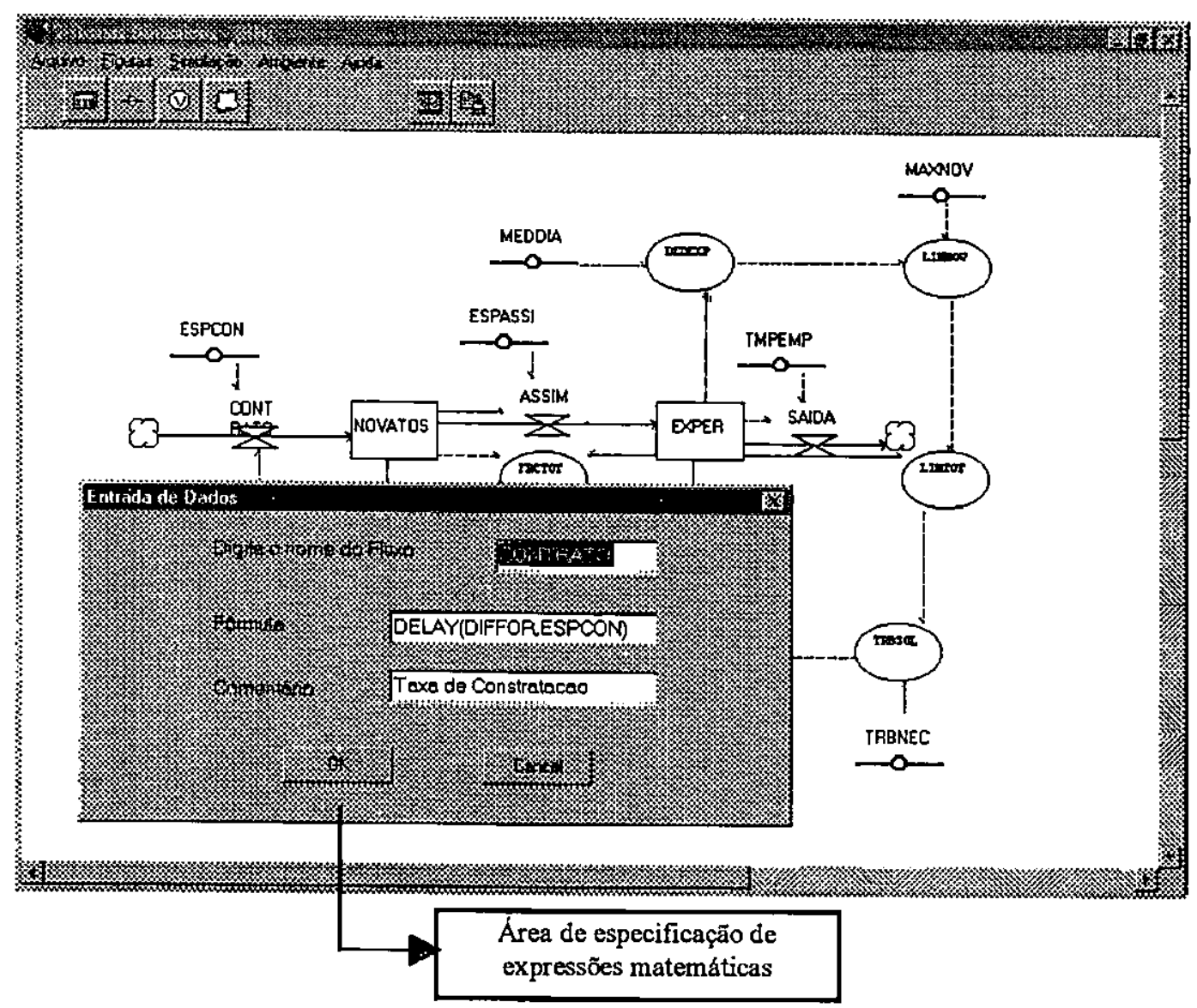

Figura 31 - Edição de componentes 


\subsubsection{Simulação do Modelo}

A simulação do modelo editado obedece a uma série de parâmetros, como exposto anteriormente na figura 24. Para a simulação do modelo de Recursos Humanos de Processo de Software foram especificados os parâmetros mostrados na figura 32 .

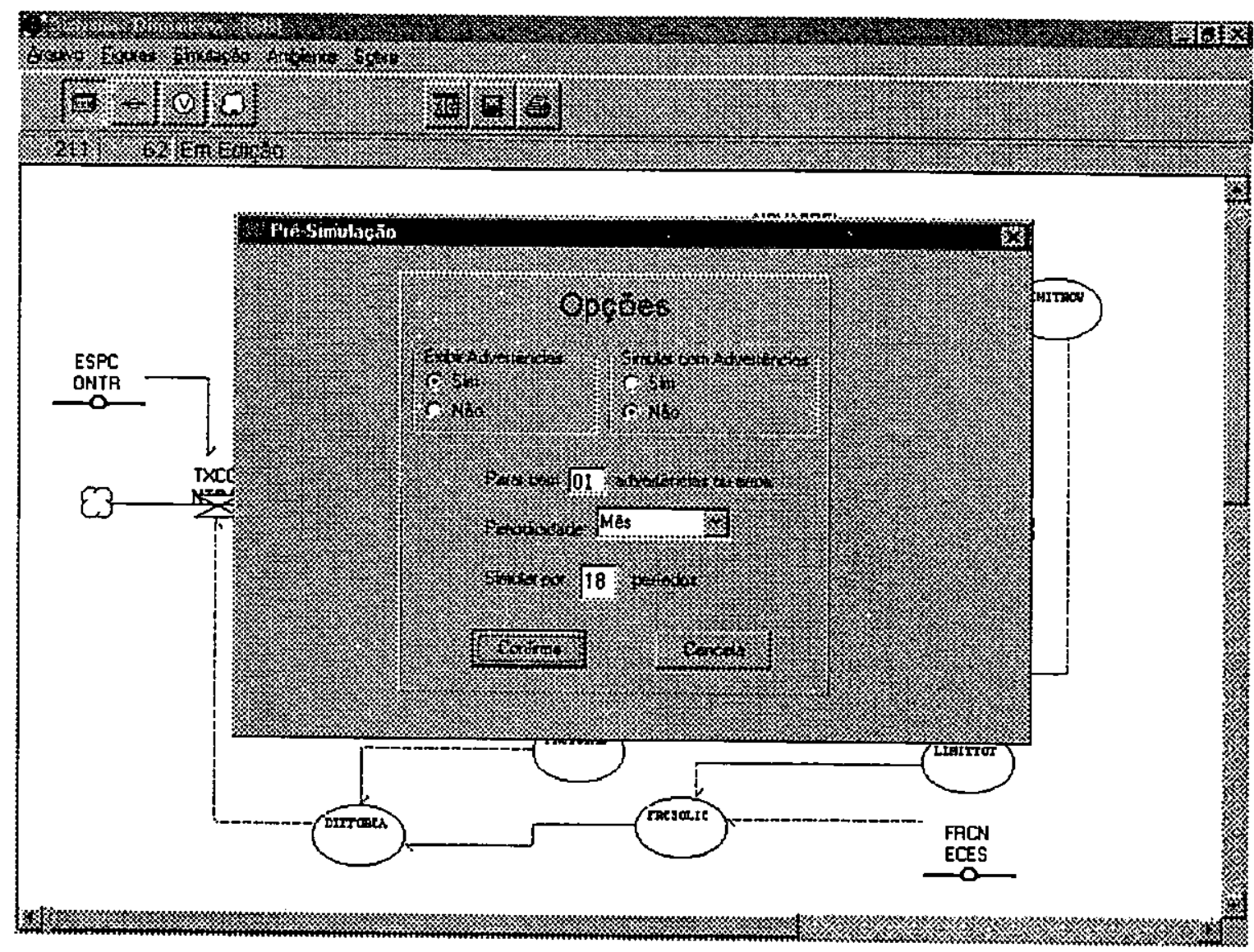

Figura 32 - Parâmetros para Simulação

Os quatro primeiros parâmetros não foram alterados, ou seja, ao criar um novo modelo a própria ferramenta estabelece um valor inicial (default). Apenas a periodicidade foi alterada para permitir a visualização da mudança de comportamento do modelo diante da alteração de seus componentes, como será discutido a seguir. 


\subsubsection{A Pré-Simulação}

Durante a edição do modelo, a ferramenta permite que o modelo esteja "momentaneamente" inconsistente $e$, portanto, é necessário uma validação do modelo antes da simulação. Considerando os parâmetros estabelecidos, é feita essa validação e o resultado da validação é exibido. A figura 33 mostra um exemplo de resultado apresentado pela validação.

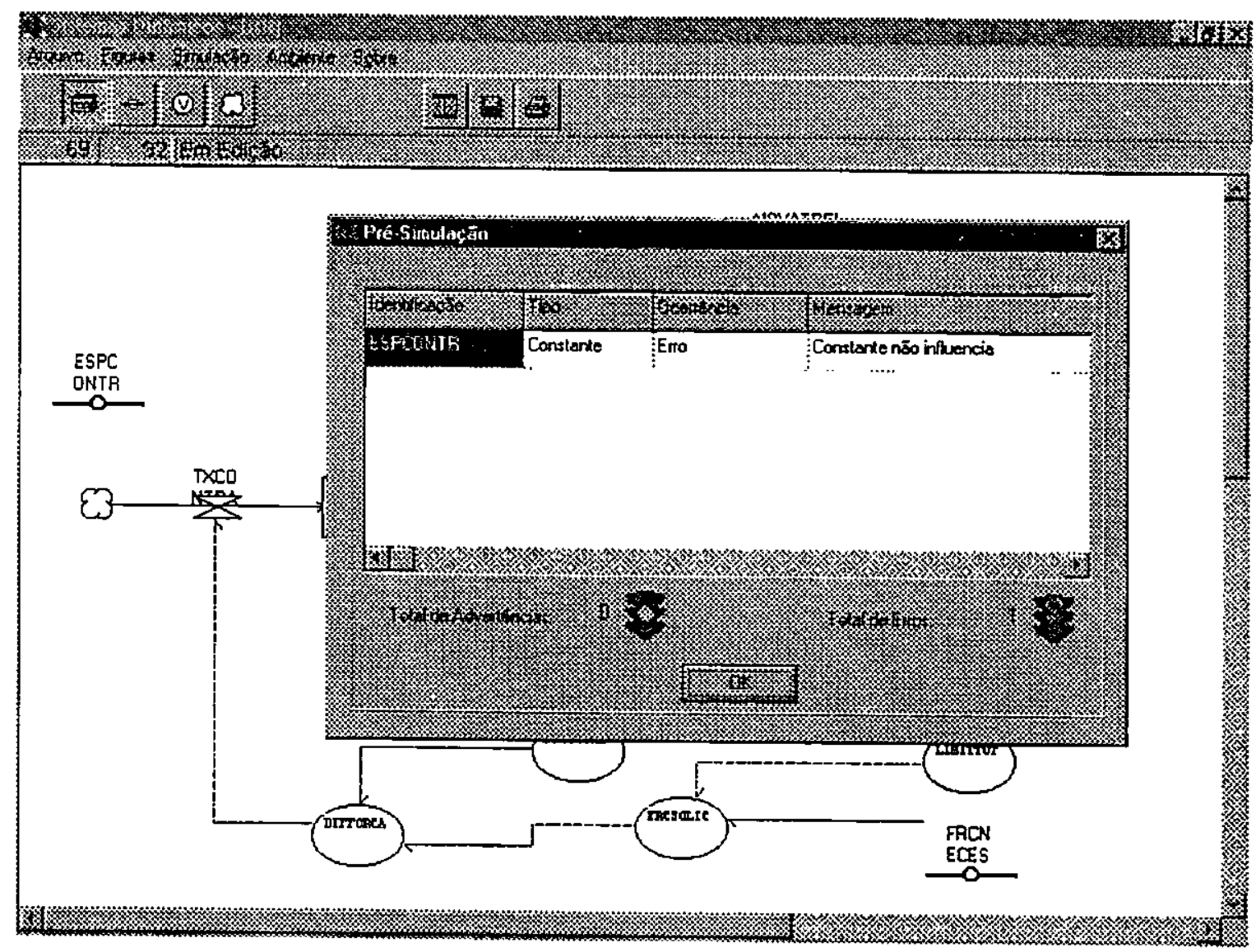

Figura 33 - Pré-Simulação

Para obter tal resultado, foi provocado um erro apagando-se a influencia de ESPCONTR em TXCONTR, como pode ser observado no plano de fundo da figura 33 . A eliminação dessa influência provocou dois erros: o primeiro, e acusado pela ferramenta, é exposto na figura 32 como uma constante (ESPCONTR) isolada no modelo, ou seja, não influencia nenhum componente. O segundo erro provocado ocorre na fórmula da taxa de contratação (TXCONTRA) pois é expressa fazendo uso da constante e essa constante não influencia a taxa, caracterizando um erro na edição. Porém, esse erro não foi relatado pela 
ferramenta pois o parâmetro para simulação estabelece que a validação é interrompida no primeiro erro ou advertência (vide figura 32).

\subsubsection{Resultado da Simulação do Modelo}

Se a validação do modelo não encontrar erro, não encontrar advertências ou mesmo que as tenha encontrado e a opção para simulação estabeleça que a ferramenta deva ignorar as advertências, a simulação é executada gerando uma série de valores em uma tabela contendo todos os elementos do modelo e os valores calculados a cada iteração. Em seguida, todos os elementos são inseridos em uma lista de componentes para que o usuário escolha os elementos que devem gerar o gráfico ou constar em um relatório. A figura 34 mostra um gráfico gerado com os valores dos níveis NOVATOS e EXERIEN(tes). A figura 35 mostra a opção de visualização de um relatório contendo dados da simulação.

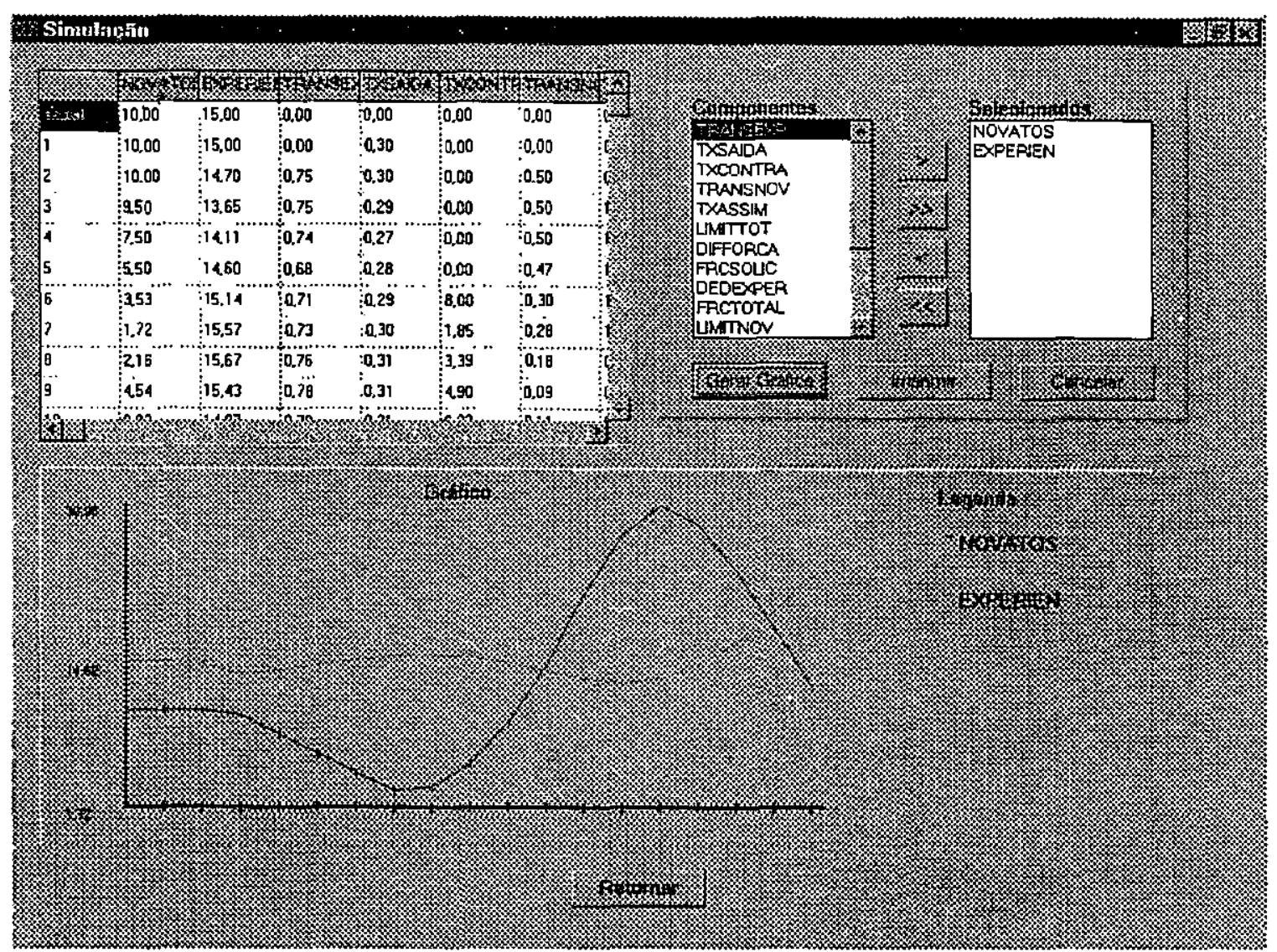

Figura 34 - Simulação do SubSistema (1) 


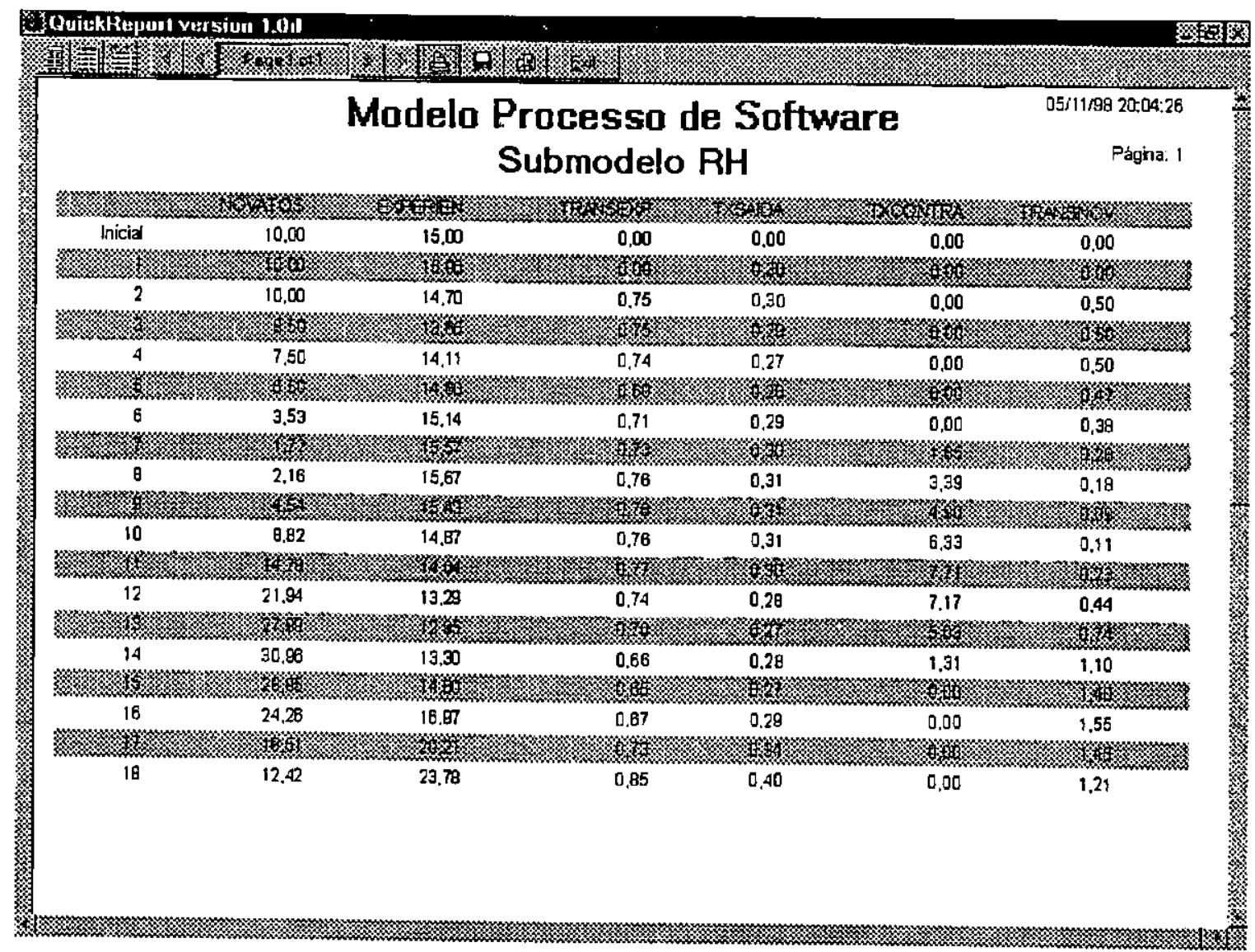

Figura 35 - Visualização dos Resultados Obtidos na Simulação

\subsubsection{Avaliação do Comportamento do Modelo}

Nota-se no gráfico da simulação que há uma variação acentuada em Novatos dada pela demora de reação do ambiente modelado diante da saída de novatos, agravada pelo tempo de espera para contratação. Dessa forma, pelo que foi modelado, ocorre uma disparidade maior entre a força de trabalho necessária e a disponível, aumentando a taxa de contratação, que atinge níveis altíssimos considerando a necessidade estabelecida. Porém, isso leva a uma reação do modelo que, devido à queda da contratação, ao aumento de transferência de novatos e de promoção de novatos à condição de experientes, traz como consequiência a constituição da equipe do projeto por uma maioria de membros considerados experientes.

Tal situação pode ser considerada indesejável por algum motivo. Nota-se na figura 34 que o nível Novatos atingiu valores superiores a força necessária. Pode ser necessária a adoção de mudanças, até mesmo de cunho organizacional, que levem o modelo a um comportamento adequado. Dessa forma, as alterações podem ser avaliadas, visualizando 
o comportamento do modelo antes da efetiva implantação de tais mudanças. Como exemplo, pode-se considerar a possibilidade de minimizar o tempo de espera para contratação, o que resulta em uma curva menos acentuada, como mostra a figura 36. Pode-se observar na figura 36, que representa o resuitado da simulação com um tempo médio de espera para contratação reduzido de 1.50 para 0.50 períodos, que no caso foi estabelecido como mensal (ver parâmetros do modelo), uma redução dos valores assumidos por Novatos e Experien(tes) em relação à simulação anterior. Por se tratar de uma nova simulação, podendo-se considerar também como um outro modelo, a escala do gráfico é gerada utilizando-se os resultados atuais e, portanto, ao visualizar o gráfico em um primeiro instante, sem observar a alteração de escala, pode passar desapercebido a minimização da amplitude da curva obtida. Isso representa que a possibilidade de reação relativamente mais rápida da organização pode proporcionar um melhor comportamento da mesma, diante de suas próprias necessidades.

Há outras possibilidades de mudanças e entre elas foi avaliado o comportamento do modelo diante da redução do índice de transferência de novatos, que foi reduzido de $5 \%$ para $0.10 \%$, mantendo-se o tempo médio de espera para contratação em 1.5 períodos. Como pode-se observar na fígura 37 , o comportamento obtido com esta mudança foi próximo ao obtido com a redução do tempo de contratação. Dessa forma, pode-se comparar possibilidades de mudanças, avaliando a relação custo/benefício. A comparação de resultados entre alternativas de mudanças permite tomar decisões que produzam melhores resultados. Vale lembrar que existem outras possibilidades de mudanças que podem ser avaliadas neste modelo, tais como minimizar a transferência, minimizar a saída de experientes, etc.

Pode ainda avaliar o comportamento do modelo diante da combinação de aiterações no modelo. Como pode-se observar na figura 38 , que mostra a simulação do modelo tendo-se alterado o tempo médio de espera para contratação ( de 1.50 para 0.50 períodos) e o índice de transferência de novatos (de $5.00 \%$ para $0.10 \%$ ), a combinação de mudanças pode trazer melhores resultados, porém, devido às relações de interdependências existentes no modelo, os resultados obtidos com a combinação não representa a soma dos resultados individuais. 


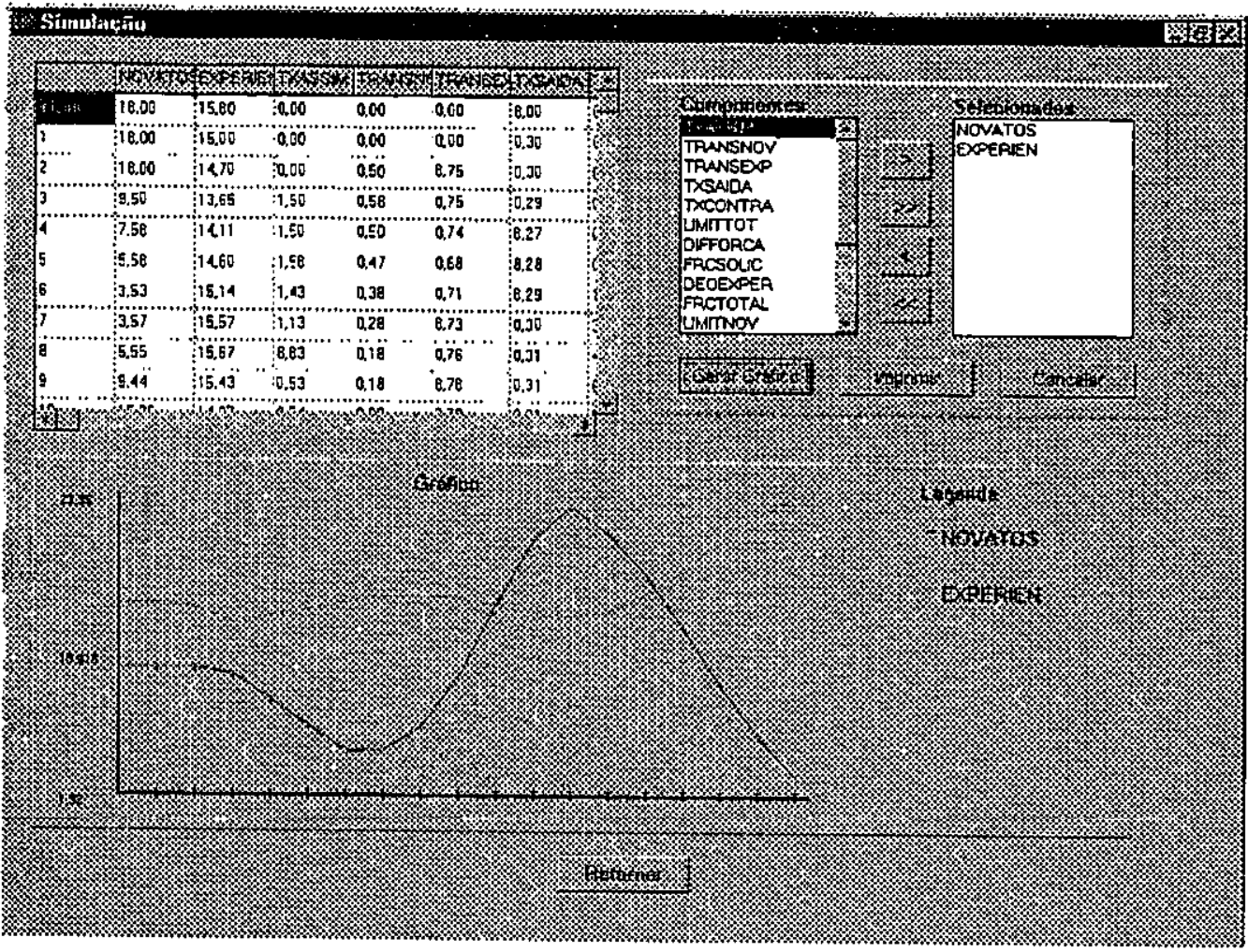

Figura 36 - Simulação do Subsistema (2)

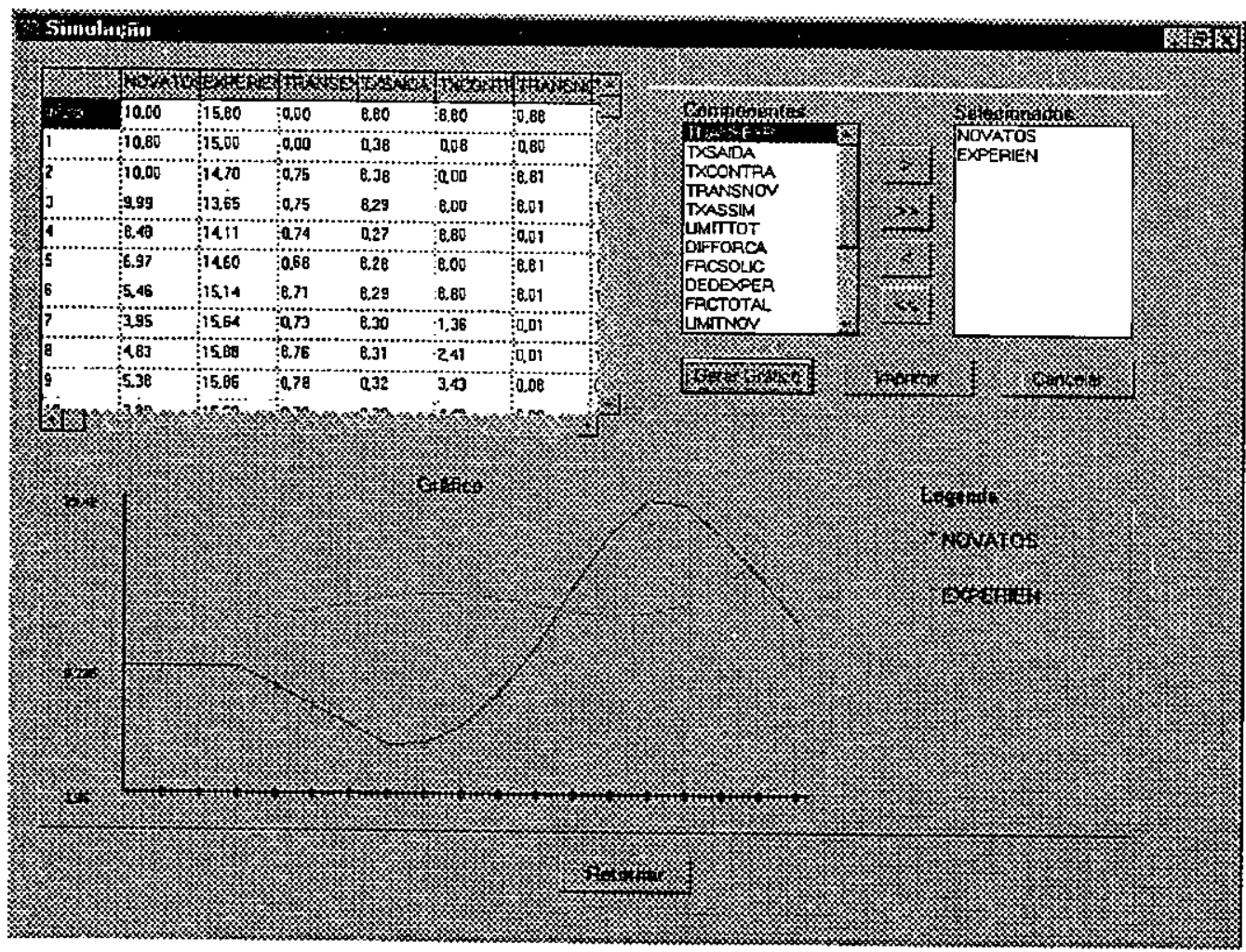

Figura 37 - Simulação do Modelo (3) 


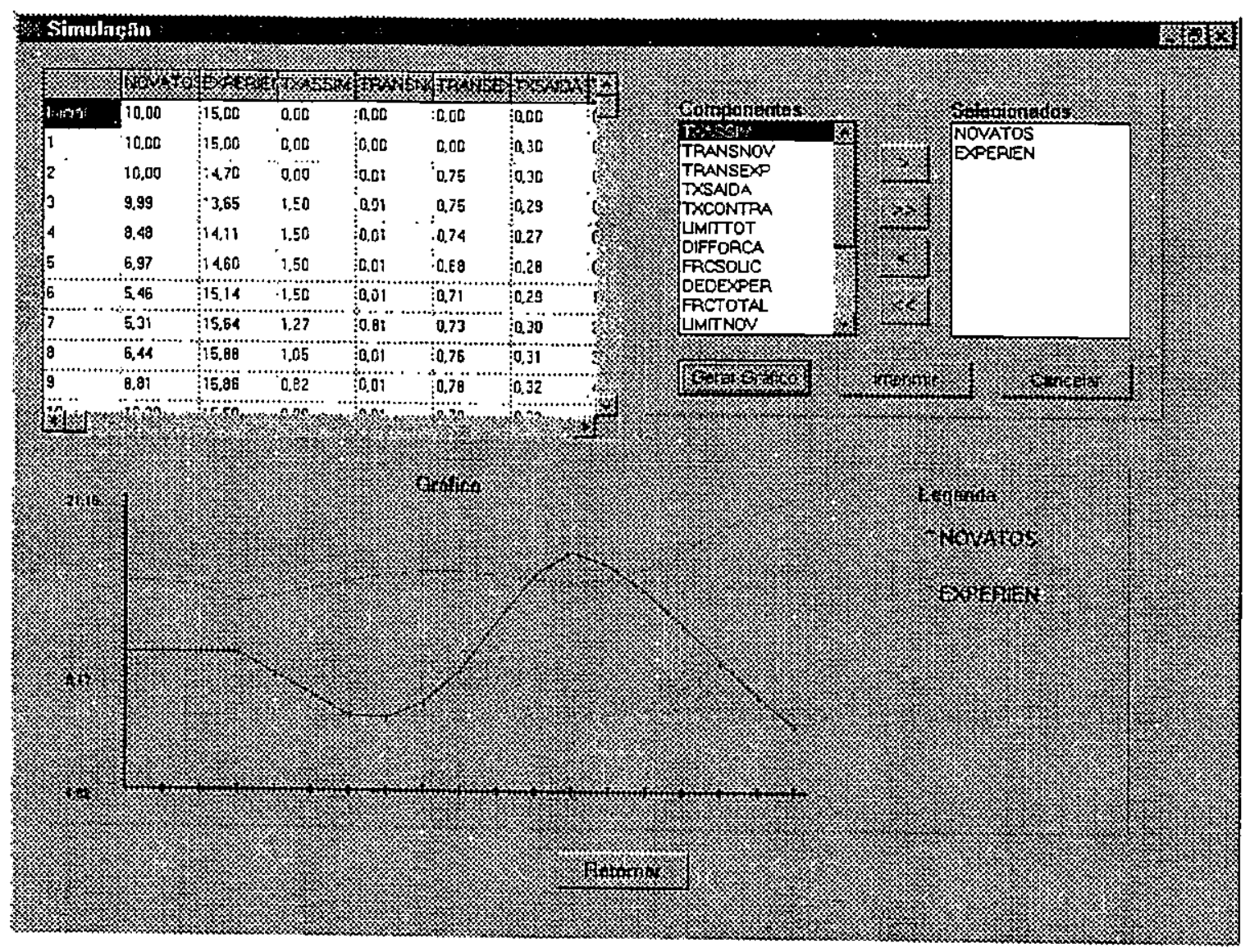

Figura 38 - Simulação do Modelo (4)

\subsection{Simulação de Filas}

Como exemplo alternativo da aplicação de conceitos de dinâmica de sistema e, por conseqüência, da utilização da ferramenta, é apresentado a seguir um modelo que representa uma ambiente de atendimento a usuários controlado por uma fila. Os usuários que esperam pelo atendimento são mantidos na fila até que exista a disponibilidade para o atendimento, podendo-se generalizar tal situação como uma concorrência de um ou mais recursos por vários requisitantes. 


\subsubsection{O Modelo}

O modelo para atendimento é relativamente pequeno, comparando-se com o discutido anteriormente. Foi constituído por apenas um subsistema, denominado de $A T E N D$, cujo detalhamento é apresentado na figura 39.

No modelo, a constante $L I M C H E G$ representa o limite máximo de clientes que chegam para serem atendidos em determinado periodo. A taxa ENTRA, que determina a quantidade de clientes que chegam para serem atendidos, considera esse limite para, durante a simulação, gerar aleatoriamente o número de clientes que entram para serem atendidos, sendo colocados na fila de espera, representada no modelo pelo nível FILA. A constante LIMATEND representa a quantidade de postos de atendimento. MEDATEND é uma constante que representa o tempo médio gasto no atendimento de um cliente. O nível ATENDIM foi criado. para armazenar os clientes que estão sendo atendidos em um determinado momento. Embora a intenção seja modelar o comportamento da fila, este nível é fundamental no controle do comportamento da fila, pois para decidir se um cliente passa a ser atendido ou não, deve-se considerar quantos já estão sendo atendidos em determinado instante. Deve-se notar que o limite máximo para o atendimento é considerado.

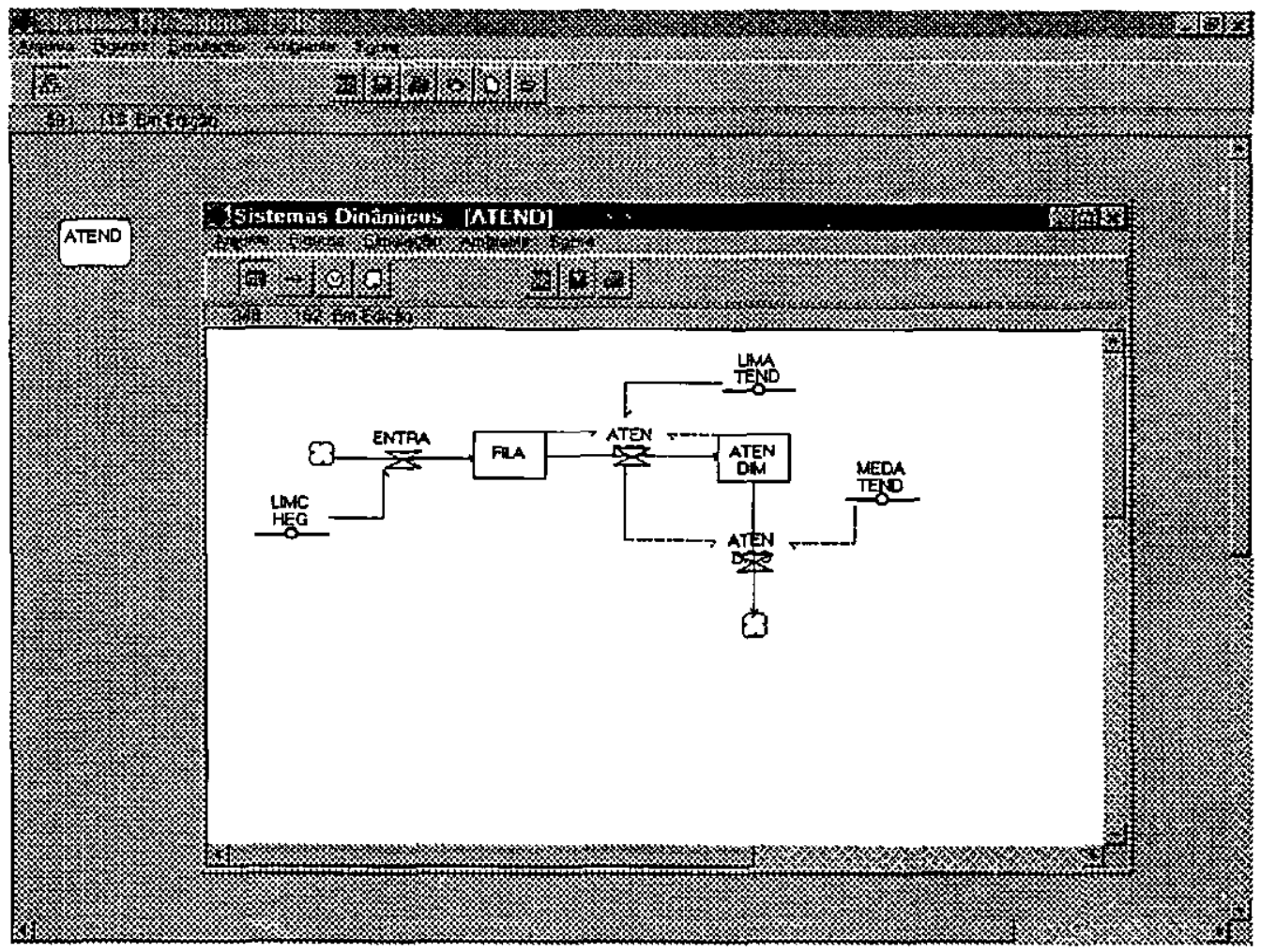

Figura 39 - Modelo de Atendimento de Fila 
A figura 40 mostra os valores iniciais assumidos pelos componentes do modelo e as expressões que regem o comportamento do modelo. Nota-se nessa figura que FILA e $A T E N D I M$ assumem valores iniciais nulos, o que é considerado na pré-simulação como uma advertência. Dessa forma, para simular este modelo é necessário alterar os parâmetros para simulação, de maneira que a validação executada na pré-simulação não impeça a simulação.

A taxa $A T E N D E R$, que controla a passagem de um cliente da FILA para o $A T E N D I M$ (ento) combina as funções $M I N$ e $M A X$, que retornam o menor e o maior entre dois valores respectivamente, para impedir que FILA assuma valores negativos na simulação. Em seus cálculos intermediários, faz uso de $A T E N D M M$ para impedir que um número de clientes maior que a capacidade de atendimento, dada por LIMATEND, seja assumido pelo próprio nível $A T E N D I M$.

A taxa ATENDIDO tem como influência a própria entrada de clientes na situação de atendimento, considerando a espera de tempo dada pela média de atendimento (MEDATEND).

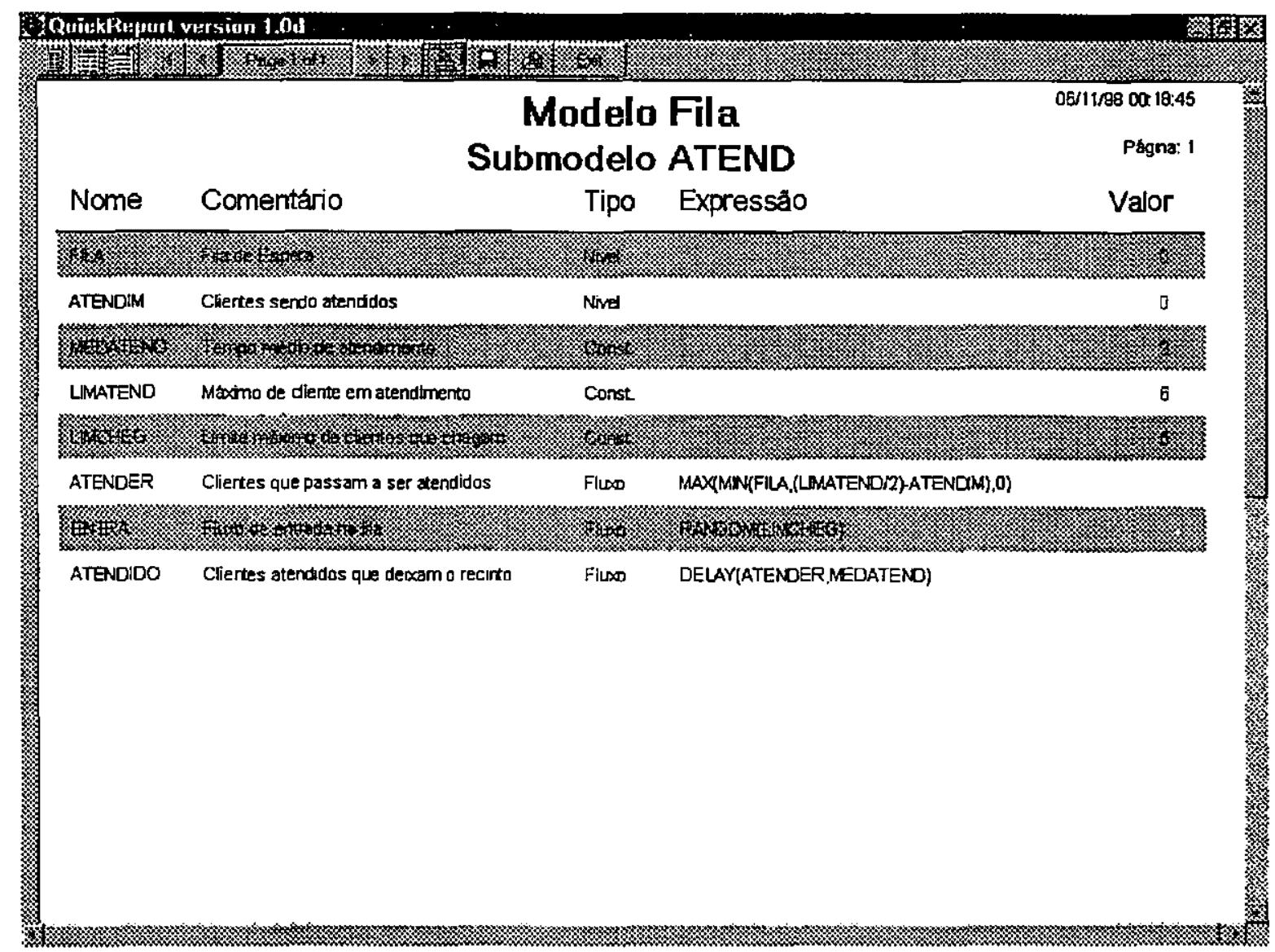

Figura 40 - Relatório do Modelo de Fila 


\subsubsection{Simulação do Modelo}

Como mencionado anteriormente, ao simular este modelo considerando as opções iniciais assumidas na criação do modelo, são acusadas advertências devido aos valores iniciais nulos dos níveis FILA e ATENDIM (ento), como mostra a figura 41 . Torna-se necessário a alteração do parâmetro Simular com Advertência, ao qual deve ser atribuído SIM, e do parâmetro Parar com $N$ Advertências ou Erros, que deve assumir um número maior que dois, que corresponde ao número de advertências que devem ser ignoradas. A figura 41 mostra os parâmetros considerados na simulação do modelo.

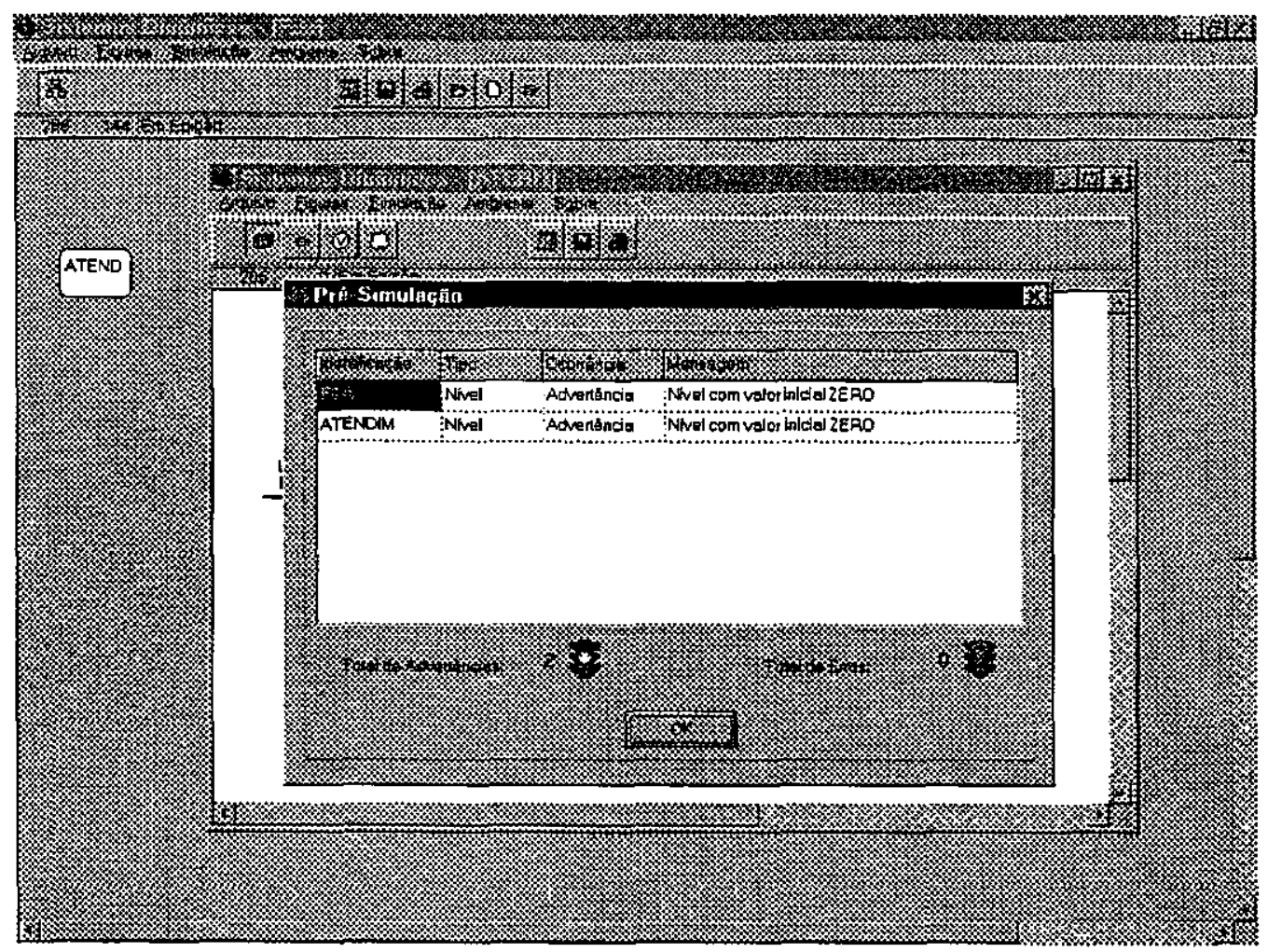

Figura 41 - Pré-Simulação do Modelo de Filas 


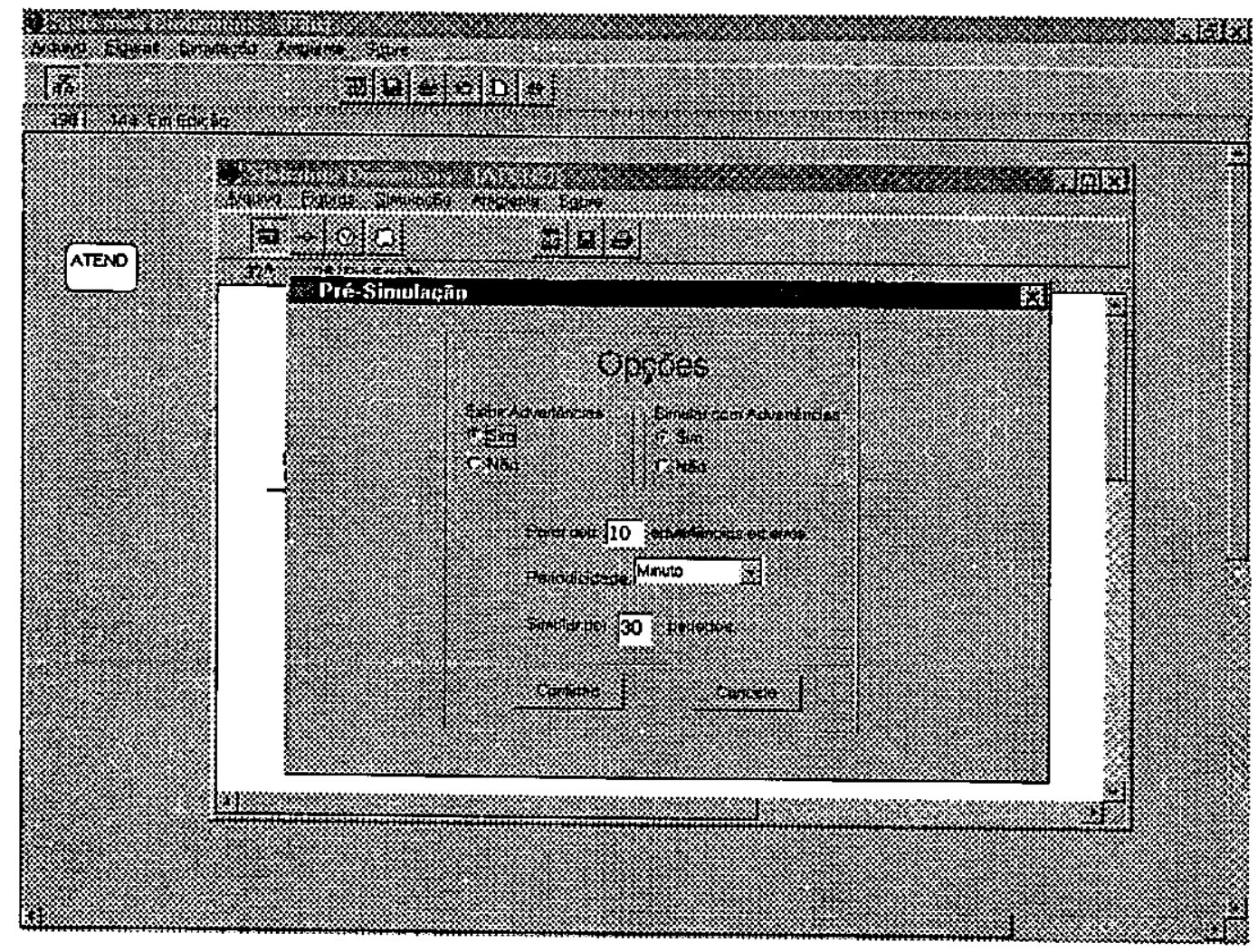

Figura 42 - Parâmetros da Simulação do Modelo de Filas

\subsubsection{Resultado da Simulação}

Pode-se observar na figura 43 a ocorrência de um rápido acúmulo de clientes na fila de espera. $\mathrm{Na}$ tentativa de minimizar este acumulo algumas alternativas podem ser avaliadas, tais como lançar mão de mais funcionários para o atendimento e melhorar o atendimento minimizando o tempo médio de atendimento.

A figura 44 mostra o comportamento do modelo diante da redução do tempo médio de espera de 3 para 2 minutos, que pode ser obtida por meio de treinamento dos funcionários atendentes ou pela melhoria do processo de atendimento, peculiar à organização. 


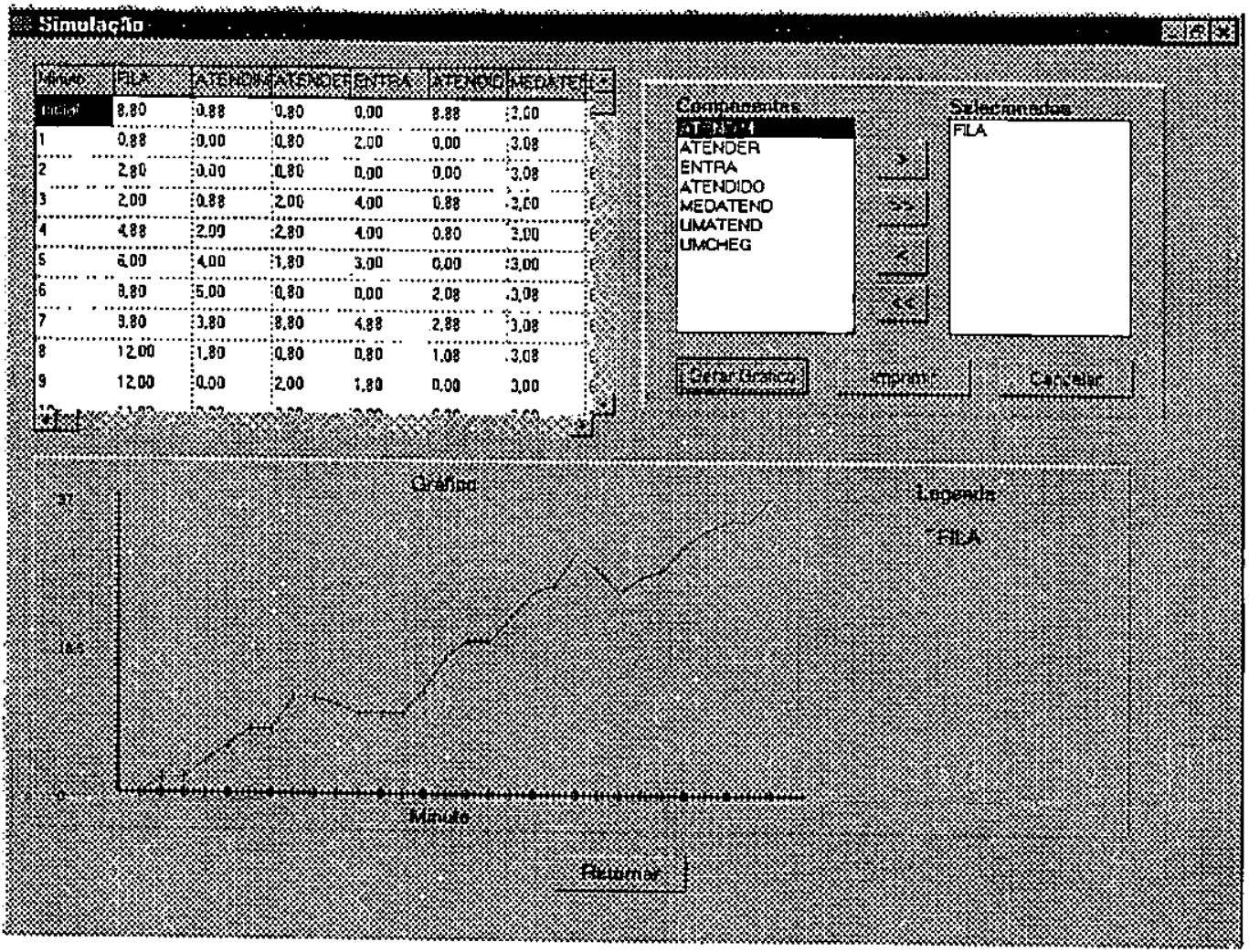

Figura 43 - Resultado da Simulação do Modelo de Fila (1)

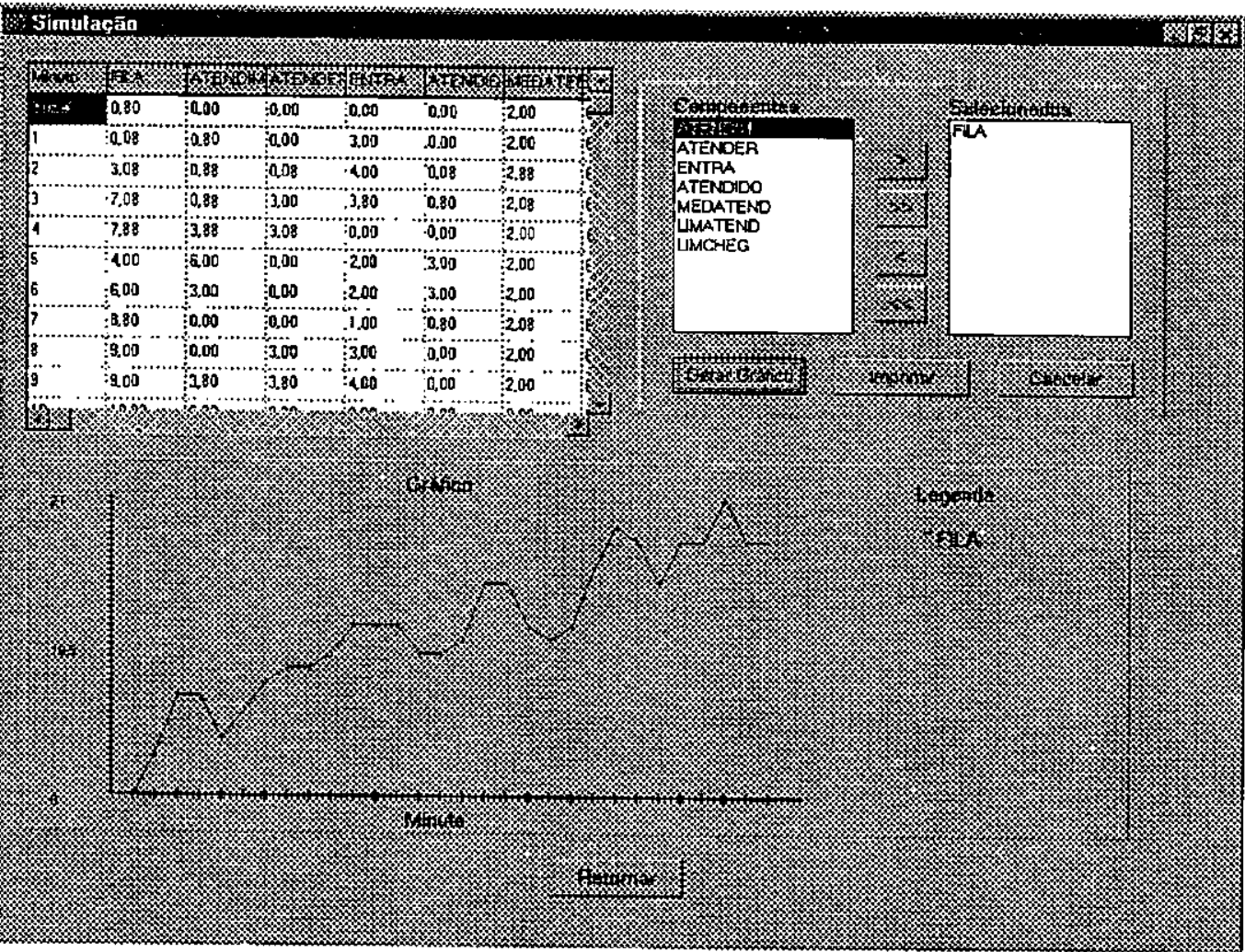

Figura 44 - Resultado da Simulação do Modelo de Fila (2) 
Outro modo de minimižar o acumulo de clientes na fila é o aumento de funcionários atendentes, o que demanda, provavelmente, a contratação de novos funcionários. A figura 45 mostra o comportamento do modelo aumentando-se de 6 para 8 funcionários de atendimento.

Porém, ambas as soluções demonstraram-se insuficientes para evitar o acumulo de clientes na fila de espera. Assim, pode-se partir para uma ação conjunta das duas alternativas, ou seja, aumentado-se o número de funcionários de atendimento (de 6 para 8 ) e reduzindo-se o tempo médio de espera (de 3 para 2 minutos). A figura 46 mostra o resultado da combinação dessas duas mudanças, na qual pode-se observar uma redução considerável no pico atingido e, além disso, uma queda no acumulo de clientes na fila.

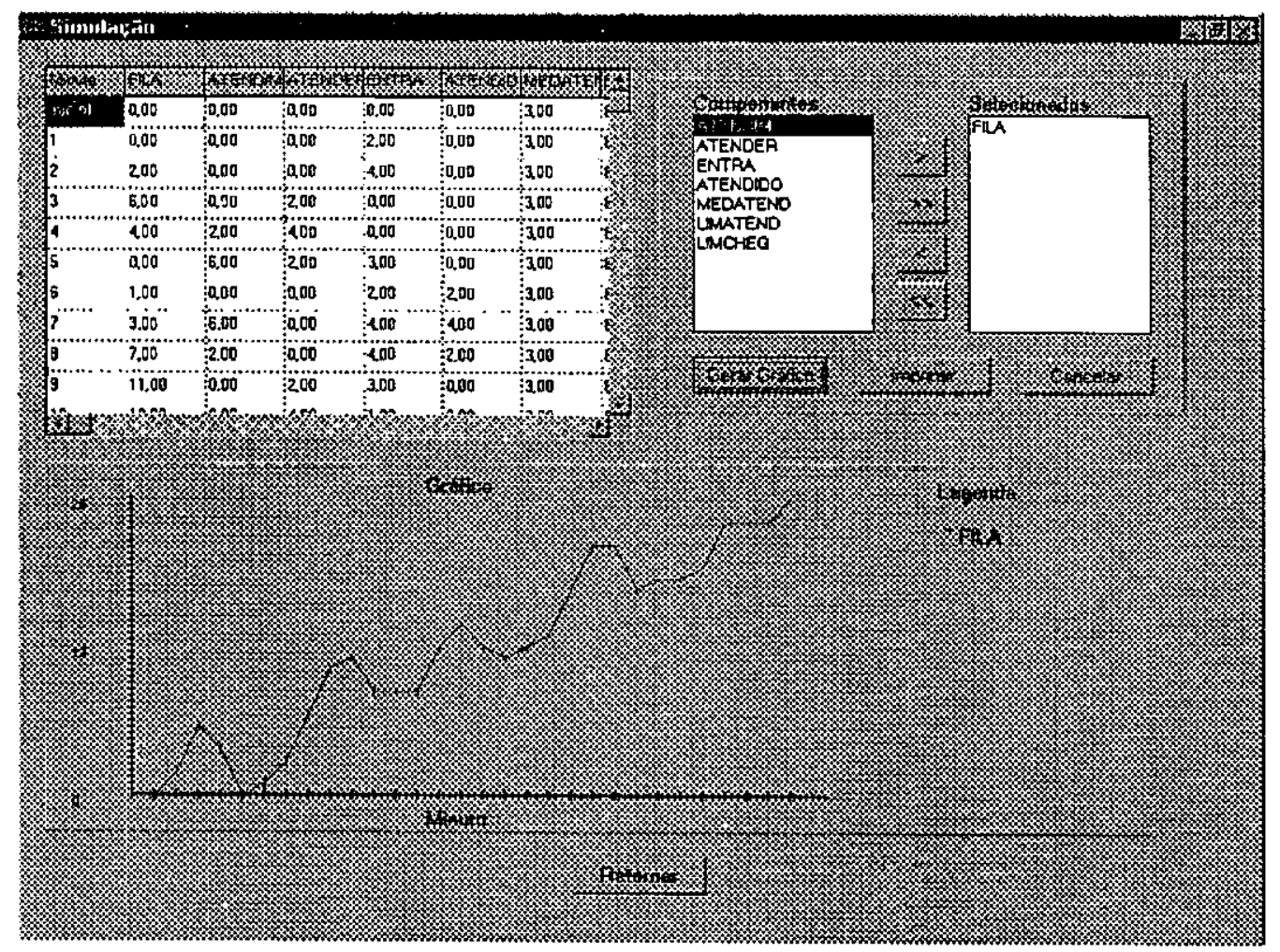

Figura 45 - Resultado da Simulação do Modelo de Fila (3)

As quatro simulações aqui apresentadas, por fazerem uso da geração de números aleatórios, podem apresentar variações sem que sejam alterados parâmetros do modelo. Assim, para cada alteração foram feitas no mínimo 5 simulações para verificar a representatividade da alteração, sendo selecionadas para apresentação as simulações que representam comportamentos medianos para cada uma das alterações. 


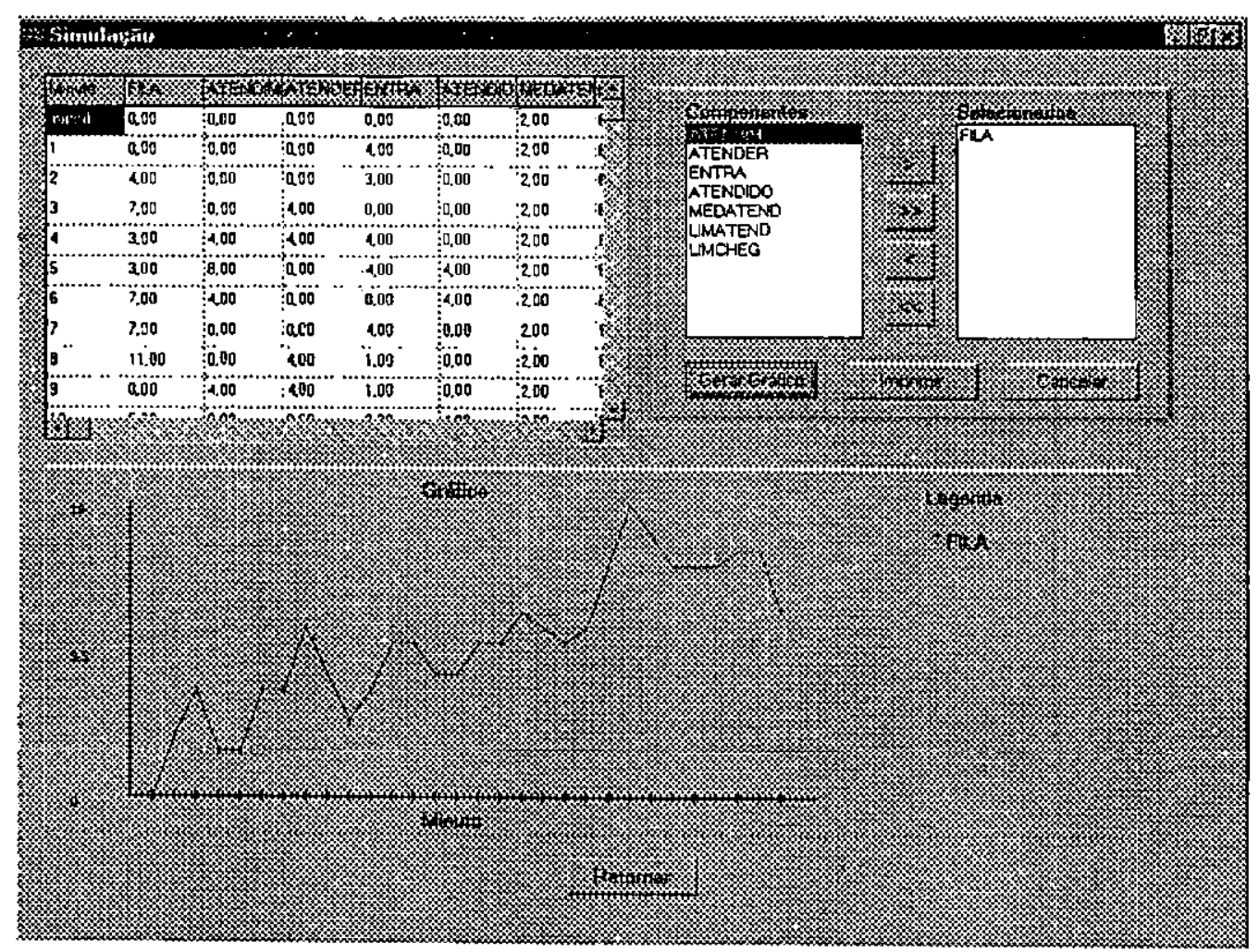

Figura 46 - Resultado da Simulação do Modelo de Fila (4)

\subsection{Considerações Finais}

Neste capítulo mostrou-se a utilização da ferramenta no apoio à tomada de decisões considerando os aspectos de dinâmica de sistema. Ficou claro que a utilização de estimativas mais próximas da realidade permite a obtenção de resultados mais realísticos, e portanto, possibilita um melhor aproveitamento da ferramenta destacando a necessidade de se construir o modelo baseando-se em dados históricos.

Dessa forma a avaliação de alternativas e suas conseqüências futuras antes de tomar decisões efetivas que impliquem em investimentos, com a possibilidade de não se obter o resultado esperado, ou mesmo que não impliquem em investimentos mas produzam resultados indesejados, constitui uma vantagem da utilização da modelagem dos aspectos dinâmicos. 


\section{Conclusão}

\subsection{Considerações Iniciais}

Embora possível de ser aplicada nas mais diversas áreas do conhecimento humano, a ferramenta desenvolvida permite explorar a investigação do impacto dos ciclos de retroalimentação no processo de desenvolvimento de software, que consiste em uma das alternativas para a melhoria do processo, pois segundo Boehm há mais oportunidade de melhorar a produtividade e a qualidade na área de gerenciamento que em áreas técnicas [BOEHM76].

Medir os aspectos "soft" da produção de software não é um processo simples, porém permite que o modelador utilize médias e estimativas mais próximas da realidade, $\mathrm{e}$ ainda avalie alternativas e suas conseqüências futuras antes de tomar alguma decisão efetiva. A criação de cenários permite a avaliação de custos e pode ajudar a definir metas a serem alcançadas, de modo a colaborar com o objetivo final: produção de software dentro de prazos e orçamentos com qualidade. A necessidade de utilização de uma ferramenta que apóie esse processo, tanto de modelagem quanto de simulação de cenários, é abrangida pela ferramenta desenvolvida.

Em princípio, a aplicação da dinâmica de sistema pode ser dificultada pela falta de disponibilidade de dados referente à organização a ser modelada, podendo ser atenuada caso haja a disponibilidade de uma base de dados histórica, como definido pelo nível três do Capability Maturity Model (CMM). Dessa forma, pode-se concentrar na equalização do 
modelo, que por meio de refinamentos, tende a minimizar a diferença entre o modelo e o mundo real.

\subsection{Contribuições}

Como proposto inicialmente, a ferramenta desenvolvida apóia a elaboração de modelo capaz de representar a dinâmica de sistemas inerentes ao processo de desenvolvimento de software seguindo a notação proposta por Forrester. Além da edição do modelo também permite a simulação possibilitando a visualização gráfica dos resultados.

Para atingir o objetivo foi necessário um levantamento das características necessárias à uma ferramenta para tal fim, definindo aspectos funcionais baseados em um estudo realizado sobre dinâmica de sistema. Características não funcionais, tais como interface e usabilidade, dentre outras, foram definidas procurando-se seguir o padrão do ambiente escolhido.

Quanto ao desenvolvimento Depois de desenvolvida, a ferramenta deve ser utilizada para exemplificar a modelagem de dinâmica de sistema, de preferência utilizando um modelo relacionado ao processo de desenvolvimento de software.

Em relação a melhoria do processo de desenvolvimento de software, em âmbito mundial, há um crescente emprego de técnicas tais com CMM (Capability Maturity Model), SPICE (Software Process Improvement and Capability dEtermination) e Dinâmica de Sistemas, esta restrita às atividades de gerenciamento de projeto. No Brasil esta é uma área insipiente, em que somente técnicas mais populares, como as citadas acima, são conhecidas. Portanto a ferramenta traz a possibilidade de despertar o interesse da comunidade brasileira e com isso servir como embrião para outras pesquisas que venham a explorar a dinâmica de sistemas em organizações nacionais criando modelos representativos da realidade brasileira. Além disso, o domínio da tecnologia permite a extensão da ferramenta como mostrado a seguir. 


\subsection{Trabalhos Futuros}

Além da vasta possibilidade de aplicação da ferramenta na modelagem de dinâmica de sistemas, são sugeridos dois trabalhos nesta linha de pesquisa: a criação de um ambiente de jogos e um módulo de acompanhamento de processos.

$O$ primeiro trata-se de um ambiente em que, baseado em modelo criado utilizando-se a ferramenta produzida, possibilita a simulação do ambiente representado pelo modelo.Os jogadores têm por objetivo minimizar os aspectos negativos e maximizar resultados por meio de alterações em parâmetros do modelo, seguindo regras préestabelecidas. Pretende-se com isso, formar um ambiente de apoio ao treinamento gerencial.

O segundo pode ser considerado como uma pequena extensão à ferramenta, possibilitando o armazenamento de dados reais coletados junto ao ambiente (organização) modelado, permitindo uma comparação entre o modelo por intermédio de sua simulação e o mundo real: previsto versus realizado. Com isso pode ser facilitada a identificação de possíveis falhas na modelagem, além de possibilitar o acompanhamento do processo modelado. Para tanto é necessária uma alteração na estrutura de simulação, na qual o instante inicial da simulação para modelos com acompanhamento passa a ser o tempo corrente e não mais o tempo inicial.

Pode-se ainda, investigar a possibilidade de criação de modelos padrões para certos grupos de ambientes, minimizando o esforço na modelagem e também a possibilidadé de erros no modelo construído. Obviamente, há a necessidade de ocorrer adequações de parâmetros inerentes a cada organização. Como exemplo de possibilidade de padrão pode-se considerar o modelo proposto por Abdel-Hammid [ABDEL-HAMMID90], mostrado parcialmente neste trabalho, como exemplo de padrão para o processo de desenvolvimento de software. 


\section{Referências Bibliográficas}

[ABDEL-HAMID89a]

[ABDEL-HAMID89b]

[ABDEL-HAMID90]

[BOEHM76]

[BOEHM81]

[BOTT82]

[CANNING77]

[COLEMAN94]

[FORRESTER61]
Abdel-Hamid, Tarek, "Lessons Learned from Modeling the Dynamics of Software Development", Communications of the ACM, Vol. 32 Num. 12 Pag, 1426-1438, December 1989.

Abdel-Hamid, Tarek, "The Dynamics of Software Project Staffing: A System Dynamics Based Simulation Approach", IEEE Transactions on Software Engineering Vol 15 Num. 2, Pag. 109-119, February 1989

Abdel-Hamid, Tarek and Madnick, Stuart E., "Software Project Dynamics : Na Integrated Approach", Pretice-Hall Inc., Englewood Cliffs, New Jersey, 1990.

Boehm, B.W., "Software Engineering" Apud Abdel-Hamid, Tarek and Madnick, Stuart E., "Software Project Dynamics : Na Integrated Approach"

Boehm, B.W., "Software Engineering Economics" Apud AbdelHamid, Tarek and Madnick, Stuart E., "Software Project Dynamics : Na Integrated Approach"

Bott, H.S., "The Personnel Crunch" Apud: Abdel-Hamid, Tarek and Madnick, Stuart E., "Software Project Dynamics : Na Integrated Approach"

Canning, R., "Progress in Project Management" Apud Abdel-Hamid, Tarek and Madnick, Stuart E., "Software Project Dynamics : Na Integrated Approach"

Coleman, Derek et al, "Object-Oriented Development: The Fusion Method", Pretice-Hall Inc., 1994.

Forrester, Jay W., "Industrial Dynamics", The M.I.T. Press., Massachusetts Institute of Technology, Cambridge, Massachusetts, 1961. 
[KREUTZER86]

[LEHMAN96]

[MERWIN78]

[PRESS95]

[RICHARDSON81]

[ROBERTS64]

[SAIEDIAN95]

[THAYER79]

[THAYER81]

[YOURDON96]
Kreutzer, Wolfgang, "System simulation: programming styles and languages", Addison-Wesley Company, 1986.

Lehman, M.M., "Process Improvement - The Way Forward", Anais do X-SBES, pag. 23-35, Outubro/1996.

Merwion, R.E., "Software Management: We Must Find a Way" Apud Abdel-Hamid, Tarek and Madnick, Stuart E., "Software Project Dynamics : An Integrated Approach"

Pressman, Roger S., "Engenharia de Software", Makron Books, São Paulo, 1995.

Merwion, G.P AND Pugh, G.L. III, "Introduction to System Dynamics Modeling and DYNAMO" Apud Abdel-Hamid, Tarek and Madnick, Stuart E., "Software Project Dynamics An Integrated Approach"

Roberts, E. B., "The Dynamics of Research and Development", Published Ph.D. dissertation, M.I.T., Cambridge, MA, 1964 Apud: Abdel-Hamid, Tarek and Madnick, Stuart E., "Software Project Dynamics : An Integrated Approach", página 30

Saiedian, Hossein and Kuzara, Richard, "SEI Capability Maturity Model's Impact on Contractors", Computer, IEEE Press, pp 1626, 1996.

Thayer,R.H.,"Modeling a Software Engineering Projects Project Management System." Apud: Abdel-Hamid, Tarek and Madnick, Stuart E., "Software Project Dynamics : An Integrated Approach"

Thayer,R.H. et al.,"Major Issues in Software Engineering Projects Managements." Apud: Abdel-Hamid, Tarek and Madnick, Stuart E., "Software Project Dynamics : An Integrated Approach"

Edward Yourdon, "Rise \& Resurrection of the American Programmer", Yourdon Press, cap. 4, 1996. 


\section{Bibliografia Complementàr}

[CALVERT97]

[CAMPO96]

[JACKSON95]

[MIANO97]

[RICHMOND94]

[SILVA96]
Calvert's, Charlie, "Borland C++ Builder Unleashed", Sams, 1997.

Campo, Marcelo R. e Price, Roberto Tom, "Um Framework Reflexivo para Ferramentas de Visualização de Software", Anais do X-SBES, pag. 153-169, Outubro/1996.

Jackson, Michael, "Software Requirements \& Specifications: a lexicon of pratice, principles and prejudices", Addison-Wesley, 1995.

Miano, John and Howe, Harold, "Borland C++ Builder How-To", Waite Group Press, 1997.

Richmond, Barry, "System Dyanmics / Systems Thinking: Let's Just Get On With It", International Systems Dynamics Conference, Scotland, 1994.

(http://www.hps-inc.com/st/paper.html)

Silva, Ricardo Pereira e Price, Roberto Tom, "Em direção a uma metodologia para o desenvolvimento de frameworks de aplicação orientados a objetos", Anais do X-SBES, pag. 325-340, Outubro/1996. 